Aus der Abteilung Kardiologie und Pneumologie

(Prof. Dr. med. G. Hasenfuß)

im Zentrum Innere Medizin

der Medizinischen Fakultät der Universität Göttingen

\title{
Induktion von myokardialem ER-Stress durch biomechanische Last und neurohumorale Stimulation
}

\author{
INAUGURAL-DISSERTATION
}

zur Erlangung des Doktorgrades

der Medizinischen Fakultät

der Georg-August-Universität zu Göttingen

vorgelegt von

Simon Kochhäuser

aus Hilden 
Dekan:

I. Berichterstatter: Prof. Dr. med. G. Hasenfuß

II. Berichterstatterlin:

III. Berichterstatter/in:

Tag der mündlichen Prüfung: 


\section{Inhaltsverzeichnis}

1. Einleitung 5

1.1 Herzphysiologie $\quad 5$

1.1.1 Mechanik der Herzaktion 5

$\begin{array}{ll}1.1 .2 \text { Herzzeitvolumen } & 6\end{array}$

1.1.3 Elektromechanische Kopplung 6

$\begin{array}{ll}1.2 \text { Herzinsuffizienz } & 8\end{array}$

1.2.1 Definition, Bedeutung und Klinik 8

1.2.2 Stadien der Herzinsuffizienz 8

1.2.2.1 Akute Belastungsanpassung 9

1.2.2.2 Herzhypertrophie 9

1.2.2.3 Veränderungen des Herzens in der Herzinsuffizienz 10

1.3 Experimentelle Modelle zur Erforschung der Herzinsuffizienz 11

1.4 Das Renin- Angiotensin- Aldosteron- System 12

1.4.1 Renales Renin- Angiotensin- Aldosteron- System 12

1.4.2 Angiotensin II 13

1.4.3 Das kardiale Renin- Angiotensin- System 14

1.5 ER- Stress $\quad 15$

1.5.1 Aufbau des Endoplasmatischen Retikulums 15

1.5.2 Funktion des Endoplasmatischen Retikulums 16

1.5.2.1 Proteinbiosynthese am Endoplasmatischen Retikulum 16

$\begin{array}{ll}\text { 1.5.2.2 Faltung und Qualitätskontrolle } & 17\end{array}$

$\begin{array}{ll}\text { 1.5.2.3 Lipidsynthese } & 18\end{array}$

1.5.3 ER-Stress 18

1.5.4 Die „unfolded protein response“ 19

$\begin{array}{ll}\text { 1.5.4.1 Signaltransduktion der UPR } & 19\end{array}$

$\begin{array}{ll}\text { 1.5.4.2 Aktivierung der UPR } & 20\end{array}$

1.5.5 ER-Stress und die UPR in Herzhypertrophie- und Insuffizienz 21

$\begin{array}{ll}1.6 \text { Fragestellungen } & 21\end{array}$

2. Material und Methoden 23

2.1 Versuchslösungen 23

2.1.1 Präparationslösung 23

2.1.2 Zellkultur-Medium 23

2.1.3 Interventionsstoffe $\quad 24$

2.2 Langzeitkulturanlage für isolierte Muskelstreifen $\quad 24$

2.2.1 Aufbau 24

2.2.1.1 Isometrische Anlage $\quad 24$

2.2.1.2 Isotone Anlage $\quad 26$

$\begin{array}{ll}\text { 2.2.2 Datenerfassung } & 27\end{array}$

$\begin{array}{ll}\text { 2.2.3 Reinigung und Autoklavierung } & 27\end{array}$

$\begin{array}{ll}2.3 \text { Versuchsprotokoll } & 27\end{array}$

2.3.1 Versuchstiere $\quad 27$

$\begin{array}{ll}2.3 .2 \text { Herzentnahme } & 27\end{array}$

2.3.3 Muskelstreifenpräparation 28

2.3.4 Einhängen der Muskelstreifen 29

2.3.5 Kalzium-Aufbau, Stimulation, Einschlagen und Dehnung 29

2.3.6 Interventionsprotokoll 29 
2.4 Monocrotaline-Modell $\quad 31$

2.4.1 Tierstamm 31

2.4.2 Probenentnahme 32

2.5 Quantitative Genexpressionsanalyse $\quad 32$

2.5.1 RNA-Isolation 32

2.5.2 Umschreiben in cDNA 33

2.5.3 Realtime-PCR 34

2.5.3.1 Funktionsprinzipien 34

2.5.3.2 Durchführung 35

2.5.3.3 Auswertung 36

2.6 Western-Immunoblot-Analyse 37

2.6.1 Pufferlösungen 37

2.6.2 Vorgehen 37

2.7 Mathematische Methoden 39

3. Ergebnisse $\quad 40$

3.1 Untersuchungen an isolierten Kaninchen-Muskelstreifen $\quad 40$

3.1.1 Lösungsmittelkontrolle $\quad 40$

3.1.2 Induktion von ER-Stress in isolierten Muskelstreifen durch Tunicamycin 42

3.1.3 Einfluss von mechanischer Last 43

3.1.3.1 Funktionelle Bedeutung der Kontraktionsform 43

3.1.3.2 Isometrische Kontraktion 44

3.1.3.3 Isotone Kontraktion 46

3.1.4 Einfluss von Angiotensin II auf myokardialen ER-Stress 47

3.1.5 Blockade des AT-II-Rezeptors unter mechanischer Belastung 49

3.2 Untersuchungen im Monocrotaline-Modell $\quad \mathbf{5 0}$

3.2.1 Messung der Expression von ER-typischen Chaperonen auf mRNA-Ebene 51

3.2.2 Messung von ER-typischen Chaperonen auf Proteinebene 51

\section{Diskussion $\quad 55$}

4.1 Untersuchungen der Expressionsantwort des isolierten Herzmuskels auf akute biomechanische Laständerungen

4.2 Untersuchungen an einem Modell für chronische Last-induzierte Herzhypertrophie

4.3 Bedeutung von ER-Stress bei mechanischer Belastung des Herzens $\quad 60$

4.4 Einfluss von Angiotensin II auf die Entstehung von kardialem ER-Stress $\quad 63$

$\begin{array}{ll}4.5 \text { Ethanol und ER-Stress } & 64\end{array}$

5. Zusammenfassung 66

6. Abkürzungsverzeichnis $\quad 68$

$\begin{array}{ll}\text { 7. Literaturverzeichnis } & 69\end{array}$ 


\section{Einleitung}

\subsection{Herzphysiologie}

\subsubsection{Mechanik der Herzaktion}

Die Aktion des menschlichen Herzens lässt sich unter mechanischen Gesichtspunkten in verschiedene Phasen einteilen.

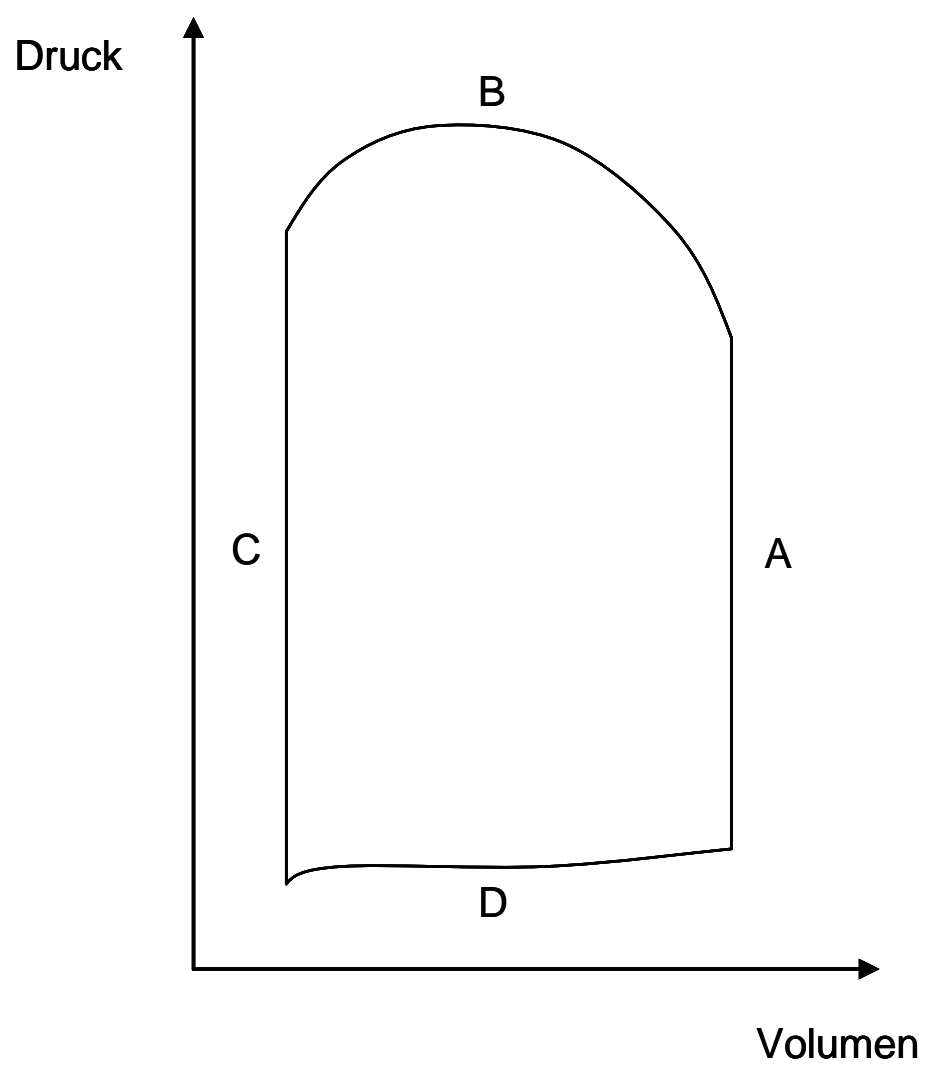

Abbildung 1: Druck-Volumen-Diagramm der Herzaktion. Erläuterung: Siehe Text.

Die Kontraktion der Ventrikel beginnt nach der Füllung der Herzkammern mit einer isometrischen Kontraktion (A). Hierbei kommt es zu einer Erhöhung der ventrikulären Wandspannung. Aufgrund des höheren Drucks in der Aorta und der Pulmonalarterie bleiben die Taschenklappen allerdings noch geschlossen und die Muskelfasern verkürzen sich nicht. Übersteigt der intraventrikuläre Druck den der abführenden Gefäße, öffnen sich die Taschenklappen, und es erfolgt die Austreibung des Blutes aus den Herzkammern (B). Durch den Druckanstieg in der frühen Austreibungsphase nimmt die Wandspannung in dieser Phase auch bei abnehmendem Volumen weiter zu. Diese Kombination aus isometrischer und isotoner Kontraktion wird auch als 
auxotone Kontraktion bezeichnet. Die Relaxation der ventrikulären Muskulatur erfolgt isometrisch (C). Die Dehnung der Ventrikelmuskulatur erfolgt passiv während der Füllung der Herzkammern (D). Diese vollzieht sich zu ca. 80\% passiv durch das Verschieben der kardialen Klappenebene nach kranial, und zu ca. 20\% durch die anschließende Kontraktion der Vorhofmuskulatur.

\subsubsection{Herzzeitvolumen}

Das Herzzeitvolumen ( $\mathrm{HZV}$ ) errechnet sich aus der Herzfrequenz (HF) und dem Herzschlagvolumen (SV) nach der Formel: $\mathbf{H Z V = H F * S V}$. Es ist einer der wichtigsten Parameter für die Beurteilung der Herzfunktion, da es die Fähigkeit des Herzens zur Aufrechterhaltung der Blutversorgung des Körpers widerspiegelt.

Das Schlagvolumen wird hierbei durch die Füllung und Vordehnung des Herzens (Vorlast), den Gefäßwiderstand (Nachlast) und die kardiale Kontraktilität (Inotropie) beeinflusst. Die Herzfrequenz wird hauptsächlich durch neurohumorale Stimulation reguliert.

\subsubsection{Elektromechanische Kopplung}

Kalziumionen spielen bei der Umsetzung von elektrischer Erregung in mechanische Kontraktion eine zentrale Rolle. Durch die elektrische Erregung der Zellmembran kommt es nicht nur zur Öffnung von Natriumkanälen, sondern zusätzlich zur Öffnung des spannungsabhängigen L-Typ-Kalziumkanals (LTCC). Das infolge des Konzentrations- und Ladungsgefälles in die Zelle einströmende Kalzium aktiviert den am Sarkoplasmatischen Retikulum (SR) lokalisierten Ryanodinrezeptor (RyR), über den eine Freisetzung der im SR gespeicherten Kalziumionen erfolgt. Dieser Vorgang wird als Kalzium-induzierte Kalziumfreisetzung bezeichnet (CICR) (Fabiato, 1983). Der im „reverse mode“ arbeitende Natrium-Kalzium-Austauscher (NCX) hat unter physiologischen Bedingungen keinen großen Anteil an der Erhöhung der zytoplasmatischen Kalziumkonzentration (Bers und Weber 2002). Diese steigt durch den Kalziumeinstrom von einem diastolischen Wert zwischen 80 und $250 \mathrm{nM}$ auf systolische Werte zwischen 0,5 und $2 \mu \mathrm{M}$ (Bers 2001).

Im Zytosol frei diffundierende Kalziumionen binden an den Myofilamenten an Troponin C ( $\mathrm{TnC}$ ) und bewirken eine Konformationsänderung die eine Interaktion von Troponin und Myosin ermöglicht (Solaro und van Eyk 1996). Aus dieser lockeren Bindung heraus entsteht Bewegung durch die Kooperation benachbarter Aktin- 
Monomere (Vibert et al. 1997). Die Hydrolyse von Adenosintriphosphat (ATP) an der Myosinquerbrücke liefert die für die mechanische Kontraktion benötigte Energie (Brenner und Eisenberg 1987).

Zur Beendigung der Kontraktion muss die zytosolische Kalziumkonzentration wieder verringert werden. Die Kalzium-ATPase des sarkoplasmatischen Retikulums (SERCA) spielt bei diesem Vorgang eine große Rolle. Unter Hydrolyse von einem Molekül ATP transportiert sie zwei Kalziumionen aus dem Zytosol in das Lumen des SR. Damit trägt sie nicht nur zur Elimination von Kalzium aus dem Zytosol bei, sondern ist auch entscheidend an der Regulation der Kalziumkonzentration im SR beteiligt. Auf diesem Weg werden ca. $3 / 4$ des zytosolischen Kalziums eliminiert (Piacentino et al. 2003). Als zweiter wichtiger Eliminationsweg ist der im „forward mode" arbeitende Natrium-Kalzium-Austauscher (NCX) zu nennen. Er befördert ein Kalziumion im Austausch gegen drei Natriumionen in den extrazellulären Raum (Crespo et al. 1990). Einen kleinen Anteil an der diastolischen Kalziumeliminierung haben die sarkolemmale Kalzium-ATPase (Caroni und Carafoli 1980) und der mitochondrale Kalzium-Uniporter (Carafoli 1975).

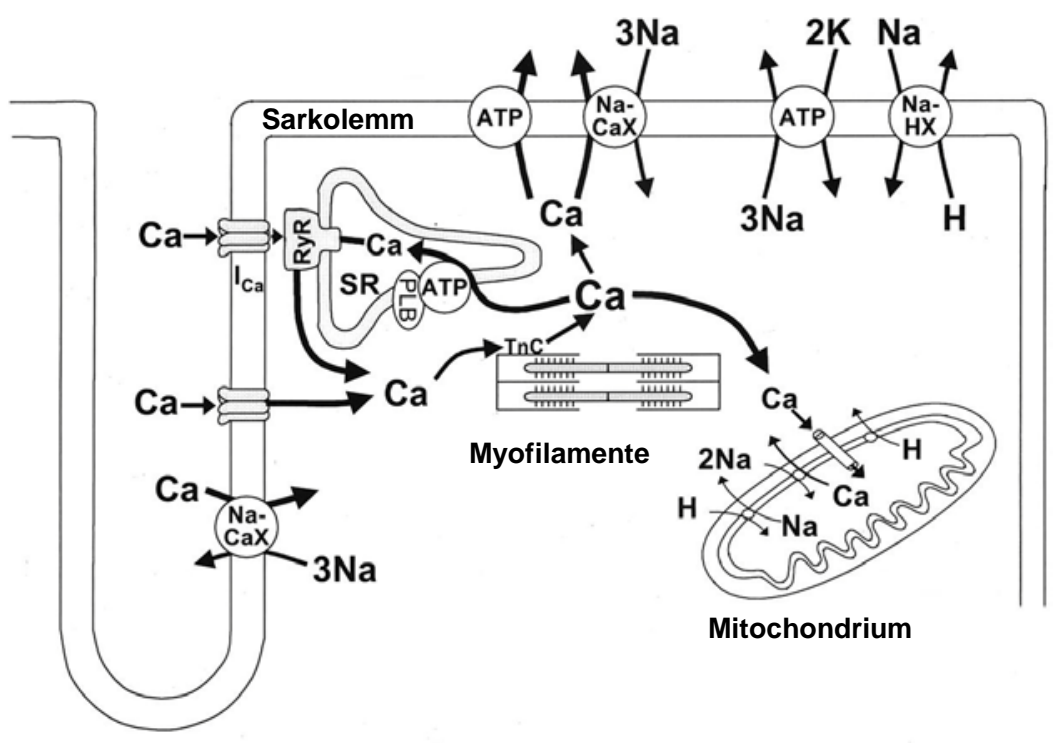

\author{
ATP+ PLB am SR: SERCA \\ SERCA: Kalzium-ATPase des \\ sarkoplasmatischen Retikulums \\ Ca: Kalziumion \\ $\mathrm{H}$ : Wasserstoffion \\ $\mathrm{K}$ : Kaliumion \\ Na: Natriumion \\ Na-CaX: Natrium-Kalzium-Austauscher \\ $\mathrm{Na}-\mathrm{HX}$ : Natrium-Protonen-Austauscher \\ ATP: Adenosintriphosphat \\ PLB: Phospholamban \\ RyR: Ryanodinrezeptor \\ SR: Sarkoplasmatisches Retikulum \\ TnC: Troponin C
}

Abbildung 2: Regulation der intrazellulären Kalziumhomöostase (modifiziert nach Bers, "Calcium fluxes involved in control of cardiac myocyte contraction", Circ Res 87, 275-281) 


\subsection{Herzinsuffizienz}

\subsubsection{Definition, Bedeutung und Klinik}

Bei der Herzinsuffizienz handelt es sich nicht um ein isoliertes Phänomen, sondern um ein komplexes Syndrom. Eine globale Definition, die auch von der Weltgesundheitsorganisation verwendet wird, beschreibt die Herzinsuffizienz als „das Unvermögen des Herzens, bei einem ausreichenden venösen Angebot und einem normalen enddiastolischen Ventrikeldruck die peripheren Organe suffizient mit oxygeniertem Blut zu versorgen“ (McMurray 1996, S. 14). Nach heutiger Auffassung ist eine genaue Definition aber nur durch eine differenzierte Betrachtung von Klinik, Anamnese und technischen Untersuchungsergebnissen möglich (Remme und Swedberg 2001).

Die Inzidenz der Herzinsuffizienz in Europa beträgt ca. 2-4 Neuerkrankungen pro 1000 Einwohner pro Jahr. Die häufigsten Ursachen sind ischämische Schädigung, Bluthochdruck und Kardiomyopathien (Cowie et al. 1999).

Klinisch kann man bei den betroffenen Patienten je nach Schwere der Erkrankung Zeichen eines kardialen Vorwärtsversagens wie z.B. Luftnot, Leistungsminderung und Zyanose und Zeichen des Rückwärtsversagens wie Venenstauung, Ödeme, Aszites oder Pleuraergüsse finden. Zusätzlich werden häufig auch allgemeine Symptome wie Herzvergrößerung, sympathische Überaktivität, oder Herzrhythmusstörungen beklagt. Anhand der Ausprägung der klinischen Symptome erfolgt die Einteilung in vier Klassen nach der New York Heart Association (NYHA). Ist keine kausale Therapie der Herzinsuffizienz möglich, liegt die 5-Jahres-Mortalität bei etwa 60\% (Mosterd et al. 2001).

\subsubsection{Stadien der Herzinsuffizienz}

1961 beschrieb Meerson drei Stadien in der Entstehung der Herzinsuffizienz. Zunächst kommt es demnach zu einer Phase der akuten Belastungsanpassung (siehe auch 1.2.2.1). Danach entsteht eine kompensierte Herzinsuffizienz mit den Zeichen der Herzhypertrophie (siehe auch 1.2.2.2). Am Ende steht die dekompensierte Herzinsuffizienz, bei der eine Reihe von unvorteilhaften Veränderungen (siehe auch 1.2.2.3) die Fähigkeit des Myokards zur Anpassung an die erhöhte Belastung beeinträchtigt. 


\subsubsection{Akute Belastungsanpassung}

Zur Kompensation einer akuten Belastung stehen dem Herz- Kreislaufsystem neben der Regulation des Gefäßtonus und des Salz- und Flüssigkeitshaushaltes auch Mechanismen am Herzmuskel selbst zur Verfügung.

So führt eine Dehnung des Herzmuskels zu einer Steigerung der Kontraktilität. Hierbei kann man eine schnelle erste Phase (Frank-Starling-Mechanismus) von einer über die nächsten 20 bis 30 Minuten dauernden zweiten Phase (Anrep-Effekt) unterscheiden. In der ersten Phase kommt es zu einer Steigerung der myofilamentären Kalziumsensitivität (Kentish et al. 1986) und zu einer räumlichen Annäherung der Myofilamente (Wang YP und Fuchs 1995). Der zweiten Phase scheint eine Erhöhung der intrazellulären Natrium- (Alvarez et al. 1999) und Kalziumkonzentration (Gannier et al. 1996, Kentish und Wrzosek 1998) zugrunde zu liegen. Die genauen Mechanismen dieses Vorgangs sind allerdings noch nicht abschließend geklärt.

Zusätzlich führt eine Erhöhung der Herzfrequenz zu einer verbesserten Kontraktilität des Herzmuskels. Diese Kraft-Frequenz-Beziehung („Force-frequency-relationship“, FFR) wurde schon 1871 von Bowditch an Froschherzen gezeigt und ist auch an humanen Herzen nachweisbar (Hasenfuß et al. 1994b, Pieske et al.1999). Die Ursache hierfür ist hauptsächlich eine verstärkte Beladung des SR mit Kalziumionen (Pieske et al. 2002). Somit steigt auch die Menge der während der nächsten Systole freigesetzten Kalziumionen, was wiederum zu einer stärkeren Kontraktion führt.

Ein wichtiger Beitrag zur Reaktion auf akute kardiale Belastung leistet die Aktivierung neurohumoraler Systeme. Diese haben neben Wirkungen auf Gefäße und Nieren auch Effekte am Herzmuskel. Katecholamine wie Adrenalin und Noradrenalin entfalten über ihre Wirkung aưr - und $\beta$-Rezeptoren eine starke, positiv inotrope Wirkung am Herzen. Das Renin-Angiotensin-Aldosteron-System und Endothelin haben ebenfalls positiv inotrope Wirkung. Die im Herzen synthetisierten natriuretischen Peptide ANP und BNP wirken durch ihren Einfluss auf die renale Diurese vorlastsenkend, verringern den Gefäßtonus und hemmen das ReninAngiotensin-Aldosteron-System (de Bold 1985, Yoshimura et al. 1991).

\subsubsection{Herzhypertrophie}

In diesem Stadium kommt es durch eine andauernde Belastung zu einer Hypertrophie der Herzmuskelzellen. Dieses Größenwachstum geht mit dem Einbau 
von zusätzlichen kontraktilen Proteinen einher, was zu einer zum Teil stark gesteigerten Proteinbiosynthese führt.

Konsequenz der Hypertrophie ist eine Vergrößerung der Wanddicke des Herzens, was nach dem Laplace'schen Gesetz: $\mathbf{K}=(\mathbf{P} * \mathbf{r}) / \mathbf{2 d}(\mathrm{K}=\mathrm{Kraft}$ pro Wandquerschnitt; $\mathrm{P}=$ Innendruck; $d=$ Wanddicke; $r=$ Radius) zu einer Abnahme der Wandspannung führt. Eine Herzhypertrophie ist physiologisch bei Sportlern und Schwangeren. Kommt sie durch pathologische Veränderungen zustande, können zwei Formen anhand der Art der Belastung unterschieden werden. Eine Druckbelastung führt zu einer konzentrischen Hypertrophie mit einem parallelen Einbau von kontraktilen Proteinen. Pathologische Volumenbelastung des Herzens führt zu einem Einbau von kontraktilen Proteinen hintereinander und einer daraus resultierenden exzentrischen Hypertrophie. In diesem stabilen Stadium der Herzhypertrophie bleibt die systolische Funktion erhalten (Takahashi et al. 1980) oder ist sogar leicht gesteigert (Grossman et al. 1975, Sasayama et al. 1977), weil durch die Massezunahme des Herzmuskels die vermehrte biomechanische Belastung kompensiert werden kann.

\subsubsection{Veränderungen des Herzens in der Herzinsuffizienz}

Makroskopisch betrachtet kommt es während der Herzinsuffizienz zu einer Größenzunahme des Herzens und zu einer Veränderung der Kammergeometrie (Remodeling). Mikroskopisch zeigen sich eine Größenzunahme der einzelnen Kardiomyozyten (Gerdes et al. 1992), sowie die Zunahme der extrazellulären Matrix mit Vermehrung der Fibroblasten (Schaper und Speiser 1992).

Es kommt weiterhin zu einer Veränderung der Genexpression, die in der Herzinsuffizienz fetale Genexpressionsmuster reaktiviert (Reexpression). Dies betrifft z.B. die kontraktilen Proteine, die in der Folge eine erhöhte Kalziumsensitivität aufweisen (Schwinger et al. 1994, Wolff et al. 1996, van der Velden et al. 2002, Brixius et al. 2002).

Des Weiteren zeigen sich infolge der chronischen Aktivierung ein vermindertes Ansprechen auf neurohumorale Stimulation sowie Veränderungen bei den Systemen zur akuten Belastungsanpassung.

Eine wichtige Rolle bei der Entwicklung der Herzinsuffizienz spielen deutliche Veränderungen der Kalziumhomöostase (Gwathmey et al. 1987, Hasenfuß et al. 1992). Es kommt zu einer Reduktion der Amplitude des Kalziumtransienten, einer Verlangsamung des Abfalls des Kalziumtransienten sowie einem erhöhten 
diastolischen Kalziumgehalt (Beuckelmann und Erdmann 1992, Beuckelmann et al. 1995, Pieske et al. 1995). Dies geschieht vermutlich vor allem infolge einer reduzierten Expression der SERCA (Studer et al. 1994, Hasenfuß et al. 1994a, Dash et al. 2001, Jiang MT et al. 2002) und einer Steigerung der Expression des NCX (Studer et al. 1994, Flesch et al. 1996). Funktionell resultieren aus diesen Veränderungen eine Minderung der systolischen Kraft, sowie eine diastolische Dysfunktion im Sinne einer Relaxationsstörung.

\subsection{Experimentelle Modelle zur Erforschung der Herzinsuffizienz}

Um die Auswirkung von erhöhter biomechanischer Last auf das Herz zu untersuchen, steht eine Vielzahl von unterschiedlichen experimentellen Ansätzen zur Verfügung. Grob kann hierbei zwischen in-vivo- und in-vitro-Modellen unterschieden werden.

\begin{tabular}{|c|c|c|c|}
\hline Methode & Lastform & Vorgehen & Quelle \\
\hline Aortenbanding & $\begin{array}{l}\text { Druckbelastung des } \\
\text { linken Ventrikels }\end{array}$ & $\begin{array}{l}\text { Operative Verengung } \\
\text { der Aorta }\end{array}$ & Rockman et al. 1991 \\
\hline Pulmonales Banding & $\begin{array}{l}\text { Druckbelastung des } \\
\text { rechten Ventrikels }\end{array}$ & $\begin{array}{l}\text { Operative Verengung } \\
\text { der A. pulmonalis }\end{array}$ & Tarnavski et al. 2004 \\
\hline Monocrotaline & $\begin{array}{l}\text { Druckbelastung des } \\
\text { rechten Ventrikels }\end{array}$ & $\begin{array}{l}\text { Durch Monocrotaline } \\
\text { induzierte Vaskulitis } \\
\text { der Lungengefäße }\end{array}$ & Kögler et al. 2003 \\
\hline Aorto-kavaler Shunt & $\begin{array}{l}\text { Volumenbelastung des } \\
\text { linken Ventrikels }\end{array}$ & $\begin{array}{l}\text { Shunt zwischen Aorta } \\
\text { und Vena cava inferior }\end{array}$ & Wang X et al. 2003 \\
\hline LAD Ligatur & $\begin{array}{l}\text { Verlust an kontraktilem } \\
\text { Gewebe }\end{array}$ & $\begin{array}{l}\text { Ligatur einer } \\
\text { Koronararterie }\end{array}$ & Tarnavski et al. 2004 \\
\hline
\end{tabular}

Tabelle 1: In-vivo-Modelle zur Erforschung der Herzinsuffizienz

Der Vorteil dieser Methoden liegt darin, dass die Zusammenhänge, die zur Entstehung der Herzinsuffizienz führen, unter realitätsnahen Bedingungen untersucht werden können. Dadurch fällt eine Übertragung der Ergebnisse auf die Praxis leichter. Der Nachteil dieser Methoden ist, dass einzelne Aspekte (z.B. veränderte biomechanische Last und begleitende neurohumorale Aktivierung) nicht isoliert untersucht werden können und es dadurch schwer fällt, den tatsächlichen Einfluss eines einzelnen Faktors richtig zu beurteilen. 


\begin{tabular}{|l|l|l|}
\hline Methode & Lastform & Quelle \\
\hline Einzelstreifen & Vorlast & Wollenberger 1985 \\
\hline Muskelstreifen & Vor- und Nachlast & Sonnenblick et al. 1965 \\
\hline Ganzherzen & Vor- und Nachlast & Neely et al. 1967 \\
\hline
\end{tabular}

Tabelle 2: In-vitro-Methoden zur Untersuchung der Herzinsuffizienz

Diese Methoden bieten den Vorteil, den Einfluss von biomechanischer Last unabhängig von anderen Einflüssen, wie neurohumoraler Stimulation, untersuchen zu können. Der Nachteil liegt hauptsächlich in der relativ kurzen Lebensdauer der Präparate, was eine längere Untersuchung in einem in-vitro-Modell schwierig macht. In früheren Studien mit isolierten Muskelstreifen konnte eine lastabhängige Regulation der kardialen Genexpression gezeigt werden (Kögler et al. 2006). Nach vorbereitenden Untersuchungen wurde beschlossen, die vorliegende Studie sowohl unter Bedingungen von erhöhter Vor- und Nachlast als auch unter nachlastfreien Bedingungen durchzuführen.

\subsection{Das Renin- Angiotensin- Aldosteron- System}

\subsubsection{Renales Renin- Angiotensin- Aldosteron- System}

Das Renin- Angiotensin- Aldosteron- System (RAAS) ist ein hormonelles System, das eine wichtige Rolle bei der Regulation des intravasalen Volumens und des peripheren Gefäßwiderstandes spielt. Die klassische Kaskade des RAAS beginnt mit der Freisetzung von Renin aus dem juxtaglomerulären Apparat der Niere. Dort wird Renin in Form einer inaktiven Vorstufe, dem Prorenin, gebildet, durch Proteolyse aktiviert und mittels kontrollierter Exozytose freigesetzt. Der hauptsächliche Reiz für die Freisetzung von Renin besteht in einer Minderdurchblutung des juxtaglomerulären Apparates infolge eines systemischen Volumenmangels oder einer lokalen Durchblutungsregulation. Das Substrat der Protease Renin ist das in der Leber gebildete und freigesetzte Peptid Angiotensinogen, welches durch Abspaltung eines N-terminalen Stückes in Angiotensin I umgewandelt wird. Angiotensin I wird durch das Angiotensin-Converting-Enzyme (ACE), das hauptsächlich im Endothel von Gefäßen lokalisiert ist, in das aktive Angiotensin II umgewandelt. Angiotensin II ist das hauptsächliche Effektorhormon des Systems, 
das eine Reihe verschiedener lokaler und systemischer Wirkungen entfaltet (siehe 1.4.2).

Zusätzlich zu diesen klassischen Komponenten des RAAS wurden in den letzten Jahren auch andere Faktoren in einen Zusammenhang mit dem RAAS gebracht. So soll die kardiale Chymase eine hohe Potenz zur Bildung von Angiotensin II haben (Urata et al. 1990). Eine andere Studie konnte ihre Aktivität allerdings nicht bestätigen (Saris et al. 2000), während Koka et al. (2006) eine Rolle der Chymase unter pathologischen Bedingungen vermuten.

Auch innerhalb der RAAS-Kaskade wurden neue Komponenten entdeckt. Wie das ACE 2 (Donoghue et al. 2000), dessen Aktivierung zu einer verstärkten Bildung von Angiotensin (1-7) führt. Angiotensin (1-7) hat vasodilatatorische und antiproliferative Effekte (Ferrario 2006).

Auch scheint mit dem AT4-Rezeptor ein spezifischer Rezeptor für Angiotensin IV, ein Abbauprodukt von Angiotensin II, zu existieren (Chai et al. 2004). Des Weiteren wurde die Existenz eines Reninrezeptors belegt (Nguyen et al. 2002), der zu einer Verstärkung der Bildung von Angiotensin II beiträgt (Danser und Deinum 2005).

\subsubsection{Angiotensin II}

Das Oktapeptid Angiotensin II ist das hauptsächliche Effektorhormon des RAAS. Mit dem AT1- und dem AT2- Rezeptor sind zwei Rezeptoren bekannt, die die Wirkungen von Angiotensin II vermitteln. Dabei handelt es sich um 7-TransmembrandomänenRezeptoren, die über eine Aktivierung des Phosphatidylinositolzyklus die intrazelluläre Kalziumkonzentration erhöhen und die Proteinkinase C aktivieren. Der AT1- Rezeptor kann zusätzlich die Adenylatzyklase aktivieren und spezifische Kaliumkanäle hemmen.

Die klassischen Effekte des Angiotensin II werden durch den AT1- Rezeptor vermittelt. Er wird in großer Zahl in den glatten Muskelzellen der Gefäßwände exprimiert und führt dort über eine Konstriktion zu einer Zunahme des peripheren Widerstandes und des Blutdruckes (Hughes 1998). Zusätzlich reguliert dieser Rezeptor auch eine zentrale Erhöhung des Blutdruckes (Ribeiro et al. 1985). Der zweite bedeutende Effekt des AT1- Rezeptors besteht in einer Vergrößerung des zirkulierenden Blutvolumens. Dies geschieht langfristig durch eine zentrale Steigerung des Durstgefühls und eine vermehrte Freisetzung von $A D H$, sowie durch die Ausschüttung von Aldosteron (Giacchetti et al. 1996). Aldosteron ist ein 
Mineralokortikoid, das in der Zona glomerulosa der Nebennierenrinde gebildet wird. Es führt über eine Zunahme der tubulären Natriumresorption zu einer Verminderung des renalen Flüssigkeitsverlustes. Schließlich verstärkt Angiotensin II über den AT1Rezeptor das Zellwachstum, die Bildung von extrazellulärer Matrix (Huckle und Earp 1994) sowie Entzündungsreaktionen und kann die Apoptose von Kardiomyozyten auslösen (Schröder et al. 2006).

Die Bedeutung des AT2- Rezeptors ist bis heute nicht abschließend geklärt. Er scheint eine Rolle bei der pränatalen Organentwicklung zu spielen. Darüber hinaus zeigt er im Bezug auf Zellwachstum und Zelldifferenzierung eher antagonistische Effekte zum AT1- Rezeptor (Stoll et al. 1995, Meffert et al. 1996).

\subsubsection{Das kardiale Renin- Angiotensin- System}

Die Methoden der Molekularbiologie sowie funktionelle Untersuchungen mit Hilfe von transgenen Tiermodellen lieferten in den letzten Jahren zunehmend Beweise für die Existenz lokaler Renin-Angiotensin-Systeme (RAS). So kann man heute davon ausgehen, dass einige der kardioprotektiven Effekte von ACE- Hemmern oder AT1Antagonisten nicht nur auf eine Senkung des Blutdruckes, sondern auch auf eine direkte Wirkung am Herzen zurückgehen.

Um die Bedeutung eines lokalen RAS abschätzen zu können, spielt es eine große Rolle, in welchem Ausmaß die einzelnen Komponenten in dem entsprechenden Organ gebildet werden, bzw. aus dem Plasma aufgenommen werden können. Gegenstand besonders kontroverser Diskussion im kardialen RAS ist die Expression von Prorenin und Renin. Zwar konnten einige Untersucher Renin- mRNA nachweisen (Dzau und Re 1987; Paul et al. 1988 und 1993). Andere widersprachen diesen Ergebnissen allerdings und führten die veröffentlichten Daten auf Verunreinigung durch systemisch zirkulierendes Renin zurück (von Lutterotti et al. 1994). In den letzten Jahren wurde ein alternatives Genprodukt, das so genannte Exon 1 Renin, entdeckt (Clausmeyer et al. 2000; Peters und Clausmeyer 2002), welches die widersprüchlichen Ergebnisse evtl. erklären könnte.

Die Aufnahme von Renin und Prorenin in kardiale Zellen durch Diffusion (de Lannoy et al. 1997; Jan Danser und Saris 2002; Peters und Claumeyer 2002) und spezifische Rezeptoraktivität (Nguyen et al. 2002 und 2004; Peters und Claumeyer 2002) ist dagegen weitaus weniger umstritten. Somit scheint es wahrscheinlich, dass 
Renin über spezifische und unspezifische Mechanismen an die kardialen Zellen gebunden wird und dort für die Spaltung von Angiotensinogen zu Verfügung steht.

Im Gegensatz zur Expression von Renin ist die Expression und Aktivität von ACE im Herzen gut belegt (Paul et al. 1993, Yamada et al. 1991). Eine lokale Synthese von Angiotensinogen wurde in geringen Mengen gezeigt (Paul et al. 1993). Funktionell bedeutender scheint allerdings die Aufnahme aus der systemischen Zirkulation ins Herz (de Lannoy et al. 1997). Experimente mit radioaktiv markiertem Angiotensin I und II konnten zeigen, dass ein Großteil der Angiotensinpeptide im Herzen aus lokaler Produktion stammen (Van Kats et al. 1998).

Kardiomyozyten exprimieren sowohl den AT1- als auch den AT2- Rezeptor (Rogers et al. 1986). Die funktionelle Bedeutung der lokalen Angiotensin- II- Produktion ist noch nicht vollständig geklärt. Analog zu Effekten von zirkulierendem Angiotensin II ist eine Rolle bei der Entstehung kardialer Hypertrophie und beim kardialen Remodeling denkbar. Im Zusammenhang mit dieser Arbeit ist besonders die potenzielle Bedeutung des kardialen RAS für die Antwort auf mechanische Dehnung sowie für die Vermittlung von Apoptose (siehe 1.4.2) interessant. Dehnung von isolierten Kardiomyozyten führt zu einer Freisetzung von Angiotensin II über einen durch p53 und JAK/STAT vermittelten Mechanismus (Sadoshima et al. 1993, Leri et al. 1998).

\subsection{ER- Stress}

\subsubsection{Aufbau des Endoplasmatischen Retikulums}

Das Endoplasmatische Retikulum (ER) besteht aus verzweigten Röhren und abgeplatteten Zisternen, die sich durch das ganze Zytosol ziehen, und vermutlich einen einzigen, membranumschlossenen Raum bilden. Morphologisch und funktionell lässt sich das sog. raue ER vom glatten ER abgrenzen. Das in sekretorischen Zellen besonders stark ausgeprägte raue ER ist durch das Vorkommen von Ribosomen an der zytosolischen Seite der Membran gekennzeichnet. Das glatte ER ist weitaus seltener und in den meisten Zellen der Ort von Vesikelbildung und Vesikelabgang (transistorisches ER). In anderen Zellen nimmt es aber auch speziellere Funktionen wahr. So spielt das glatte ER der 
Muskelzellen (Sarkoplasmatisches Retikulum) als Kalziumspeicher eine wichtige Rolle in der Regulation von Kontraktion und Relaxation (siehe 1.1.3 S. 6f.).

\subsubsection{Funktion des Endoplasmatischen Retikulums}

\subsubsection{Proteinbiosynthese am Endoplasmatischen Retikulum}

Alle Transmembranproteine, die luminalen Proteine des ER, des Golgi-Apparates und der Lysosomen sowie ein großer Teil der sekretorischen Proteine werden an der Membran des rauen ER gebildet und durchlaufen Faltung und Qualitätskontrolle im Lumen des ER.

Gehört ein Protein zu einer der oben genannten Gruppen und ist somit zur Synthese am ER vorgesehen, so enthält sein Aminosäurecode eine oder mehrere Signalsequenzen. Wird diese Signalsequenz von einem, im Zytosol vorhandenen, „signal recognition particle“ (SRP) erkannt, bindet das SRP an die Signalsequenz und stoppt die Translation. Das SRP vermittelt nun durch eine Interaktion mit dem an der ER-Membran lokalisierten SRP-Rezeptor die Bindung des Ribosoms an die Membran des ER. In der Nähe des SRP-Rezeptors befindet sich ein Translokator, der sich bei Kontakt mit der Signalsequenz öffnet und so den Transport des Proteins in das Lumen des ER ermöglicht. Gleichzeitig verhindert der Translokator durch eine enge Assoziation mit dem Ribosom den Verlust von niedermolekularen Stoffen aus dem Inneren des ER. Auf der Innenseite der ER-Membran bindet sofort das Chaperonprotein "glucose related protein 78“ (Grp78) an die wachsende Polypeptidkette und sorgt durch zyklischen Wechsel von Bindung und Freisetzung für einen nach luminal gerichteten Transport des Proteins. Am Ende des Translokationsprozesses wird die Signalsequenz abgespalten und das Protein in das ER-Lumen freigesetzt. Der Transport von Proteinen in das ER erfolgt also nicht wie bei anderen Zellorganellen posttranslationell, sondern in aller Regel kotranslationell. Transmembranmoleküle enthalten neben einer Signalsequenz für den Beginn des Transfers auch noch eine oder mehrere Transferstoppsequenzen. Solche Sequenzen stoppen die Translokation und verankern das Protein nach dem Verlassen des Translokators in der ER- Membran. Durch eine Kombination aus Transferstart- und Transferstoppsequenzen können somit auch Transmembranproteine mit mehreren Transmembrandomänen erzeugt werden. 


\subsubsection{Faltung und Qualitätskontrolle}

Alle an der ER-Membran synthetisierten Proteine durchlaufen Faltung und Qualitätskontrolle im ER. Ein wichtiger Bestandteil dieses Prozesses ist die Glykosylierung der Proteine mit vorgefertigten Oligosacchariden durch die Oligosaccharyl-Transferase. Dadurch entstehen verzweigte Saccharidseitenketten, die oft aus neun Molekülen Mannose und drei endständigen Glukosemolekülen bestehen.

Die Proteine dürfen das ER nur verlassen, wenn sie korrekt gefaltet sind. Im Lumen des ER befinden sich Chaperonproteine wie z.B. Grp78, die diesen Prozess beschleunigen und die Bildung von Aggregaten falsch gefalteter Proteine verhindern sollen. Um zu gewährleisten, dass nur korrekt gefaltete Proteine das ER verlassen, muss es zudem ein System zur Qualitätskontrolle geben. Bei diesem Vorgang spielt die Anzahl der einzelnen Zuckerreste in der Oligosaccharidseitenkette eine wichtige Rolle.

Durch das Enzym Glukosidase kommt es zu einer „Trimmung“ der Glukosereste, bis nur noch ein Molekül Glukose gebunden ist. Dieser einzelne, endständige Glukoserest führt zur Bindung von Calreticulin oder Calnexin. Diese $\mathrm{Ca}^{2+}$ abhängigen Chaperone halten die ungefalteten Proteine im ER fest und fördern die Ausbildung der richtigen Struktur. Das Enzym Glukosidase spaltet den verbleibenden Glukoserest $a b$ und löst somit die Bindung an die Chaperone. Ist das Protein zu diesem Zeitpunkt richtig gefaltet, kann es das ER verlassen. Ist die Faltung weiterhin unvollständig, fügt die Glukosyltransferase einen neuen Glukoserest an, es kommt zur erneuten Bindung mit Calnexin oder Calreticulin und der Kreislauf beginnt von neuem.

Trotz dieses Kontrollmechanismus erreichen viele Polypeptide nicht den Zustand der vollständigen Faltung. Hat ein Protein auch nach mehrmaligem Durchlauf des Calnexin/Calreticulin- Zyklus seinen korrekten Faltungszustand nicht erreicht, wird es aus dem ER ausgeschleust, im Zytosol ubiquitiniert und degradiert. Dieser Prozess wird „ER-assoziierte Degradation“ (ERAD) genannt.

Bei der Entscheidung, welche Proteine der ERAD zugeführt werden, spielt die Anzahl der Zuckerreste eine wichtige Rolle. Anders als bei der Kontrolle des Faltungszustandes ist hier aber die Anzahl der Mannosereste entscheidend. Entfernt das Enzym Mannosidase einen Mannoserest aus der Saccharidseitenkette, bindet das entsprechende Protein an das „ER degradation enhancing a-mannosidase-like 
protein" (EDEM), welches die Retranslokation in das Zytosol einleitet (Molinari et al. 2003; Oda et al. 2003). Ein anderes Protein, das in diesem Rahmen eine Rolle spielt, ist Osteosarcoma 9 (OS9) (Szathmary et al. 2005), das zusätzlich evtl. auch an der Selektion unglykosylierter Proteine beteiligt sein könnte (Bhamidipati et al. 2005). Der Mechanismus der Retranslokation über die ER-Membran zurück in das Zytosol ist noch nicht abschließend geklärt. Es wird vermutet, dass ein Komplex um das Protein Derlin-1 an der Bildung eines Membrankanals beteiligt ist, durch den der Rücktransport stattfindet (Ye et al. 2004). Im Zytosol angekommen, werden die Proteine ubiquitiniert und im Proteasom degradiert.

\subsubsection{Lipidsynthese}

Nahezu alle Hauptlipidklassen, darunter auch Phospholipide und Cholesterin, werden an der ER-Membran synthetisiert. Dabei befindet sich das aktive Zentrum der daran beteiligten Enzyme auf der zytosolischen Seite der Membran.

Die Herstellung des häufigsten Membranbausteins, der Phospholipide, beginnt mit der Synthese der hydrophoben Phosphatidsäure, deren Einbau die LipidDoppelschicht vergrößert. Erst dann werden die hydrophilen Kopfgruppen angebaut, welche die biologischen Eigenschaften bestimmen. Eine sog. Scamblase schwenkt einige der Phospholipide auf die luminale Seite der ER-Membran, um eine gleichmäßige Verteilung in der Doppelschicht zu erreichen.

Für den Transport der im ER gebildeten Membranbestandteile zu den Zellorganellen, die keine Vesikel mit dem ER austauschen, wie z.B.Mitochondrien, sind vermutlich spezielle Phospholipid-Austauschproteine verantwortlich.

\subsubsection{ER-Stress}

Unter ER-Stress versteht man einen Zustand, bei dem es zu einer Akkumulation von ungefalteten Proteinen im ER kommt. Eine solche Akkumulation kann entweder durch eine Behinderung der Faltungs- und Eliminationsprozesse im ER oder durch eine verstärkte Proteinsynthese am ER bedingt sein.

Eine Vielzahl von Situationen kann zu einer Störung der ER-Funktion führen: Ein Glukosemangel beeinträchtigt z.B. die ATP- abhängige Faltung und Glykosylierung der Proteine. Ein vermehrter Anfall von Sauerstoffradikalen beeinträchtigt das oxidative Milieu im ER und behindert so die Ausbildung von Disulfidbindungen bei der Proteinfaltung. Von besonderer Bedeutung für die Funktion des ER in 
Muskelzellen ist die $\mathrm{Ca}^{2+}$ - Abhängigkeit einiger ER-Chaperone (siehe 1.5.2.2). Diese führt dazu, dass jede Störung des $\mathrm{Ca}^{2+}$ - Haushaltes in der Zelle auch die Kapazität des ER zur Proteinfaltung beeinträchtigt.

Auch eine gesteigerte Belastung des ER mit Proteinen führt zu ER-Stress. Die Menge an neu synthetisierten Proteinen in der Zelle unterliegt sehr starken physiologischen Schwankungen in Abhängigkeit von der Zellaktivität und den äußeren Bedingungen.

\subsubsection{Die „unfolded protein response“}

Kommt es zu einer Überlastung der Faltungskapazität und zu einer Akkumulation von ungefalteten Proteinen im ER, versucht die Zelle diesen ER-Stress mit Hilfe der sog. „unfolded protein response“ (UPR) zu bewältigen. Die UPR soll das Gleichgewicht aus Proteinbiosynthese und Faltungskapazität des ER wieder herstellen. Hierzu wird die Proteinsynthese global gehemmt und gleichzeitig die Expression funktionell wichtiger Proteine spezifisch gesteigert (siehe auch 1.5.4.1). Unter anderem kommt es früh zu einer Steigerung der Expression des Chaperons Calreticulin. Aus diesem Grund ist Calreticulin gut als molekularer Marker für die Entstehung von ER-Stress und die UPR geeignet.

Eine, besonders in Muskelzellen bedeutsame, Möglichkeit zur Regulation der Faltungskapazität des ER ist die Beeinflussung des Kalziumstoffwechsels. Da eine Erhöhung der Kalziumkonzentration im ER zu einer verbesserten Funktion einiger Chaperone (siehe auch 1.5.2.2, S16-18) führt, ist auch die Steigerung der SERCAExpression Teil der UPR (Caspersen et al. 2000, Højmann et al. 2001).

Kann der ER-Stress nicht kompensiert werden, führt eine andauernde Aktivierung der UPR zur Apoptose der betroffenen Zelle, um den Organismus vor der unkontrollierten Bildung fehlgefalteter Proteine zu schützen.

\subsubsection{Signaltransduktion der UPR}

Es sind drei proximale Sensorproteine für die UPR bekannt. Das erste ist das „inositol-requiring protein 1“ (IRE1). Die Aktivierung von IRE1 (siehe 1.5.4.2) erlaubt eine Dimerisierung und Autophosphorylierung, die wiederum die spezifische Endoribonuklease-Funktion von IRE1 aktiviert (Tirasophon et al. 1998). Das Substrat dieser Endoribonuklease-Funktion ist die mRNA des "X-box-binding protein 1“ (XBP1): Während die Vorstufe der XBP1-mRNA für ein relativ instabiles Protein 
kodiert, führt die Translation der von IRE1 gespleißten Variante zur Expression eines potenten Transkriptionsfakors (Yoshida et al. 2001). XBP1 führt zur Regulation von Bestandteilen des ERAD-Systems (Yoshida et al. 2003), der Lipidsynthese (Sriburi et al. 2004) und ER-Chaperonen wie z.B. Grp78 oder Calreticulin (Lee et al. 2003).

Ein anderes proximales Sensorprotein ist die „protein kinase RNA-like ER kinase“ (PERK). Ähnlich wie bei IRE1 dimerisiert die PERK bei ER-Stress und wird durch Phosphorylierung aktiviert. Aktivierte PERK phosphoryliert und hemmt den

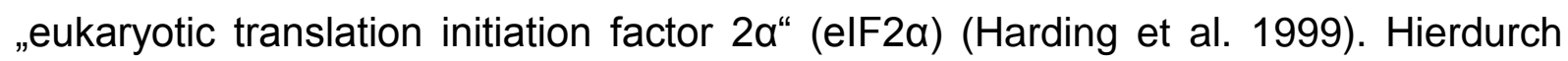
wird eine schnelle Abnahme der Proteinbelastung des ER erreicht. Paradoxerweise verstärkt die Phosphorylierung von ebF2durch PERK selektiv die Tran slation bestimmter mRNA. Dieses Phänomen ist am besten untersucht für den „activating transcription factor 4" (ATF4) (Harding et al. 2000), der unter anderem eine Rolle bei der Vermittlung von Apoptose hat (Jiang HY et al. 2004).

Der "activating transcription factor 6“ (ATF6) ist ein Transmembranprotein, das ebenfalls als ein ER-Stress-Sensor fungiert. Im Normalzustand wird ATF6 durch die Bindung von Grp78 an seine luminalen Anteile im ER festgehalten. Nach dem Lösen der Bindung unter ER-Stress wird ATF6 in den Golgi-Apparat transportiert und dort aktiviert (Haze et al. 1999). So kann ATF6 in den Nukleus gelangen und dort die Expression verschiedener Proteine regulieren, die zur Verbesserung der Faltungskapazität des ER beitragen (Yoshida et al. 1998, Li M et al. 2000).

\subsubsection{Aktivierung der UPR}

Die Aktivierung der drei Sensorproteine der UPR ist im Einzelnen noch nicht abschließend geklärt. Alle drei Proteine sind Transmembranmoleküle mit einer Domäne im ER-Lumen und einer im Zytosol. Es konnte gezeigt werden, dass das Chaperon Grp78 im ungestressten Zustand einen Komplex mit IRE1, ATF6 und PERK bildet, der unter ER-Stress dissoziiert (Shen et al. 2002; Bertolotti et al. 2000; Okamura et al 2000). Zudem konnte gezeigt werden, dass eine Überexpression von Grp78 die Aktivierung der UPR verhindert (Dorner et al. 1992).

Diese Erkenntnisse führten zu dem Modell, dass Grp78 an die luminale Seite der UPR-Sensoren bindet und so deren Aktivierung verhindert. Kommt es zu einer Akkumulation von ungefalteten Proteinen im ER, bindet Grp78 aufgrund der größeren Affinität an diese Proteine, wird so von den Sensoren titriert und die UPR wird aktiviert. Durch die nachfolgend erhöhte Expression von Grp78 läge außerdem 
ein negatives Feedback zur Regulation der UPR vor. Dieses Modell lässt aber nur die Aktivierung aller drei Sensoren gleichzeitig zu. Deshalb ist anzunehmen, dass neben diesem Aktivierungsweg noch andere Möglichkeiten zum Starten der UPR existieren.

\subsubsection{ER-Stress und die UPR in Herzhypertrophie- und Insuffizienz}

Im Rahmen von Herzhypertrophie- und Insuffizienz kommt es zu Wechselwirkungen mit dem Endoplasmatischen Retikulum. So findet z.B. die Synthese der im Rahmen der Membranexpansion benötigten Lipide im ER statt. Auch sind viele der für den Kalziumhaushalt relevanten Proteine wie die SERCA oder der NCX (siehe auch

1.2.2.3, S.10f) Transmembranmoleküle, deren Synthese, Faltung und Qualitätskontrolle am ER stattfindet (siehe auch 1.5.2). Auf der anderen Seite beeinträchtigen Störungen der Kalziumhomöostase, wie sie typischerweise in der Herzinsuffizienz auftreten, auch die Funktion des Endoplasmatischen Retikulums (siehe auch 1.5.2.2).

Auch in einigen Studien konnte ein Zusammenhang zwischen ER-Stress und Herzhypertrophie- und Insuffizienz gefunden werden. Dabei ist die Rolle von ERStress bei der Entwicklung der Herzinsuffizienz aber umstritten. Hamada und Kollegen konnten 2004 zeigen, dass die Provokation von ER-Stress in einem transgenen Tiermodell zu einer dilatativen Kardiomyopathie führt (Hamada et al. 2004). Eine andere Studie bestätigt zwar den Einfluss von durch ER-Stress induzierter Apoptose bei der Entwicklung der Herzinsuffizienz, belegt aber auch einen möglicherweise positiven Effekt der ersten Phase der UPR (Okada K et al. 2004).

Zudem lassen die Ergebnisse dieser Studie einen Zusammenhang zwischen der Wirkung von Angiotensin II und der Entstehung von myokardialem ER-Stress vermuten.

\subsection{Fragestellungen}

Im Zusammenhang mit den in diesem Kapitel dargelegten Sachverhalten werden im Rahmen dieser Arbeit folgende Fragen bearbeitet:

1. Lässt sich in isolierten Herzmuskelstreifen des Kaninchens unter Kulturbedingungen über 6 Stunden ER-Stress auslösen und auf molekularer Ebene nachweisen? 
2. Führt eine Erhöhung von Vor- und/oder Nachlast zu einer nachweisbaren Induktion ER-spezifischer Chaperone in isolierten Herzmuskelstreifen des Kaninchens?

3. Führt Angiotensin II Last-unabhängig zu einer Induktion ER-spezifischer Chaperone in isolierten Muskelstreifen?

4. Hat die lokale Synthese von Angiotensin II Einfluss auf die Entstehung von ER-Stress unter mechanischer Belastung?

5. Kommt es im Rahmen der chronischen Druck-induzierten Rechtsherzhypertrophie von Monocrotaline- behandelten Ratten zu einer Änderung der kardialen Expression ER-spezifischer Chaperone auf mRNA- und Proteinebene?

6. Finden sich im Monocrotaline-Modell Hinweise darauf, ob eine ggf. nachweisbare Induktion der kardialen Expression ER-spezifischer Chaperone vorzugsweise durch biomechanische Last oder aber durch neurohumorale Stimulation vermittelt ist? 


\section{Material und Methoden}

\subsection{Versuchslösungen}

\subsubsection{Präparationslösung}

Die bei der Präparation eingesetzte Lösung basiert auf einer von Krebs und Henseleit (Kögler et al. 2003) entwickelten Lösung. Diese Pufferlösung setzt sich wie folgt zusammen:

\begin{tabular}{|c|c|c|c|}
\hline Stoff & Summenformel & $\begin{array}{l}\text { Konzentration } \\
{[\mathrm{mmol} / \mathrm{l}]}\end{array}$ & Firma \\
\hline Natriumchlorid & $\mathrm{NaCl}$ & 116,1 & Merck \\
\hline Kaliumchlorid & $\mathrm{KCl}$ & 5,0 & Merck \\
\hline Magnesiumchlorid-hexahydrat & $\mathrm{MgCl}_{2}\left(6 \mathrm{H}_{2} \mathrm{O}\right)$ & 1,2 & Merck \\
\hline Natriumsulfat & $\mathrm{Na}_{2} \mathrm{SO}_{4}$ & 1,2 & Merck \\
\hline Natriumdihydrogenphosphat-Monohydrat & $\mathrm{NaH}_{2} \mathrm{PO}_{4}\left(\mathrm{H}_{2} \mathrm{O}\right)$ & 2,0 & Merck \\
\hline D-Glukose* & Glc & 10 & Merck \\
\hline Natriumhydrogencarbonat* ${ }^{\star}$ & $\mathrm{NaHCO}_{3}$ & 20 & Roth \\
\hline Kalziumchlorid* & $\mathrm{CaCl}_{2}$ & 0,25 & Fluka \\
\hline
\end{tabular}

Tabelle 3: Zusammensetzung der Krebs-Henseleit-Lösung (KH-Lösung)

Um den Sauerstoffverbrauch des entnommenen Gewebes zu verringern, wurde der Basislösung 2,3-Butan-Dione-Monoxime (BDM) in einer Konzentration von $20 \mathrm{mM}$ (entspricht $2 \mathrm{~g} / \mathrm{l}$ ) hinzugefügt. BDM wirkt kardioplegisch und bietet durch eine Trennung der Aktin- und Myosinfilamente Schutz vor Hyperkontrakturen infolge von Kalziumüberladungen (Mulieri et al. 1989).

Zur Vereinfachung des Versuchsablaufs wurde eine 10x konzentrierte Stammlösung hergestellt und bei $4^{\circ} \mathrm{C}$ gelagert. Am Versuchstag wurde die Stammlösung verdünnt, und die mit * gekennzeichneten Stoffe sowie BDM wurden hinzugefügt. Anschließend wurde die Lösung mit Carbogen $\left(95 \% \mathrm{O}_{2}+5 \% \mathrm{CO}_{2}\right)$ gesättigt.

\subsubsection{Zellkultur-Medium}

Um es den Zellen zu ermöglichen, über den gesamten Versuchszeitraum ihren Stoffwechsel aufrecht zu erhalten, wurde bei den Langzeitversuchen ein Zellkulturmedium mit folgender Zusammensetzung eingesetzt: 


\begin{tabular}{|l|l|l|}
\hline Stoff & Konzentration & Firma \\
\hline M199+25 mM HEPES & & Gibco \\
\hline Bovine serum albumine & $0,2 \%$ & New England BioLabs \\
\hline L-carnitine & $2,0 \mathrm{mM}$ & Sigma \\
\hline Taurine & $5,0 \mathrm{mM}$ & Sigma \\
\hline Creatine & $5,0 \mathrm{mM}$ & Sigma \\
\hline DL-glutamic acid & $2,0 \mathrm{mM}$ & Sigma \\
\hline Insulin & $20 \mathrm{I.U} . / \mathrm{I}$ & Aventis \\
\hline Penicillin G & $100 \mathrm{I.U} . / \mathrm{ml}$ & Sigma \\
\hline Streptomycin & $70 \mu \mathrm{M}$ & Sigma \\
\hline
\end{tabular}

Tabelle 4: Zusammensetzung des Zellkulturmediums

Das M199 Medium wurde mit den anderen Stoffen außer dem Insulin gemischt, steril filtriert und bei $+4{ }^{\circ} \mathrm{C}$ gelagert. Am Versuchstag wurde Insulin zugegeben, das Medium mit $100 \%$ Sauerstoff begast und auf $37^{\circ} \mathrm{C}$ erwärmt.

\subsubsection{Interventionsstoffe}

Folgende Stoffe wurden eingesetzt, um den Einfluss verschiedener Signalwege auf die myokardiale Genexpression zu untersuchen:

\begin{tabular}{|l|l|l|}
\hline Stoff & Firma & Lösungsmittel \\
\hline Tunicamycin & Sigma & DMSO \\
\hline Angiotensin II & Sigma & Ethanol, $\mathrm{H}_{2} \mathrm{O}$ \\
\hline Irbesartan & Sanofi-Aventis & DMSO \\
\hline
\end{tabular}

Tabelle 5: Interventionsstoffe

\subsection{Langzeitkulturanlage für isolierte Muskelstreifen}

\subsubsection{Aufbau}

\subsubsection{Isometrische Anlage}

Zur Untersuchung des Einflusses von mechanischer Last auf die Genexpression eines isolierten myokardialen Muskelstreifens wurde eine Langzeitkulturanlage der Firma Scientific Instruments (Heidelberg) eingesetzt (Janssen et al. 1998; Janssen et al. 1999). Das System besteht aus einer Inkubationskammer, einem Kraftaufnehmer, einem Stimulator sowie einer Pumpe und einem Reservoir für die Gaszirkulation. 


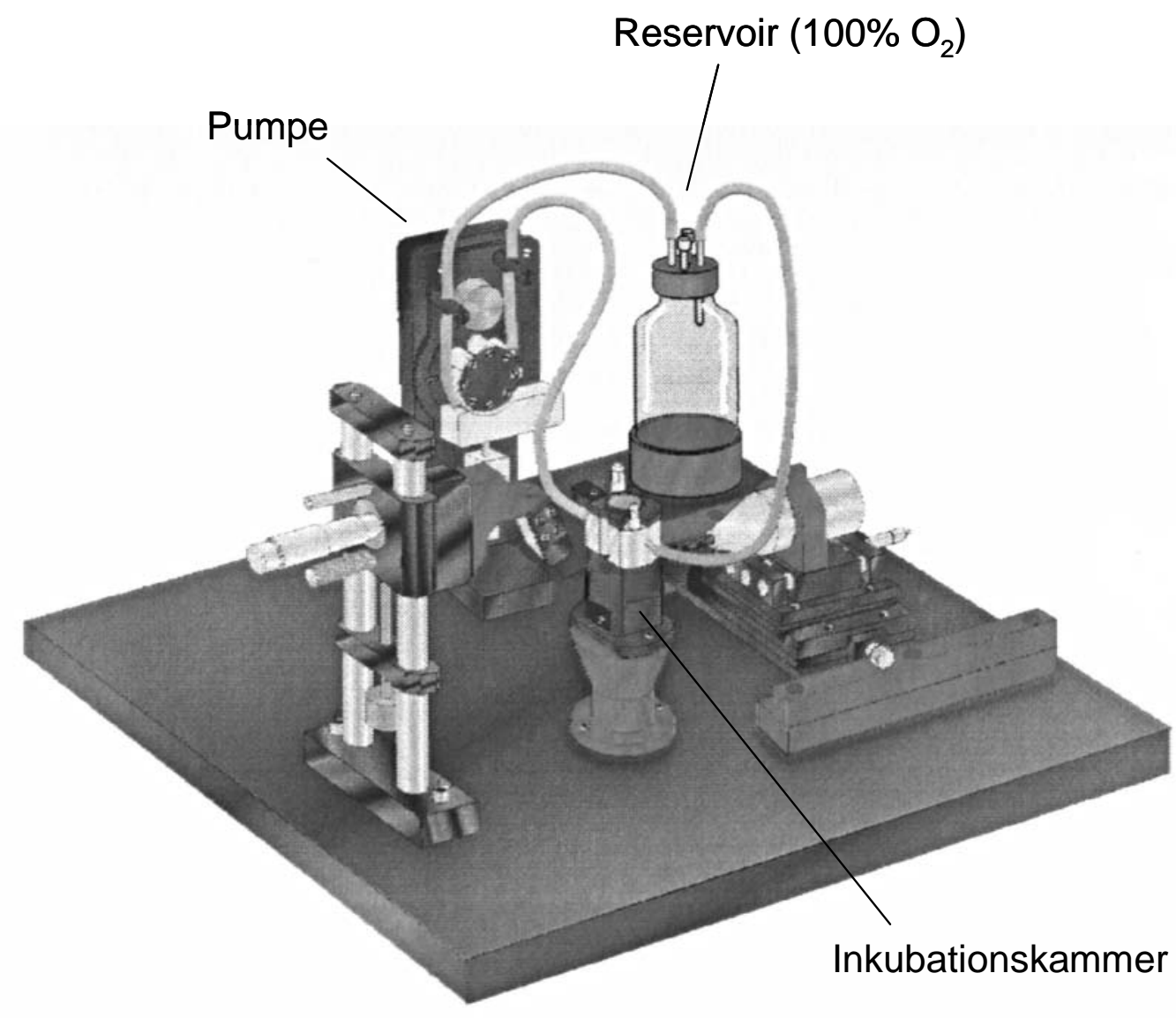

Abbildung 3: Langzeitkulturanlage für isolierte Muskelstreifen (mit freundlicher Genehmigung der Firma Scientific Instruments, modifiziert)

Die Inkubationskammer ist aus einem unteren Teil mit dem eigentlichen Organbad sowie einem abnehmbaren oberen Teil zusammengesetzt. In zusammengebautem Zustand ist sie nur durch fünf Öffnungen mit der Umgebung verbunden, um die Gefahr von bakteriellen Kontaminationen oder anderen äußeren Einflüssen auf das Experiment so gering wie möglich zu halten.

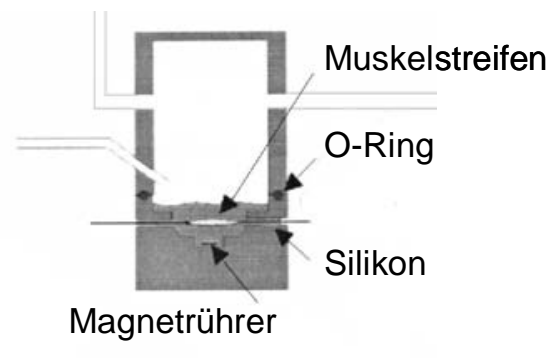

Abbildung 4: Inkubationskammer (mit freundlicher Genehmigung der Firma Scientific Instruments, modifiziert) 
Zwei der Öffnungen befinden sich im unteren Teil der Kammer und erlauben das Einführen der Befestigungseinrichtungen in das Organbad. Zur Befestigung der Muskelstreifen verwendeten wir einen mit dem Kraftaufnehmer verbunden Korb aus Platindraht und einen über eine Kanüle an einer Mikrometerschraube befestigten Haken aus Insektenpins. Um ein Austreten von Flüssigkeit zu verhindern, wurden die Öffnungen nach Einführen von Korb und Haken mit Silikon abgedichtet.

Eine verschließbare Öffnung im oberen Teil der Kammer dient dem Austausch von Flüssigkeiten mit Hilfe von Spritzen und Injektionskanülen. Ein Magnetrührer am Boden der Kammer sorgt für eine kontinuierliche Bewegung der Flüssigkeiten.

Zwei weitere Öffnungen sorgen für den Anschluss der Inkubationskammer an das Gaszirkulationssystem. Reiner Sauerstoff wird vor Versuchsbeginn in ein Reservoirgefäß gefüllt und anschließend mit Hilfe einer Pumpe und ca. $2 \mathrm{~mm}$ durchmessender Verbindungsschläuche aus Kunststoff durch die Inkubationskammer geleitet. Auf diese Weise entsteht ein Gasfluss von ca. 10 $\mathrm{ml} / \mathrm{min}$. Zusätzlich ist zum Überdruckausgleich ein mit Aqua dest. gefülltes Glas über einen abzweigenden Schlauch in die Zirkulation eingeschaltet.

Die Stimulation der Muskelstreifen erfolgt über einen bipolaren Impuls, der mit Hilfe eines externen Stimulators (Scientific Instruments) über die Befestigungsvorrichtungen appliziert wird. Die Dauer, Spannung und Frequenz der Impulse kann am Stimulator eingestellt werden.

\subsubsection{Isotone Anlage}

Die isotone Anlage ist eine Erweiterung des unter 2.2.1.1 beschriebenen Aufbaus, die nachlastfreie (isotone) Versuchsbedingungen ermöglicht. Die Mikrometerschraube wird hierbei durch einen Motor ersetzt, der durch das System gesteuert wird. Verändert sich die Spannung des Muskels, wird der Motor so angesteuert, dass er sich synchron zur Kontraktion des Muskels bewegt und dadurch anstatt einer isometrischen Kontraktion eine isotone Verkürzung des Muskels erfolgt. Nach der Relaxation des Muskelstreifens fährt der Motor in die Ausgangsposition zurück und stellt somit die ursprünglich eingestellte Ruhespannung des Muskels wieder her. 


\subsubsection{Datenerfassung}

Die durch den Muskelstreifen infolge der externen Stimulation entwickelte Kraft wird mit Hilfe eines Kraftaufnehmers registriert, der über eine starre Verbindung mit dem Korb verbunden ist. Dieses analoge Kraftsignal wird verstärkt und durch eine A/DWandlerkarte in ein digitales Signal umgewandelt, das auf einem Computer aufgezeichnet wird.

Die Programme zur Verarbeitung der digitalen Signale wurden von P. Janssen auf Basis der Softwareumgebung LabView (National Instruments) entwickelt.

\subsubsection{Reinigung und Autoklavierung}

Nach Abschluss jedes Versuches wurde die Anlage gründlich mit Aqua dest. gespült und zur Prophylaxe von bakteriellen Kontaminationen über Nacht mit einer PenicillinStreptomycin-Lösung in Aqua dest. befüllt.

Aufgrund des hohen Risikos von bakterieller Besiedlung im Verlauf mehrerer aufeinander folgender Experimente wurden alle mit Zellkulturmedium in Kontakt kommenden Teile der Anlage nach zwei bis drei Versuchen abgebaut, in Autoklavierbeuteln verpackt und für 20 Minuten bei $121{ }^{\circ} \mathrm{C}$ und einem Druck größer $210 \mathrm{kPa}$ dampfautoklaviert. Grundsätzlich wurde beim Umgang mit der Anlage immer auf eine saubere und möglichst keimfreie Handhabung geachtet.

\subsection{Versuchsprotokoll}

\subsubsection{Versuchstiere}

Bei den Versuchen wurden ausschließlich weibliche Kaninchen der Rasse „Chinchilla bastard“ (Charles River Laboratories, Kislegg) verwendet. Das Körpergewicht betrug jeweils zwischen 1,5 und $2 \mathrm{~kg}$. Im Rahmen der Studie wurden keine Tierversuche im Sinne des Tierschutzgesetzes (TierSchG) durchgeführt. Die Tötung zur Entnahme von Gewebe für wissenschaftliche Zwecke wurde gemäß § 4 Abs. 3 TierSchG unter dem Aktenzeichen T8.02 bei der Bezirksregierung in Braunschweig angezeigt.

\subsubsection{Herzentnahme}

Nach Punktion einer Ohrvene wurden 2500 IE Heparin (Liquemin, Roche) zur Antikoagulation injiziert. Daraufhin wurde durch die Gabe von 0,1 g Thiopental- 
Natrium (Thiopental-Nycomed, Nycomed) eine tiefe Analgesie und Anästhesie bis zum Atemstillstand erzeugt. Nach Erlöschen des Cornealreflexes und der Schmerzreflexe wurde das Bauchfell unterhalb des Rippenbogens durch einen breiten Schnitt eröffnet. Danach erfolgte transdiaphragmal die Eröffnung der Brusthöhle. Durch zwei Schnitte in der Medioklavikularlinie konnte die Thoraxvorderwand mit Hilfe einer am Proc. xiphoideus befestigten Klemme abgeklappt werden. Am freiliegenden Herz wurde das Perikard vorsichtig entfernt und die Aorta stumpf vom umgebenden Bindegewebe gelöst und durchtrennt. Das Herz wurde entnommen und in ein Becherglas mit Carbogen-gesättigter BDMhaltiger Präparationslösung gegeben. Zum Schluss wurden die Koronararterien retrograd über die Aorta mit Carbogen-begaster BDM-haltiger Präparationslösung perfundiert. Alle Arbeitsschritte nach dem Eintritt des Atemstillstandes mussten sowohl sorgfältig als auch zügig durchgeführt werden, um die Zeit der Herzischämie so kurz wie möglich zu halten.

\subsubsection{Muskelstreifenpräparation}

Unter Benutzung eines Stereomikroskops wurde das Herz in BDM-haltiger $\mathrm{KH}$ Lösung mit Nadeln fixiert, und mit Hilfe von kleinen Pinzetten und einer Federschere wurden Muskelstreifen aus der rechten Herzkammer entnommen. Hierzu erfolgte zunächst ein Einschnitt von der Art. pulmonalis aus in Richtung der Herzspitze in einem Abstand von ca. 0,5 cm zum Herzseptum. Danach wurde am Rand der Aorta entlang in Richtung der Trikuspidalklappe präpariert und der Herzvorhof von der Kammer getrennt. Nun konnte die freie Wand des rechten Ventrikels zur Seite geklappt werden, um Zugang zu den Papillarmuskeln und Trabekeln zu erlangen. Es wurden Trabekel und Papillarmuskeln ausgewählt, die eine Länge von mindestens 2 $\mathrm{mm}$ hatten und deren kleinerer Durchmesser höchstens $1000 \mu \mathrm{m}$ betrug. Die Muskelstreifen wurden mit einem Block Myokards am Ende entnommen, um, nach sorgfältiger Präparation, die Befestigung im Drahtkorb am Kraftaufnehmer der Langzeitkulturanlage zu ermöglichen. Bei Trabekeln wurde am anderen Ende ebenfalls ein kleiner Block Myokard belassen, mit dem das Präparat am Haken fixiert werden konnte. Bei Papillarmuskeln hingegen wurde zu diesem Zweck ein Teil der Chordae tendiniae bzw. der Trikuspidalklappe erhalten. Bei allen Präparationsschritten wurde darauf geachtet, die Muskelstreifen möglichst nicht zu berühren oder zu dehnen, um eine Beschädigung des Präparates zu verhindern. 


\subsubsection{Einhängen der Muskelstreifen}

Die gereinigten Langzeitkulturanlagen wurden zunächst mit BDM-haltiger Präparationslösung befüllt, und die Muskelstreifen anschließend aus der Präparierschale in die Anlage überführt. Unter Stereomikroskopsicht wurden die Streifen mit Hilfe von feinen Pinzetten möglichst dehnungsfrei in der Anlage fixiert, indem das Präparat vorsichtig durch die Öffnung des Drahtkorbs geführt wurde und anschließend mit Hilfe des Hakens am Kraftaufnehmer befestigt wurde. Dabei wurde darauf geachtet, dass die Ränder des Myokardblocks möglichst gerade und gleichmäßig an der Kante der Drahtöse anlagen. Außerdem sollte die Längsachse des Muskelstreifens in Verlängerung der Achse des Kraftaufnehmers zu liegen kommen, um eine optimale Übertragung der Kraft zu gewährleisten.

\subsubsection{Kalzium-Aufbau, Stimulation, Einschlagen und Dehnung}

Nach dem Schließen der Kulturkammer wurden $4 \mathrm{ml}$ Krebs-Henseleit-Lösung mit einer Kalziumkonzentration von 0,25 mM zugegeben, sodass ein Gesamtvolumen von $5 \mathrm{ml}$ in der Kammer vorhanden war. Es folgte der Aufbau der Kalziumkonzentration durch zweimaligen Austausch von jeweils $4 \mathrm{ml}$ Pufferlösung gegen Lösung der nächsthöheren Konzentrationsstufe bis zu einer Kalziumkonzentration von $1,0 \mathrm{mM}$ und schließlich von $4 \mathrm{ml}$ Zellkulturmedium mit einer Kalziumkonzentration von 1,26 mM. Diesem Zellkulturmedium waren, je nach Versuchsprotokoll, pharmakologische Substanzen zugesetzt worden (siehe 2.3.6). Anschließend wurde die Luftzirkulation mit 100\% Sauerstoff gefüllt, geschlossen und gestartet.

Gleichzeitig wurde mit der elektrischen Stimulation der Muskelstreifen begonnen und die Stimulationsspannung gegebenenfalls erhöht, bis eine Kontraktion im Stereomikroskop sichtbar war oder am Computer gemessen werden konnte. Die hierzu nötige Stimulationsspannung betrug in der Regel 4-8 V.

Abschließend wurden die Muskelstreifen vollständig entdehnt und für 60 min ohne oder mit sehr geringer messbarer Kraftentwicklung stimuliert, um den Präparaten eine Gewöhnung an die veränderten Bedingungen zu ermöglichen.

\subsubsection{Interventionsprotokoll}

Im Anschluss an die einstündige Erholungsphase wurde ein Teil der Streifen auf eine Vorspannung von $3 \mathrm{mN} / \mathrm{mm}^{2}$ gedehnt und für sechs $\mathrm{h}$ inkubiert. Die Streifen der 
mechanisch unbelasteten Versuchsgruppen blieben für den gesamten Versuchszeitraum ungedehnt, und die Inkubationszeit begann direkt nach der Erholungsphase. Am Ende der sechs Stunden wurde das Experiment durch Abschalten der Stimulation und Zugabe von BDM-haltiger $\mathrm{KH}$-Lösung beendet. Es folgte die Beurteilung des Muskelstreifens auf makroskopische Zeichen einer Kontraktur, z.B. Veränderungen der Farbe, Form oder Länge des Muskels. Zusätzlich wurde das Experiment anhand der Kraftdaten beurteilt. Gedehnte Streifen wurden nur weiter analysiert, wenn die entwickelte Kraft am Ende des Experiments mindestens 50\% der entwickelten Kraft am Anfang des Experiments entsprach. Ungedehnte Streifen durften nur eine Kraft von weniger als 0,5 mN/mm² entwickeln. Waren diese Bedingungen erfüllt, wurde der Muskelstreifen an beiden Enden abgeschnitten, kurz auf einem saugfähigen Fließpapier trockengetupft und in ein Eppendorf-Reaktionsgefäß mit $50 \mu$ RNAlater-Puffer (Quiagen, Hilden) überführt. Das Präparat wurde anschließend in flüssigem Stickstoff eingefroren und bis zur weiteren Verwendung (Genexpressionsanalyse) bei $-80^{\circ} \mathrm{C}$ gelagert.

Unter Berücksichtigung der Dehnungszustände und der verschieden Interventionsstoffe wurden folgende Gruppen zur späteren Analyse der Genexpression unterschieden:

1. Ungedehnte Muskelstreifen $+3 \mu \mathrm{g} / \mathrm{ml}$ Tunicamycin

2. Ungedehnte Muskelstreifen + DMSO als Lösungsmittelkontrolle

3. Ungedehnte Muskelstreifen + Ethanol als Lösungsmittelkontrolle

4. Isometrisch kontrahierende Muskelstreifen ohne Zusätze

5. Isoton kontrahierende Muskelstreifen ohne Zusätze

6. Ungedehnte Muskelstreifen ohne Zusätze

7. Ungedehnte Muskelstreifen $+10^{-8} \mathrm{M}$ Angiotensin II

8. Gedehnte Muskelstreifen $+1 \mu \mathrm{g} / \mathrm{ml}$ Irbesartan

9. Gedehnte Muskelstreifen + DMSO als Lösungsmittelkontrolle 


\subsection{Monocrotaline-Modell}

\subsubsection{Tierstamm}

Um den Einfluss biomechanischer Last auf die Genexpression über einen längeren Zeitraum und unter in-vivo Bedingungen zu untersuchen, wurden Gewebeproben verwendet, die im Rahmen einer vorherigen Studie unserer Arbeitsgruppe in Zusammenarbeit mit dem Pharmakologischen Institut der Martin-Luther Universität Halle/Saale gewonnen worden waren (Kögler et al. 2003).

Gegenstand dieser Studie waren unter anderem Genexpressionsanalysen in einem Tiermodell der isolierten Rechtsherzhypertrophie. Die Protokolle für alle tierexperimentellen Maßnahmen waren von der für die MLU Halle zuständigen Tierschutzkommission geprüft und genehmigt worden.

Zur Erzeugung der Rechtsherzhypertrophie erhielten männliche Wistar-Ratten im Alter von sechs Wochen eine einmalige subkutane Injektion von $50 \mathrm{mg} / \mathrm{kg}$ Körpergewicht des Pflanzenalkaloides Monocrotaline (MCT). Monocrotaline wird in der Leber zu toxischen Metaboliten umgewandelt (Lafranconi und Huxtable 1984) und führt dann spezifisch zu einer obliterierenden Vaskulitis in den Arterien und Arteriolen des Lungenkreislaufs. Die resultierende Erhöhung des Perfusionswiderstandes im kleinen Kreislauf führt zu einer erheblichen pulmonalen Hypertonie und anschließender Rechtsherzhypertrophie (Ito et al., 2000). Als Kontrollgruppe dienten Tiere des gleichen Stamms, denen im gleichen Alter eine äquivalente Menge 0,9\%iger Kochsalzlösung injiziert wurde.

Im Verlauf wurden die Tiere täglich gewogen und besonders bei den mit MCT behandelten Ratten auf Veränderungen der körperlichen Aktivität, der Nahrungsaufnahme oder der Atemtätigkeit geachtet. Da die spontane Nahrungsaufnahme der MCT-behandelten Tiere niedriger war als in der Kontrollgruppe, wurde die Nahrung der Kontrolltiere auf die jeweils am Vortag gefressene Futtermenge der MCT-Tiere beschränkt. Gemäß einer Auflage der Tierschutzbehörde erhielt ein Kontrolltier allerdings niemals weniger als 12,5 g Futter pro Tag.

Zwischen dem 19. und 23. Tag nach Injektion zeigten die Versuchstiere eine deutliche Verschlechterung des Allgemeinzustandes. Sobald klinische Zeichen wie Einschränkung der Aktivität, Tachypnoe oder als terminales Zeichen Blutspuren im 
Nasenbereich (Lafranconi et al., 1984) einen kritischen Zustand eines Tieres anzeigten, wurde es für den weiteren Versuchsablauf vorbereitet.

\subsubsection{Probenentnahme}

Zur Anästhesie der Tiere wurde ein luftdichtes Glasgefäß sowie ein 50 ml SarstedtReaktionsgefäß mit etwas Zellstoff gefüllt und anschließend mit einigen Tropfen des Inhalationsanästhetikums Halothan (Eurim-Pharm, Piding) befüllt. Das ausgewählte Versuchstier wurde dann in das Glasgefäß umgesetzt und nach Aussetzen der Atmung in Rückenlage auf eine Präparierunterlage gelegt. Durch möglichst luftdichtes Aufsetzten des Sarstedtgefäßes wurde die Narkose bis zum Erlöschen der Schmerzreflexe fortgesetzt.

Die Entnahme des Herzens sowie die Eröffnung der rechten Herzkammer erfolgten analog dem in 2.3.2 beschriebenen Vorgehen. Zusätzlich wurden Proben aus der linken Herzkammer entnommen.

\subsection{Quantitative Genexpressionsanalyse}

\subsubsection{RNA-Isolation}

Die Isolation von RNA wurde mit den Reagenzien und nach dem Protokoll des NucleoSpin-RNA/Protein-Kit (Macherey-Nagel) durchgeführt. Hierzu wurden die Muskelstreifen zunächst aufgetaut und in 353,5 $\mu$ l Lyse-Puffer (350 $\mu \mathrm{l} \mathrm{RP1} \mathrm{+} \mathrm{3,5} \mu \mathrm{l}$ $\beta$-Mercaptoethanol) überführt. Um eine bessere Homogenisierung zu gewährleisten, wurden die Proben in flüssigem Stickstoff erneut gefroren und anschließend ca. 5 Minuten bei Raumtemperatur angetaut. So vorbereitet konnten die Proben mit Hilfe eines Stabhomogenisators (ART, Mühlheim) mechanisch homogenisiert werden.

Die so gewonnenen Lysate wurden nun in NucleoSpin-Filter-Einheiten pipettiert und für eine Minute bei $11.000 \mathrm{~g}$ zentrifugiert, um sie zu reinigen und die Viskosität der Lösung für die folgenden Reaktionsschritte zu verringern. Die gereinigte Lösung wurde mit $350 \mu \mathrm{l}$ Ethanol (70\%) versetzt und anschließend in eine NucleoSpinRNA/Protein-Säule überführt. Durch $30 \mathrm{~s}$ Zentrifugation bei $11.000 \mathrm{~g}$ wurden Nukleinsäuren spezifisch an die Membran der Säule gebunden. Um störende Salze aus der Membran zu entfernen, wurde die NucleoSpin-RNA/Protein-Säule in ein neues Eppendorf-Reaktionsgefäß überführt, $350 \mu \mathrm{l}$ MDB-Puffer hinzugefügt und 
anschließend eine Minute bei $11.000 \mathrm{~g}$ zentrifugiert. Um die ebenfalls an die Säulenmembran gebunden DNA zu entfernen, wurde $95 \mu \mathrm{l}$ DNA-Reaktionsgemisch (9,5 $\mu$ l DNase I + 85,5 $\mu$ l DNA-Reaktionspuffer) auf die Membran pipettiert und für 15 min bei Raumtemperatur inkubiert.

Durch Zugabe von $200 \mu \mathrm{l}$ RA2-Puffer und Zentrifugation für $30 \mathrm{~s}$ bei $11.000 \mathrm{~g}$ wurde die DNase dann inaktiviert und ein erster Schritt zur Waschung der Membran durchgeführt. Es folgte ein zweiter Waschschritt mit $600 \mu \mathrm{l}$ RA3-Puffer und $30 \mathrm{~s}$ Zentrifugation sowie die endgültige Waschung mit $250 \mu \mathrm{l}$ RA3-Puffer und zweiminütiger Zentrifugation bei jeweils $11.000 \mathrm{~g}$. Die gereinigte Säule wurde nun in ein Nuclease-freies Eppendorf-Reaktionsgefäß überführt und die RNA durch Zugabe von $60 \mu \mathrm{l}$ Nuclease-freiem Wasser sowie einer Minute Zentrifugation bei $11.000 \mathrm{~g}$ aus der Säulenmembran gelöst.

Nach der anschließenden photometrischen Bestimmung der RNA-Menge und Qualität wurden die Proben in flüssigem Stickstoff eingefroren und bis zur Weiterverarbeitung bei $-80^{\circ} \mathrm{C}$ gelagert.

\subsubsection{Umschreiben in cDNA}

Zur späteren quantitativen Analyse der Genexpression musste die RNA zunächst in cDNA umgeschrieben werden. Hierzu wurden jeweils 200 ng der gewonnen RNA eingesetzt und $2 \mu$ l Random-Primer in einer Konzentration von 50 ng/ $\mu$ l (MWG) und 1 $\mu \mathrm{l} 10 \mathrm{mM}$ dNTP (Bioline) hinzugefügt. Diese Mischung wurde mit einer entsprechenden Menge DEPC-Wasser (Sigma) auf ein Volumen von $10 \mu \mathrm{l}$ aufgefüllt und 5 min bei $65^{\circ} \mathrm{C}$ inkubiert und anschließend für mindestens eine Minute auf Eis gelagert.

Pro Reaktionsansatz waren $9 \mu \mathrm{l}$ RT-Reaktionsmix bestehend aus $2 \mu \mathrm{l}$ 10xRT-Puffer (Invitrogen), $4 \mu \mathrm{l} 25 \mathrm{mM} \mathrm{MgCl} 2$ (Sigma), $2 \mu \mathrm{l}$ 0,1 M DTT (Invitrogen) und $1 \mu \mathrm{l}$ RNaseOUT (Invitrogen) vorbereitet. Nach vorsichtigem Mischen von $9 \mu$ RTReaktionsmix und $10 \mu$ der vorbereiteten Probe und einer Inkubation von 2 min bei Raumtemperatur folgte die Zugabe von $1 \mu$ der Reversen-TranskriptaseSuperScript-II (Invitrogen). Anschließend wurden die Proben für $10 \mathrm{~min}$ bei $25^{\circ} \mathrm{C}, 50$ min bei $42{ }^{\circ} \mathrm{C}$ und 15 min bei $70{ }^{\circ} \mathrm{C}$ inkubiert, und dann wieder auf Eis gelagert. Nun erfolgte die Zugabe von $1 \mu \mathrm{RNase}-\mathrm{H}$ (Invitrogen) und eine abschließende Inkubation von $20 \mathrm{~min}$ bei $37^{\circ} \mathrm{C}$. Den Proben wurde $2 \mu$ für die direkt im Anschluss stattfindende Realtime-PCR entnommen und der Rest bei $-80^{\circ} \mathrm{C}$ gelagert. 


\subsubsection{Realtime-PCR}

\subsubsection{Funktionsprinzipien}

Die Realtime-PCR erlaubt die quantitative Messung der DNA-Konzentrationen während der Amplifikation in Echtzeit. Die Grundlage liefert der fluoreszierende Farbstoff SYBRGreen, der in der Lage ist, mit hoher Spezifität an doppelsträngige DNA zu binden, wodurch sich die emittierte Fluoreszenz im Vergleich zu ungebundenem SYBRGreen deutlich erhöht. Dadurch ist die Stärke der Fluoreszenz direkt proportional zur Menge an doppelsträngiger DNA in der Reaktionslösung. Unsere Versuche wurden in einem LightCycler ${ }^{\circledR}$ (Roche) gemäß den Angaben des Herstellers durchgeführt. Hierbei wurde durch das Gerät die von jeder Probe emittierte Fluoreszenz in ein elektrisches Signal umgewandelt und am Ende jedes Amplifikationszykluses aufgezeichnet. Nach Ablauf der gewünschten Anzahl von Zyklen wurde dann die Stärke der Fluoreszenz graphisch gegen die Zykluszahl aufgetragen und für jede Probe die cDNA-Menge zu Beginn des Versuchs errechnet (siehe 2.3.3.3). Die Kontrolle der Spezifität der Amplifikation erfolgte mit Hilfe einer Schmelzkurvenanalyse. Da kurze, unspezifische Reaktionsprodukte einen niedrigeren Schmelzpunkt aufweisen als spezifische, kann die Spezifität der Reaktion anhand der Schmelztemperatur und der Abweichung der einzelnen Schmelzkurven voneinander überprüft werden.

$\mathrm{Da}$ die Menge an eingesetztem Material und somit auch die Menge der DNA zwischen den einzelnen Präparaten schwankt, ist es nötig die Ergebnisse auf die DNA-Gesamtmenge zu normalisieren. Hierzu wird die DNA eines Proteins bestimmt, dessen Expression in allen Präparaten ähnlich ist und durch die Versuchsbedingungen nicht beeinflusst wird. Durch die Bildung des Quotienten kann dann die DNA-Menge des Zielproteins auf die Menge der insgesamt eingesetzten DNA normalisiert werden. 


\subsubsection{Durchführung}

Jede Glaskapillare wurde mit folgenden Reagenzien auf ein Volumen von $20 \mu \mathrm{l}$ befüllt:

\begin{tabular}{|l|l|l|}
\hline Stoff & Konzentration/Menge & Firma \\
\hline cDNA & $2 \mu \mathrm{l}$ & \\
\hline Primer & $0,5 \mu \mathrm{M}$ & MWG \\
\hline Taq-DNA-Polymerase & $1 \mathrm{U}$ & Invitrogen \\
\hline $10 x P C R-P u f f e r$ & $2 \mu \mathrm{l}$ & Invitrogen \\
\hline dNTP & $0,2 \mathrm{mM}$ & BioLine \\
\hline $\mathrm{MgCl}_{2}$ & $2,5 \mathrm{mM}$ & Merck \\
\hline BSA & $500 \mathrm{mg} / \mathrm{l}$ & New England BioLabs \\
\hline DMSO & $50 \mathrm{ml} / \mathrm{l}$ & Sigma \\
\hline $1 / 1000$ SYBRGreen stock & $1 \mu \mathrm{l}$ & Roche \\
\hline
\end{tabular}

Tabelle 6: Realtime-PCR Reagenzien

Um zu vermeiden, dass es vor Versuchsbeginn bereits zur Bildung unspezifischer Nebenprodukte kommt, lag die Polymerase zunächst kovalent gebunden und dadurch inaktiviert vor. Diese kovalenten Bindungen wurden vor Beginn der eigentlichen Amplifikation durch 10 min Denaturierung bei $95{ }^{\circ} \mathrm{C}$ gelöst und die Polymerase dadurch aktiviert.

Anschließend folgten 40 Zyklen, in deren Verlauf die Proben amplifiziert wurden. In jedem Zyklus wurden die Proben zunächst für $10 \mathrm{~s}$ auf $95^{\circ} \mathrm{C}$ erhitzt, anschließend für $5 \mathrm{~s}$ bei $60{ }^{\circ} \mathrm{C}$ inkubiert und schließlich $15 \mathrm{~s}$ bei $72{ }^{\circ} \mathrm{C}$ amplifiziert. Zum Schluss wurde der Schmelzpunkt ermittelt, indem die Probe einmalig für $15 \mathrm{~s}$ auf $95^{\circ} \mathrm{C}$ erhitzt und dann für $10 \mathrm{~s}$ bei $70^{\circ} \mathrm{C}$ gehalten wurde.

In jedem Lauf wurden die zu untersuchenden Proben doppelt eingesetzt, um durch Bildung eines Mittelwertes Messfehler zu minimieren. Zusätzlich enthielt jeder Durchgang acht Standardproben zur Erstellung der Standardkurve.

Folgende mRNAs wurden mit den angegebenen Primern (MWG) untersucht: 


\begin{tabular}{|l|l|l|}
\hline Protein & & Primer \\
\hline BNP & $\begin{array}{l}\text { Sense } \\
\text { Antisense }\end{array}$ & $\begin{array}{l}\text { TGC TCT TGC ACC TGT } \\
\text { GCA GCT GCT GTA TCT CAG AAA }\end{array}$ \\
\hline Grp78 & $\begin{array}{l}\text { Sense } \\
\text { Antisense }\end{array}$ & $\begin{array}{l}\text { TGA TGT GTC TCT TCT CAC CA } \\
\text { GCT CTG TTG TCT TTC CTG AC }\end{array}$ \\
\hline CRT & $\begin{array}{l}\text { Sense } \\
\text { Antisense }\end{array}$ & $\begin{array}{l}\text { GAG TAC AAG GGT GAG TGG AA } \\
\text { GTT GGT GAT GAG GAA GTT GT }\end{array}$ \\
\hline GaPDH & $\begin{array}{l}\text { Sense } \\
\text { Antisense }\end{array}$ & $\begin{array}{l}\text { TGC CGA GTA CGT GGT GGA AT } \\
\text { ATG GCG TGC ACC GTG GTC AT }\end{array}$ \\
\hline
\end{tabular}

Tabelle 7: Primer für Realtime-PCR

\subsubsection{Auswertung}

Die Auswertung der ermittelten Daten erfolgte mit Hilfe der Lightcycler-DataAnalysis-Software. Grundlage der Auswertung war die wie oben beschrieben erhaltene graphische Korrelation zwischen der Stärke der emittierten Fluoreszenz und der Zykluszahl. 
2.6 Western-Immunoblot-Analyse

2.6.1 Pufferlösungen

\begin{tabular}{|c|c|c|c|}
\hline Puffer & Stoff & Konzentration & Firma \\
\hline \multirow[t]{14}{*}{ Homogenisationspuffer } & $\begin{array}{l}\text { NP } 40 \text { (EPEGAL CA- } \\
630)\end{array}$ & $10 \mu \mathrm{l} / \mathrm{ml}$ & Sigma \\
\hline & Glycerol & $100 \mu \mathrm{l} / \mathrm{ml}$ & Roth \\
\hline & $\mathrm{NaCl}$ & $137 \mathrm{mM}$ & Merck \\
\hline & Tris $\mathrm{pH} 7,4$ & $20 \mathrm{mM}$ & Merck \\
\hline & $\mathrm{NaF}$ & $20 \mathrm{mM}$ & Merck \\
\hline & Sodium orthovanadate & $1 \mathrm{mM}$ & Roth \\
\hline & Sodium pyrophosphate & $1 \mathrm{mM}$ & Merck \\
\hline & $\beta$-Glycerophosphat & $50 \mathrm{mM}$ & Sigma \\
\hline & EDTA pH 8,0 & $10 \mathrm{mM}$ & Merck \\
\hline & EGTA pH 7,0 & $1 \mathrm{mM}$ & Merck \\
\hline & Aprotinin & $4 \mu \mathrm{g} / \mathrm{ml}$ & Sigma \\
\hline & Leupeptin & $4 \mu \mathrm{g} / \mathrm{ml}$ & Sigma \\
\hline & Pepstatin A & $4 \mu \mathrm{g} / \mathrm{ml}$ & Sigma \\
\hline & PMSF & $1 \mathrm{mM}$ & Sigma \\
\hline \multirow[t]{3}{*}{ Elektrophoresepuffer } & Tris $\mathrm{pH} 8,3$ & $15,1 \mathrm{~g} / \mathrm{l}$ & Merck \\
\hline & Glycine & $72 \mathrm{~g} / \mathrm{l}$ & Roth \\
\hline & SDS & $5 \mathrm{~g} / \mathrm{l}$ & Sigma \\
\hline \multirow[t]{2}{*}{ Transferpuffer } & Tris $\mathrm{pH} 8,3$ & $19,2 \mathrm{~g} / \mathrm{l}$ & Merck \\
\hline & Glycine & $72 \mathrm{~g} / \mathrm{l}$ & Roth \\
\hline \multirow[t]{4}{*}{ Laemmlipuffer } & Tris pH 6,8 & $3 \mathrm{mg} / \mathrm{ml}$ & Merck \\
\hline & Glycerol & $400 \mu \mathrm{l} / \mathrm{ml}$ & Sigma \\
\hline & 2-Mercaptoethanol & $400 \mu \mathrm{l} / \mathrm{ml}$ & Sigma \\
\hline & Bromphenol Blau & $0,2 \mathrm{mg} / \mathrm{ml}$ & Sigma \\
\hline
\end{tabular}

Tabelle 8: Pufferlösungen für Western-Immunoblot-Analyse

\subsubsection{Vorgehen}

Zur Aufbereitung der Proben wurden die Muskelstreifen in $20 \mu \mathrm{l}$ eisgekühltem Homogenisationspuffer zunächst mit Hilfe eines Wenton-Mikro-GewebeGlashomogenisators (NeoLab, Heidelberg) mechanisch homogenisiert. Das Lysat 
wurde in ein neues Eppendorf-Reaktionsgefäß überführt, das ursprüngliche Reaktionsgefäß noch einmal mit $20 \mu \mathrm{l}$ Homogenisationspuffer gespült, die Proteinkonzentration doppelt mit dem BCA-Assay (Pierce) bestimmt und die gesamten $40 \mu \mathrm{l}$ Lysat bei $-80^{\circ} \mathrm{C}$ eingefroren. Um eine gleichmäßige Auftragung zu gewährleisten wurde die aufgetrage Probenmenge auf die Gesamtproteinmenge normalisiert .

Am Versuchstag wurden die Proben in Homogenisationspuffer auf ein Volumen von $16 \mu \mathrm{l}$ und eine Konzentration von $2 \mu \mathrm{g} / \mu \mathrm{l}$ verdünnt. Nach Zugabe von $4 \mu \mathrm{l}$ Blaupuffer und $10 \mu \mathrm{l}$ 5xLaemmli-Puffer wurden die Proben $5 \mathrm{~min}$ bei $95{ }^{\circ} \mathrm{C}$ denaturiert und anschließend 2 min bei 8000 rpm zentrifugiert. Nach Übertragung des Überstandes in die Tasche eines vorbereiteten 10\%igen SDS-Polyacrylamid-Gels (BioRad) konnten die Proteine in einer vertikalen Plattenelektrophorese nach der Methode von Laemmli (1970) bei 0,05 A ohne Voltbegrenzung für $1,5 \mathrm{~h}$ elektrophoretisch aufgetrennt werden. Die beiden äußeren Taschen jedes Gels wurden zur Abschätzung des Proteingewichts mit einem löslichen Molekulargewichtsmarker (BioRad) beladen.

Um die Proteine aus dem SDS-Gel auf eine Nitrozellulosemembran (Schleicher und Schuell) zu übertragen, wurde anschließend eine horizontale Elektrophorese bei $4{ }^{\circ} \mathrm{C}$ durchgeführt. Hierzu wurde folgendes Transfersandwich benutzt:

Kathode - 2x Filterpapier - Gel - Nitrozellulosemembran - 2x Filterpapier - Anode Nach einer Stunde Elektrophorese bei 0,5 A wurde die Nitrozellulosemembran entnommen und mit doppelt destilliertem Wasser abgewaschen. Anschließend wurde die Membran über Nacht mit 5\%igem Milchpulver bei $+4{ }^{\circ} \mathrm{C}$ geblockt, um unspezifische Bindungen an die Proteine zu verhindern.

Am nächsten Tag wurde die Milchpulverlösung mit TBS/Tween (BioRad) ausgewaschen und die Membran zur Analyse der unterschiedlich großen Proteine getrennt. Es folgte die Inkubation mit dem ersten, proteinspezifischen Antikörper, der jeweils in 0,5\%igem Milchpulver verdünnt wurde. 


\begin{tabular}{|l|l|l|l|}
\hline Protein & Verdünnung & Inkubation & Herkunft \\
\hline Grp78 & $1: 5.000$ & über Nacht, $4{ }^{\circ} \mathrm{C}$ & $\begin{array}{l}\text { Kaninchen, freundlicherweise zur Verfügung } \\
\text { gestellt von Dr. Phuc Nguyen van }\end{array}$ \\
\hline CRT & $1: 10.000$ & über Nacht, $4^{\circ} \mathrm{C}$ & $\begin{array}{l}\text { Schaf, freundlicherweise zur Verfügung gestellt } \\
\text { von Dr. Phuc Nguyen van }\end{array}$ \\
\hline Calsequestrin & $1: 10.000$ & $2 \mathrm{~h}$ bei $25^{\circ} \mathrm{C}$ & Maus, Bioreagents \\
\hline
\end{tabular}

Tabelle 9: Antikörper für Western-Immunoblot

Nach Abschluss der Inkubation wurden die Membranen für 3x 5 min mit TBS/Tween gewaschen und anschließend für eine Stunde mit in 0,5\%igen Milchpulver 1:10.000 (Grp78: 1:5000) verdünnten fluoreszierenden anti-IgG-Antikörpern (Dako, Dänemark) der entsprechenden Spezies inkubiert.

Nach erneutem dreimaligem Waschen mit TBS/Tween wurden die Membranen für 5 min mit Chemolumineszenz-Reaktionslösung (Pierce) inkubiert. Nach einer Belichtung von ca. 1 min konnten die spezifischen Banden auf einem Röntgenfilm dargestellt werden. Diese wurden mit einem CCD-Kamerasystem (Multilmage Light Cabinet, Alpha Innotech) digitalisiert und quantifiziert.

\subsection{Mathematische Methoden}

Die zur Qualitätskontrolle der Muskelstreifenexperimente genutzten Kraftdaten ergaben sich aus der entwickelten Kraft pro Querschnittsfläche. Die Querschnittsfläche wurde in Annahme einer elliptischen Form nach folgender Formel aus beiden Durchmessern berechnet:

Fläche $A=\underline{d}_{1} \underline{x} \underline{d}_{2} \underline{x} \underline{\pi}$

4

Alle Werte sind als Mittelwert \pm mittlerer Standardfehler (SEM) angegeben. Zur statistischen Auswertung der Genexpression und Proteinanalyse wurde ein Student t-Test für unverbundene Stichproben verwendet. Das Signifikanzniveau für alle Experimente wurde auf $p<0,05$ festgelegt. 


\section{Ergebnisse}

\subsection{Untersuchungen an isolierten Kaninchen-Muskelstreifen}

Mit Hilfe des Modells der isolierten Muskelstreifen in Kultur sollte im ersten Abschnitt der Studie untersucht werden, ob im gesunden isolierten Myokard des Kaninchens durch pharmakologische und biomechanische Interventionen ER-Stress ausgelöst und nachgewiesen werden kann. Darüber hinaus sollten mögliche an der Vermittlung von ER-Stress im Myokard beteiligte Mechanismen untersucht werden.

Um zu verhindern, dass es durch die unterschiedlichen Massen der Muskelstreifen und die damit verbundene Erhöhung der Gesamtmenge an gewonnener mRNA zu einem systematischen Messfehler kommt, wurden alle Ergebnisse normalisiert ausgewertet. Zu diesem Zweck ermittelten wir die Menge der für das Protein Glycerinaldehyd-3-Phosphat-Dehydrogenase (GaPDH) codierenden mRNA, die hauptsächlich von der Menge des eingesetzten Gewebes abhängig ist und - wie in Vorversuchen aus unserer Arbeitsgruppe gezeigt werden konnte - durch eine biomechanische Intervention über $6 \mathrm{~h}$ nicht in ihrer Expression beeinflusst wird. Durch Bildung eines Quotienten aus der Menge an Chaperon-mRNA und GaPDHmRNA konnte somit eine zuverlässige Normalisierung erreicht werden.

Mit derselben Methode wurden auch die Ergebnisse der Expressionsuntersuchungen der Monocrotaline-behandelten Ratten normalisiert.

\subsubsection{Lösungsmittelkontrolle}

Die in dieser Studie untersuchten pharmakologisch wirksamen Substanzen konnten nicht direkt in die Superfusions- oder Kulturlösung eingebracht werden: Einerseits ließen sie sich teilweise aufgrund ihrer hydrophoben Eigenschaften nur schwer in eine wässerige Lösung überführen (Tunicamycin, Irbesartan), und andererseits waren die wirksamen Konzentrationen so gering (z.B. Angiotensin II: $10 \mathrm{nM}$ ), dass nur Mikrogramm- oder noch geringere Mengen der Reinsubstanz erforderlich waren. Dies machte eine exakte Einwaage unmöglich. Daher wurden zunächst höher konzentrierte Stammlösungen der betreffenden Substanzen in einem Lösungsmittel hergestellt und daraufhin kleine Aliquots der Stammlösungen in der eigentlichen Versuchslösung auf die Zielkonzentration herunterverdünnt. Um auszuschließen, 
dass ein anscheinender Effekt einer Substanz in Wirklichkeit nicht auf die Substanz, sondern auf Auswirkungen des Lösungsmittels zurückzuführen war, wurden Lösungsmittelkontrollversuche durchgeführt. In dieser Studie wurden Tunicamycin und Irbesartan im organischen Lösungsmittel DMSO gelöst, während Angiotensin II in Ethanol gelöst werden sollte.

In den Kontrollversuchen wurden isolierte rechtsventrikuläre Muskelstreifen des Kaninchens über $6 \mathrm{~h}$ in ungedehntem Zustand in Gegenwart und Abwesenheit der jeweiligen Lösungsmittel inkubiert und daraufhin mögliche Auswirkungen auf die mRNA-Expression der Zielgene untersucht. DMSO wurde in einer Konzentration von $0,5 \mu \mathrm{l} / \mathrm{ml}$ (entsprechend $0,5 \%$ o (V/V)) und Ethanol in einer Konzentration von 0,1 $\mu \mathrm{l} / \mathrm{ml}$ (entsprechend $0,1 \%(\mathrm{~V} / \mathrm{V})$ ) in jeweils $\mathrm{n}=10$ Muskelstreifen eingesetzt. Als gemeinsame Kontrollgruppe dienten Muskelsteifen $(n=8)$, die in Zellkulturmedium ohne jeden Lösungsmittelzusatz für sechs Stunden lastfrei inkubiert wurden.
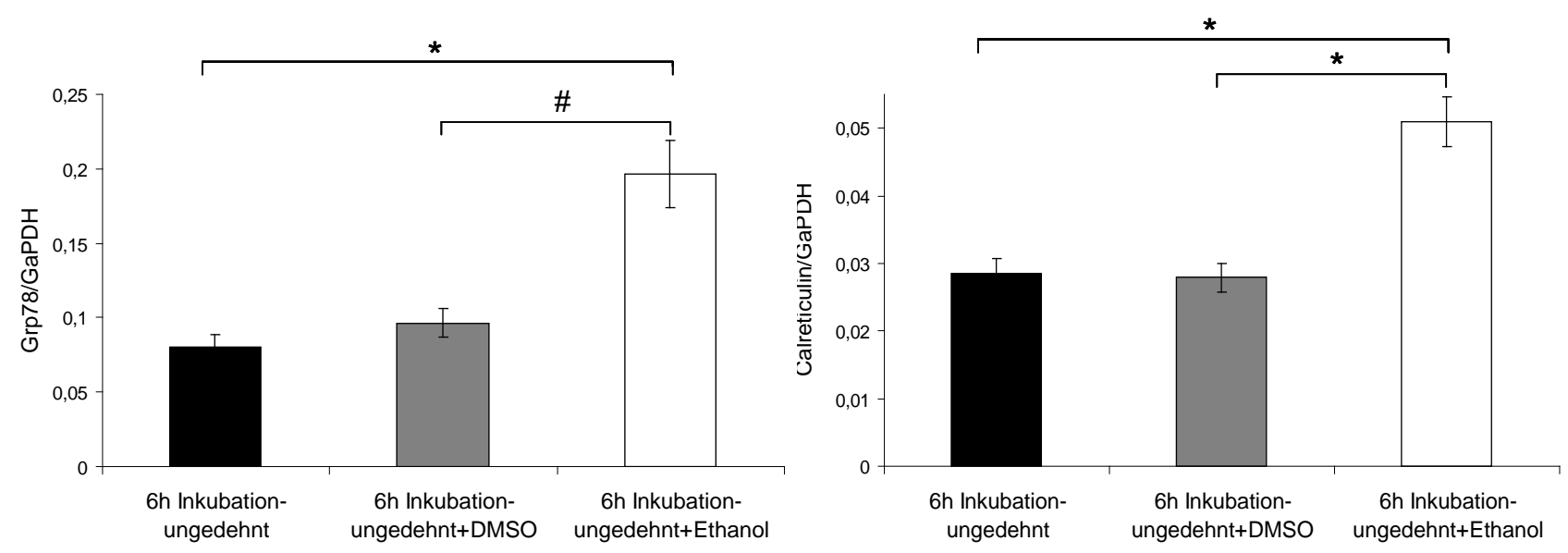

Abbildung 5: Quantitative Expression der mRNA von Grp78 und Calreticulin aus rechtsventrikulären Kaninchenmuskelstreifen, nach $6 \mathrm{~h}$ Inkubation ohne Zusätze $(n=8)$, oder unter Zugabe von $0,5 \mu \mathrm{l} / \mathrm{ml}$ DMSO ( $n=10)$, bzw. 0,1 $\mu \mathrm{l} / \mathrm{ml}$ Ethanol $(n=10)$. (Signifikanzen: * $p<0,001 ; \# p<0,01)$

Analysiert wurde die mRNA-Expression der ER-Chaperone Grp78 und Calreticulin. Dabei zeigte sich kein signifikanter Unterschied zwischen den ohne

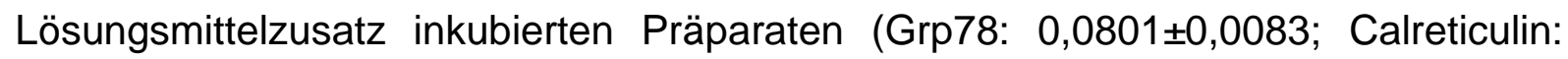
0,0286 $\pm 0,0022$ ) und den mit DMSO behandelten Proben (Grp78: 0,0965 $\pm 0,0098$; Calreticulin: 0,0279 $\pm 0,0021$ ) (Grp78: $p=0,3656$; Calreticulin: $p=0,8693$ ). Im Gegensatz dazu wurde die mRNA-Expression sowohl von Grp78 (0,1966 $\pm 0,0225)$ als auch von Calreticulin $(0,0510 \pm 0,0037)$ im Vergleich zu den unbehandelten Kontrollstreifen durch die Einwirkung von Ethanol erheblich und statistisch signifikant 
( $p<0,001$ für beide Gene) erhöht. Auch beim Vergleich zwischen den beiden lösungsmittelbehandelten Gruppen zeigte sich in der Ethanolgruppe eine signifikant höhere Expression von Grp78 $(p=0,0033)$ und Calreticulin $(p<0,001)$ als in der DMSO-Gruppe.

\title{
3.1.2 Induktion von ER-Stress in isolierten Muskelstreifen durch
}

\section{Tunicamycin}

Um zu überprüfen, ob der verwendete experimentelle Ansatz (Präparat, Versuchsapparatur, Zeitspanne) prinzipiell geeignet ist, in einem multizellulären Verband ER-Stress auszulösen und auf molekularer Ebene nachweisen zu können, wurden rechtsventrikuläre Muskelstreifen aus Kaninchenherzen isoliert und für sechs Stunden in Anwesenheit von $3 \mu \mathrm{g} / \mathrm{ml}$ Tunicamycin inkubiert. Tunicamycin hemmt die Glykosylierung von Proteinen im endoplasmatischen Retikulum, und verhindert so ihren Weitertransport aus dem ER. Hierdurch kommt es zu einer Akkumulation von ungefalteten Proteinen, was schließlich eine Stressantwort auslöst (Positivkontrolle). Als Vergleichsgruppe dienten Muskelstreifen, die mit einer äquivalenten Konzentration von DMSO behandelt wurden.
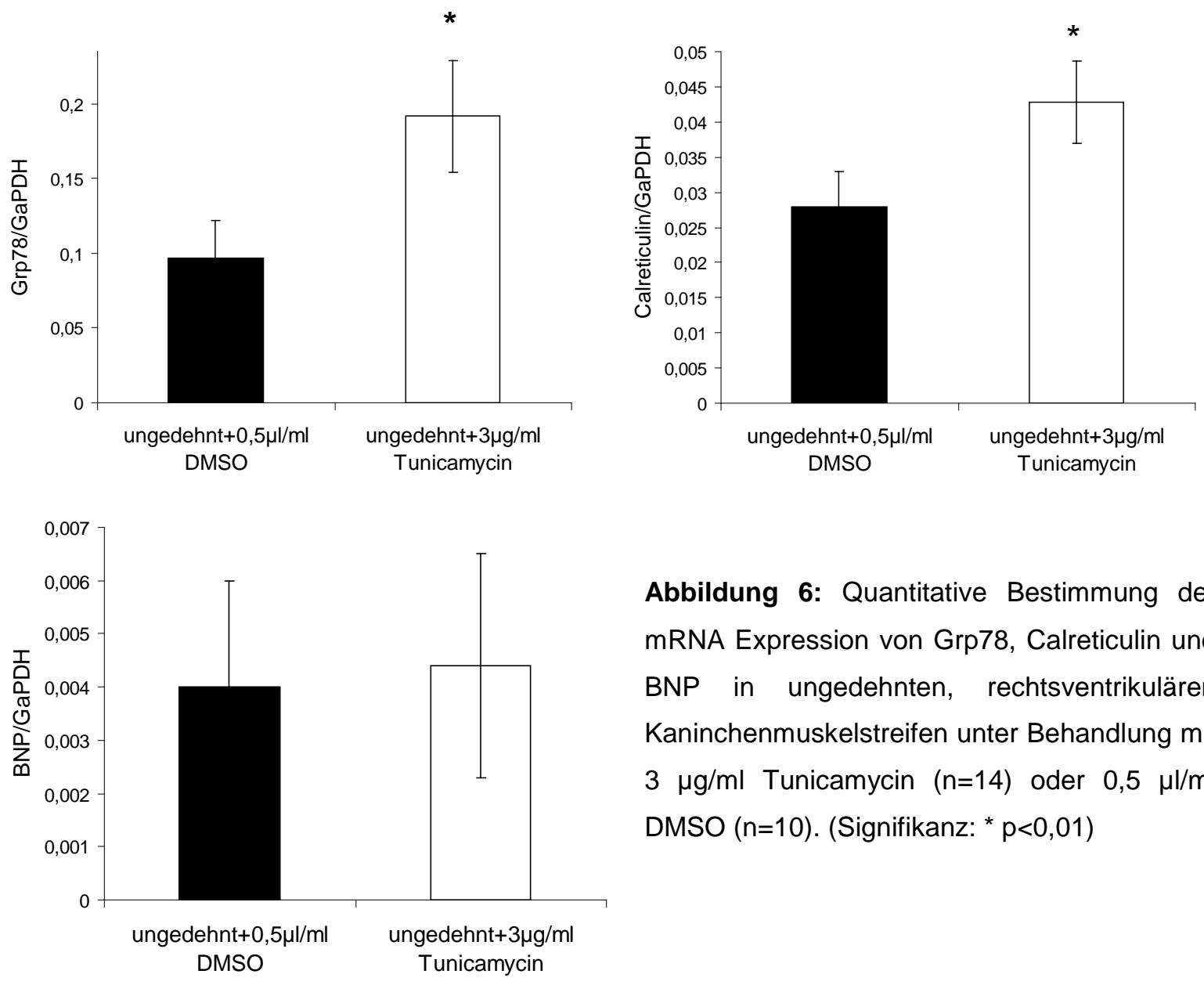

\begin{abstract}
Abbildung 6: Quantitative Bestimmung der mRNA Expression von Grp78, Calreticulin und BNP in ungedehnten, rechtsventrikulären Kaninchenmuskelstreifen unter Behandlung mit $3 \mu \mathrm{g} / \mathrm{ml}$ Tunicamycin ( $\mathrm{n}=14$ ) oder $0,5 \mu \mathrm{l} / \mathrm{ml}$ DMSO $(n=10)$. (Signifikanz: * $p<0,01)$
\end{abstract}


Unter Behandlung mit Tunicamycin kam es zu einer signifikanten Verstärkung der mRNA-Expression sowohl von Grp78 (Tunicamycin: 0,1916 $\pm 0,0375$; DMSO: $0,0965 \pm 0,0250 ; p=0,0021$ ) als auch von Calreticulin (Tunicamycin: 0,0428 $\pm 0,0059$; DMSO: $0,0279 \pm 0,0050 ; p=0,0039$ ). Somit ist gezeigt, dass in dem verwendeten experimentellen System ER-Stress prinzipiell auf molekularer Ebene nachgewiesen werden kann.

Als Kontrolle für die Aktivierung hypertropher Signaltransduktionswege bestimmten wir die Expression des brain-natriuretic-peptide (BNP) auf mRNA Ebene. BNP wird im Rahmen einer hypertrophen Reaktion des Myokards verstärkt gebildet (vgl. 4.1.2). Auf die Expression von BNP hatte die Gabe von Tunicamycin keinen signifikanten $(p=0,812)$ Einfluss (Tunicamycin: 0,0044 $\pm 0,0021$; DMSO: 0,004 $\pm 0,002$ ).

\subsubsection{Einfluss von mechanischer Last}

Gesteigerte biomechanische Last ist für den Herzmuskel ein wesentlicher Hypertrophie-auslösender Stimulus. Um zu untersuchen, ob am Herzmuskel eine Hypertrophieantwort mit einer veränderten Expression der ER-Chaperone einher geht, wurden isolierte rechtsventrikuläre Muskelstreifenpräparate des Kaninchens unter definierten Bedingungen biomechanischen Laststeigerungen ausgesetzt und die daraus resultierenden Genexpressionsänderungen auf mRNA-Ebene analysiert.

\subsubsection{Funktionelle Bedeutung der Kontraktionsform}

Neben der gesteigerten biomechanischen Last als Stimulus hat auch die Kontraktionsform Einfluss auf die Entstehung Hypertrophie-bedingter Veränderungen im Herzmuskel. Neben der Genexpression wurde deshalb auch die Funktion der Muskelstreifen untersucht.

Abbildung 7 zeigt anhand einer exemplarischen Einzelkontraktion den Unterschied zwischen den isometrischen und den isotonen Versuchsbedingungen. Es ist jeweils die pro Querschnittsfläche entwickelte Kraft, sowie im Fall der isotonen Kontraktion zusätzlich die Verkürzung in Prozent der Ausgangslänge angegeben. Da isometrisch kontrahierende Muskelstreifen aufgrund des starren Versuchsaufbaus (siehe 2.2.1.1, S. 24-26) nicht verkürzen können, wurde bei den isometrischen Versuchen die Verkürzung nicht aufgezeichnet. 

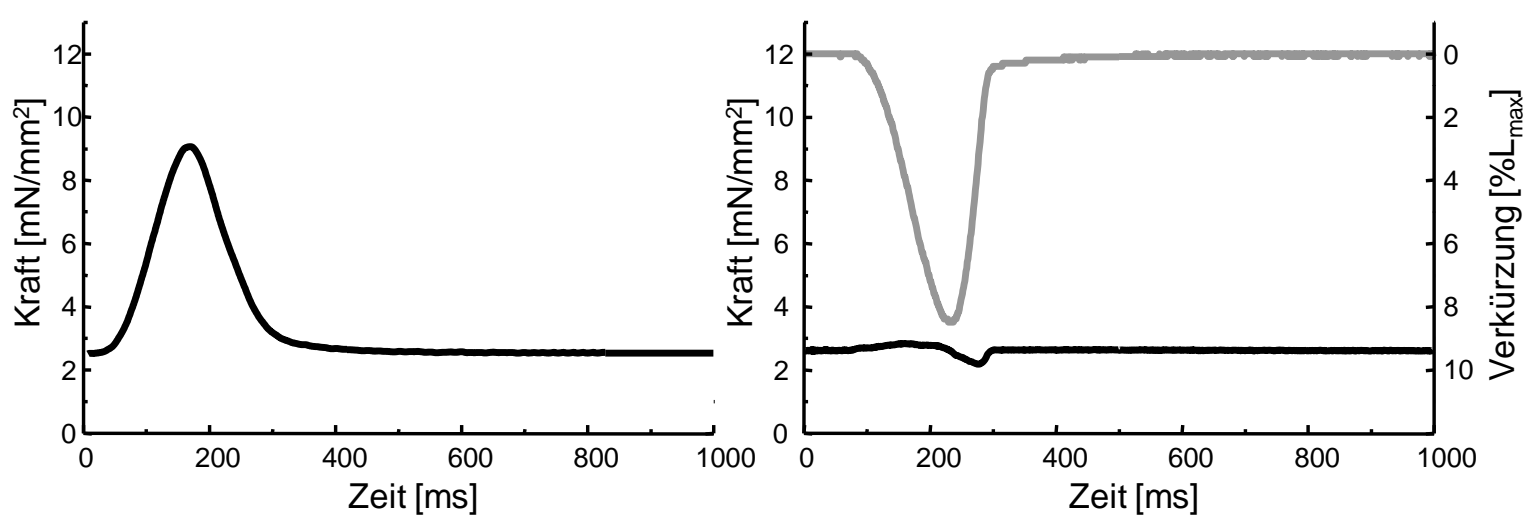

Abbildung 7: Entwickelte Kraft bzw. Verkürzung im Laufe einer isometrischen und einer isotonen Einzelkontraktion

Während es unter isometrischen Versuchsbedingungen zu einer starken Kraftentwicklung kommt, wird diese unter isotonen Bedingungen kaum registriert. Dafür verkürzt der Muskelstreifen hier um etwa acht Prozent seiner Ruhelänge.

Neben den Einzelkontraktionen sollte auch der Verlauf der entwickelten Kraft bzw. der Verkürzung registriert werden. Zu diesem Zweck wurden alle dreißig Minuten die Werte registriert und, normalisiert auf den Ausgangswert, dargestellt.

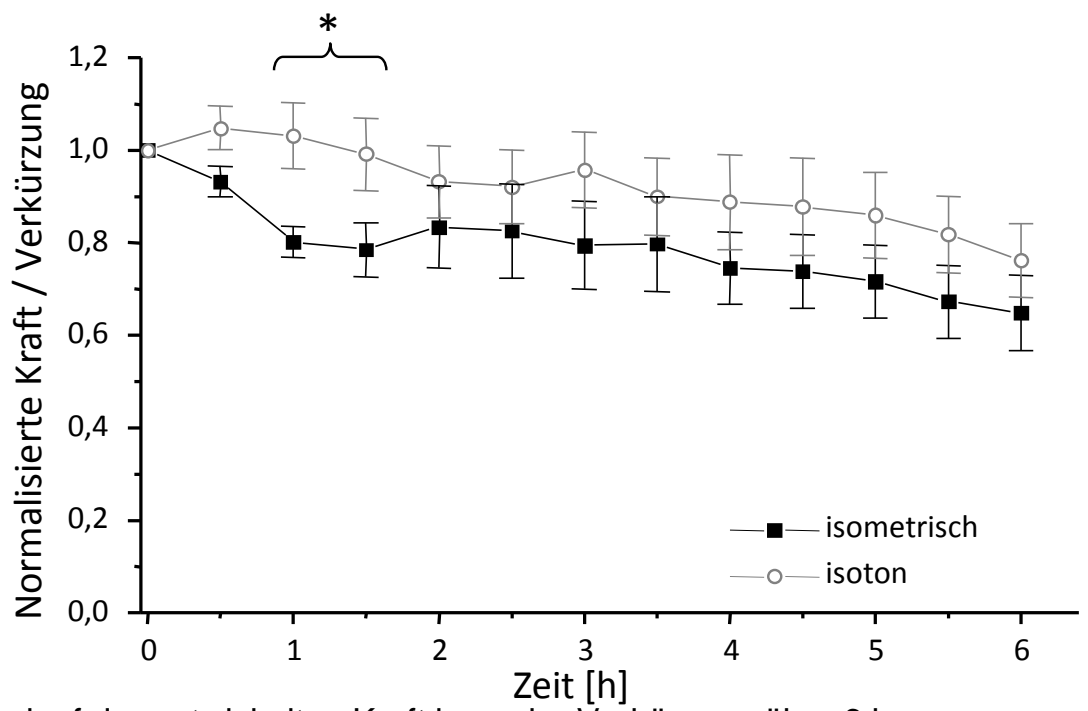

Abbildung 8: Verlauf der entwickelten Kraft bzw. der Verkürzung über $6 \mathrm{~h}$

\subsubsection{Isometrische Kontraktion}

Die Muskelstreifen wurden, wie in Abschnitt 2.3 beschrieben, durch Dehnung auf eine Ruhespannung von $3 \mathrm{mN} / \mathrm{mm}^{2}$ Querschnittsfläche und repetitive elektrische Stimulation unter isometrischen Bedingungen für sechs Stunden einer erhöhten Vor- 
und Nachlast ausgesetzt $(\mathrm{n}=8)$. Da es sich um einen in-vitro-Versuch am isolierten Herzmuskelgewebe handelte, war ein Einfluss von systemischen Faktoren, wie neuronaler Stimulation oder humoraler Aktivierung, auszuschließen. Als Ursachen für eine Änderung der Genexpression kamen bei diesem Versuchsaufbau somit nur ein direkter Einfluss der mechanischen Belastung oder eine auto- bzw. parakrine Stimulation der Zellen in Frage. Als Kontrollgruppe dienten Muskelstreifen, die für sechs Stunden ohne jede mechanische Belastung (komplett schlaff) inkubiert worden waren $(n=8)$.
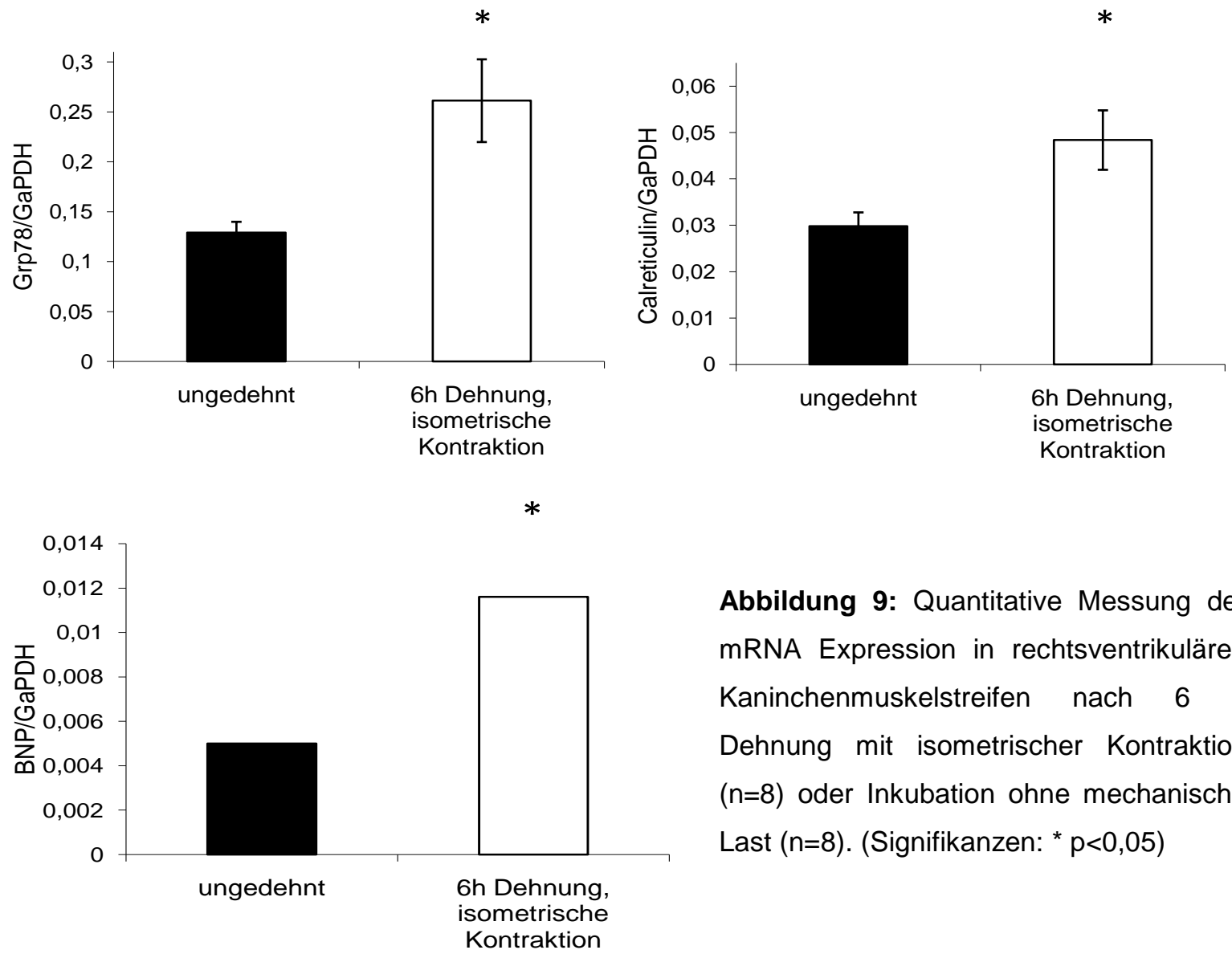

Abbildung 9: Quantitative Messung der mRNA Expression in rechtsventrikulären Kaninchenmuskelstreifen nach $6 \mathrm{~h}$ Dehnung mit isometrischer Kontraktion $(n=8)$ oder Inkubation ohne mechanische Last $(n=8)$. (Signifikanzen: * $p<0,05)$

In den einer erhöhten Vor- und Nachlast ausgesetzten Muskelstreifen zeigte sich auf mRNA-Ebene eine signifikante $(p=0,0390)$ Steigerung der Expression des molekularen Hypertrophiemarkers BNP (isometrisch: 0,0116 $\pm 0,0023$; ungedehnt: 0,0050 $\pm 0,0014)$. Dieser erwartete Befund bestätigt, dass die Muskelstreifen tatsächlich einem überschwelligen biomechanischen Reiz ausgesetzt waren, der geeignet war, im Muskelstreifen eine molekulare Hypertrophieantwort auszulösen. Damit einher ging eine signifikante $(p=0,0202)$ Verstärkung der mRNA-Expression 
von Grp78 (0,2614 $\pm 0,0414)$ im Vergleich zu den ungedehnten Streifen $(0,1290 \pm 0,0109)$. Auch die Expression von Calreticulin war in den mechanisch belasteten Streifen höher als in den ungedehnten (isometrisch: 0,0484 $\pm 0,0064$; ungedehnt: $0,0298 \pm 0,0030)(p=0,0339)$. Dies belegt, dass die biomechanische Laststeigerung mit einer auf molekularer Ebene nachweisbaren ER-Stress-Situation einher ging.

\subsubsection{Isotone Kontraktion}

Die im vorigen Abschnitt beschriebene Dehnung der Muskelstreifen hatte eine gesteigerte Vorlast- (passive Dehnung) und Nachlast- (aktive Kontraktion gegen den starren Widerstand einer isometrischen Aufhängung) Komponente. Die beobachteten Expressionsveränderungen könnten daher prinzipiell durch eine Steigerung allein der Vorlast, allein der Nachlast, oder aber der kombinierten Lasterhöhung zuzuschreiben sein. Um mehr Informationen darüber zu erhalten, welche Lastform primär für die Entstehung von ER-Stress in kardialem Muskelgewebe verantwortlich ist, setzten wir isolierte rechtsventrikuläre Kaninchenmuskelstreifen ein, die für sechs Stunden einer reinen Vorlasterhöhung (passive Dehnung auf eine Ruhespannung von $3 \mathrm{mN} / \mathrm{mm}^{2}$ Querschnittsfläche und dann aktive Kontraktion unter isotonen Bedingungen, also mit vernachlässigbarer Nachlast) ausgesetzt worden waren $(n=8)$. Die Menge der mRNA von BNP, Grp78 und Calreticulin wurde gemessen und sowohl mit ungedehnten Muskelstreifen $(n=8)$, als auch mit den isometrisch belasteten Präparaten $(n=8)$ verglichen. 

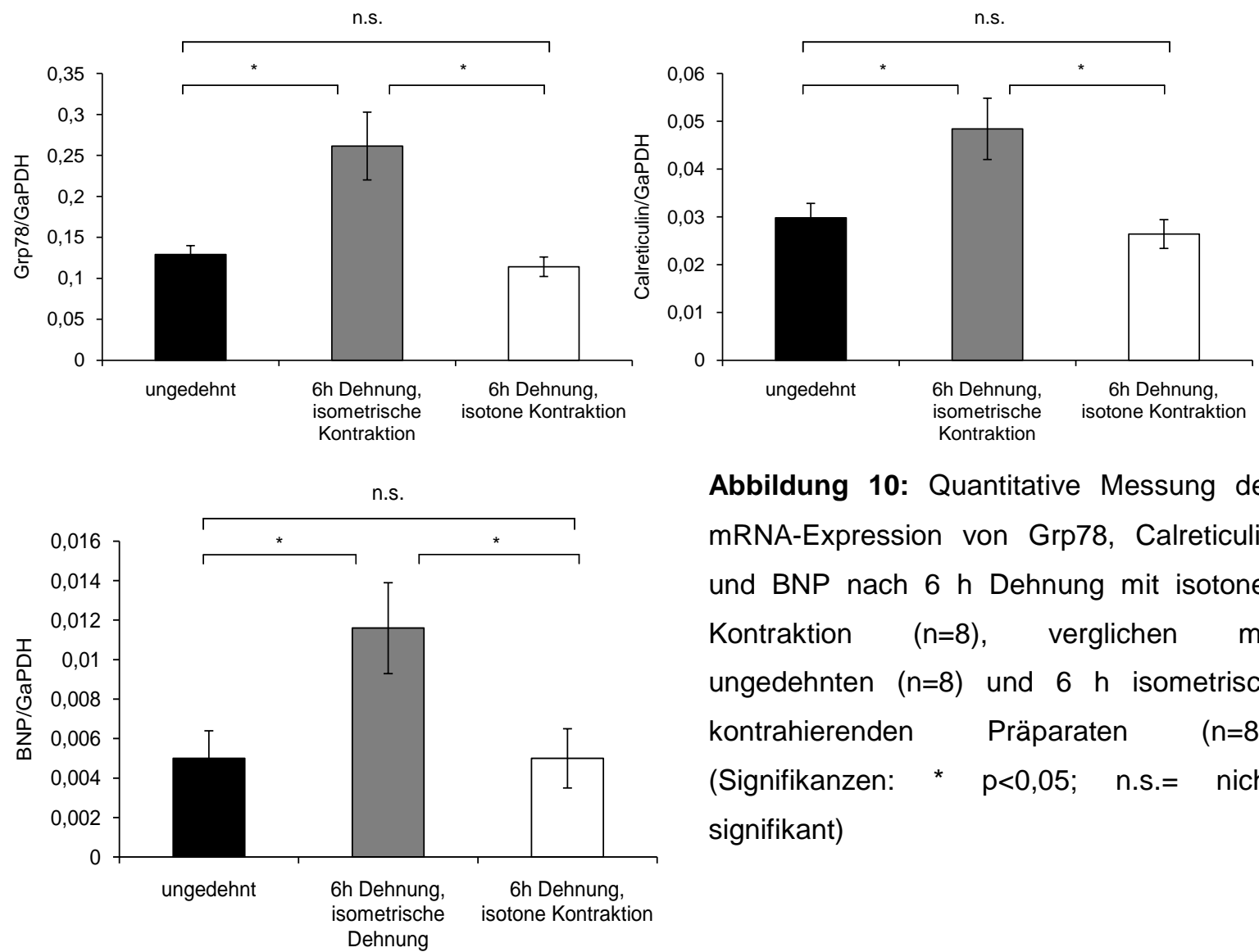

Abbildung 10: Quantitative Messung der mRNA-Expression von Grp78, Calreticulin und BNP nach $6 \mathrm{~h}$ Dehnung mit isotoner Kontraktion $\quad(n=8)$, verglichen mit ungedehnten $(\mathrm{n}=8)$ und $6 \mathrm{~h}$ isometrisch kontrahierenden Präparaten $(n=8)$. (Signifikanzen: * $p<0,05 ; \quad n . s .=$ nicht signifikant)

Nach sechs Stunden Inkubation war die mRNA-Expression von BNP in den gedehnten, isoton kontrahierenden Muskelstreifen $(0,0050 \pm 0,0015)$ unverändert im Vergleich zu den ungedehnten Muskelstreifen der Kontrollgruppe $(0,0050 \pm 0,0014$; $\mathrm{p}=0,9841$ ). Auch hinsichtlich der mRNA-Expression der beiden ER-Chaperone Grp78 (isoton: $0,1141 \pm 0,0120$; ungedehnt: 0,1290 $\pm 0,0190 ; p=0,4033$ ) oder Calreticulin (isoton: 0,0264 $\pm 0,0033$; ungedehnt: 0,0298 $\pm 0,0030 ; p=0,4918$ ) ließ sich keine Expressionsänderung feststellen. Im Vergleich mit den isometrisch belasteten Präparaten war die Expression von BNP wie auch der beiden ER-Chaperone signifikant (Grp78: $p=0,0123$; Calreticulin: $p=0,0163$ ) niedriger (Grp78: isoton: 0,1141 $\pm 0,0120$; isometrisch: 0,2614 $\pm 0,0414$; Calreticulin: isoton: $0,0264 \pm 0,0033$; isometrisch: 0,0484 $\pm 0,0064)$.

\subsubsection{Einfluss von Angiotensin II auf myokardialen ER-Stress}

Im nächsten Schritt wurde untersucht, ob auch ein neurohumoraler HypertrophieStimulus, ohne direkten Einfluss auf das endoplasmatische Retikulum, zu einer vermehrten Expression der ER-Chaperone führt. Hierzu wurden erneut Experimente in Abwesenheit von mechanischer Belastung durchgeführt. Als neurohumoraler 
Stimulus wurde Angiotensin II eingesetzt, das auf Herzmuskelzellen eine bekannte, starke hypertrophe Wirkung ausübt.

Die Versuche wurden an isolierten, mechanisch unbelasteten rechtsventrikulären Kaninchenmuskelstreifen durchgeführt. Ursprünglich sollte für Angiotensin II Ethanol als Lösungsmittel verwendet werden. Aufgrund der Ergebnisse der initial durchgeführten Kontrollexperimente (vgl. Abschnitt 3.1.1, S.40-42), die einen eigenständigen Effekt von Ethanol auf die Expression von ER-Chaperonen selbst in niedriger Konzentration gezeigt hatten, wurde anstelle von Ethanol destilliertes Wasser als Lösungsmittel verwendet.

Zunächst wurde untersucht, ob Angiotensin II die mRNA-Expression des molekularen Hypertrophiemarkers BNP beeinflusst: Im Vergleich mit den Kontrollpräparaten ( $n=5 ; 0,0063 \pm 0,0013)$ zeigte sich nach 6-stündiger Behandlung mit $10 \mathrm{nmol} / \mathrm{L}$ Angiotensin II ( $\mathrm{n}=6 ; 0,1519 \pm 0,0557)$ ein signifikanter Anstieg der BNP mRNA auf im Mittel etwa das Dreifache $(p=0,04756)$. Dies belegt, dass unter unseren experimentellen Bedingungen die typische Angiotensin II zugeschriebene pro-hypertrophe Wirkung nachweisbar war.

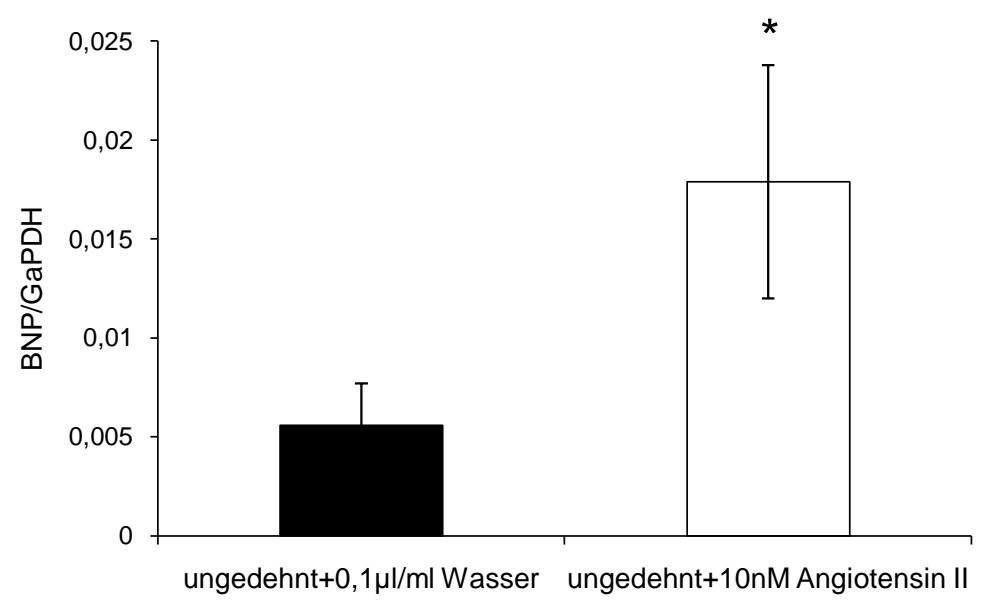

Abbildung 11: Quantitative Expression von BNP in isolierten rechtsventrikulären Kaninchenmuskelstreifen nach $6 \mathrm{~h}$ Behandlung mit Angiotensin II $(n=6)$ im Vergleich mit Kontrollpräparaten $(n=5)$. (Signifikanz: * $p<0,05)$ 

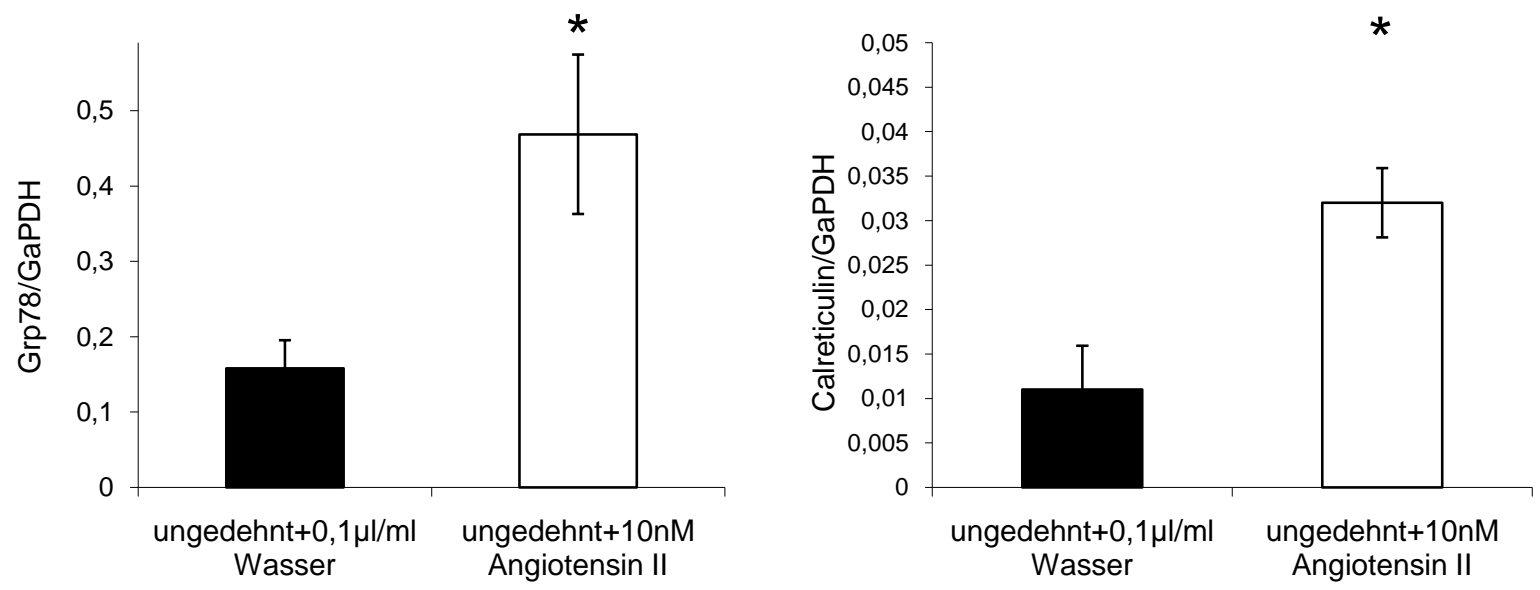

Abbildung 12: Quantitative Expression der mRNA von Grp78 und Calreticulin in rechtsventrikulären Kaninchenmuskelstreifen. Nach $6 \mathrm{~h}$ Behandlung mit Angiotensin II $(\mathrm{n}=6)$ verglichen mit Kontrollen $(n=5)$. (Signifikanz: * $p<0,05)$

Darüber hinaus steigerte Angiotensin II aber auch die mRNA-Expression von Grp78 (Angiotensin II: 0,4684 $\pm 0,1057$; Kontrolle: 0,1579 $\pm 0,0374 ; p=0,0317$ ) und Calreticulin (Angiotensin II: 0,0320 $\pm 0,0039$; Kontrolle: 0,0110 $\pm 0,0049 ; p=0,0146$ ) signifikant.

\subsubsection{Blockade des AT-II-Rezeptors unter mechanischer Belastung}

Unter Berücksichtigung der bis zu diesem Zeitpunkt gewonnenen Erkenntnisse sollte abschließend die Frage geklärt werden, ob die endogene Produktion und Ausschüttung von Angiotensin II einen Anteil an der durch isometrische Last vermittelten Erhöhung der Expression von Grp78 und Calreticulin hat. Zu diesem Zweck wurden rechtsventrikuläre Kaninchenmuskelstreifen wie in den vorherigen Versuchen für sechs Stunden isometrisch gedehnt und zusätzlich mit $1 \mu \mathrm{g} / \mathrm{ml}$ des Angiotensin-II-Typ-1-Rezeptorantagonisten Irbesartan behandelt $(n=10)$. Als Kontrollgruppe dienten ohne Irbesartan inkubierte, isometrisch gedehnte Streifen mit DMSO als Lösungsmittel $(n=7)$. 

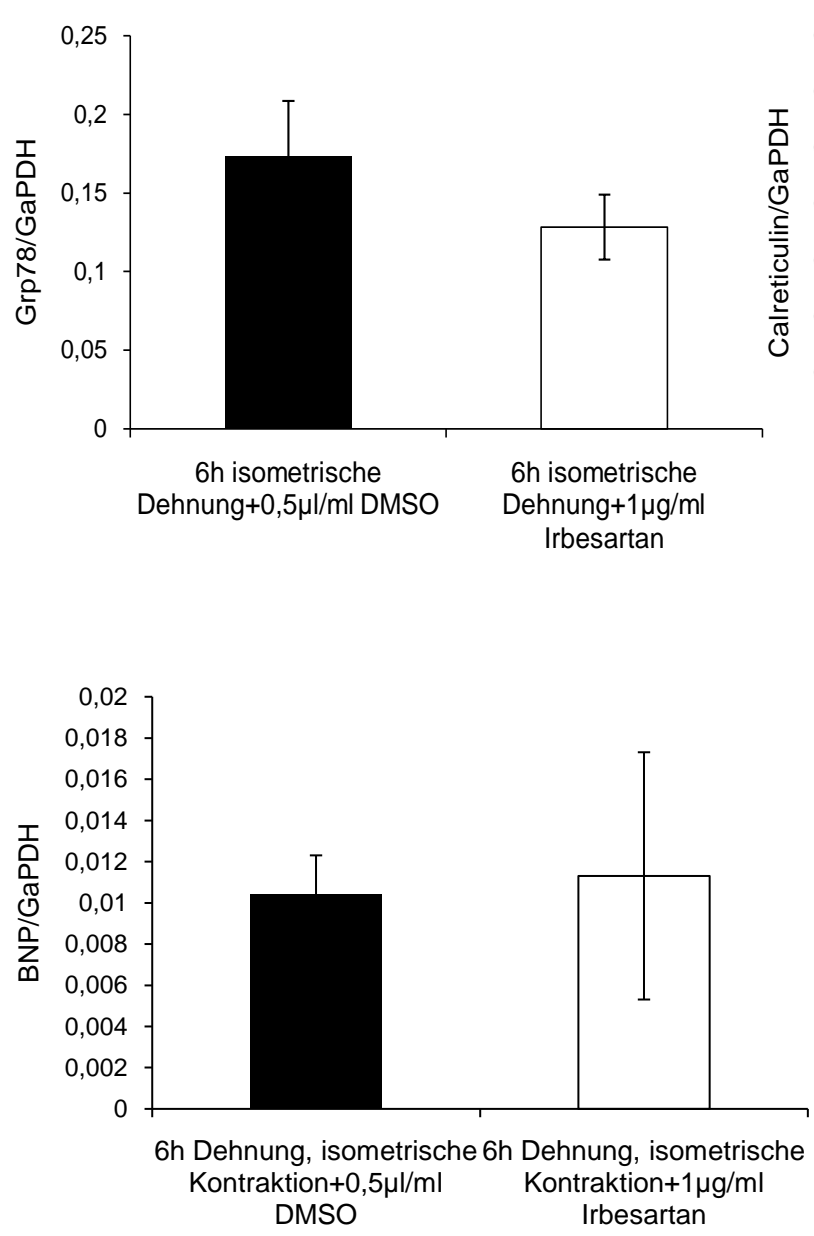

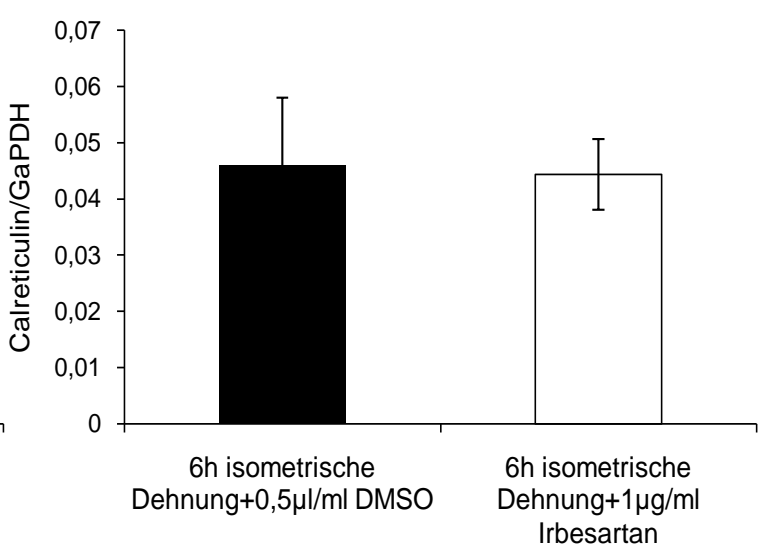

Abbildung 12: Quantitative Bestimmung der mRNA aus rechtsventrikulären Kaninchenmuskelstreifen nach $6 \mathrm{~h}$ Dehnung, isometrischer Kontraktion, mit $(n=10)$ und ohne $(n=7)$ die Zugabe von Irbesartan.

In diesen Versuchen ließ sich kein signifikanter Einfluss von Irbesartan auf die lastabhängige Expression der ER-Chaperone nachweisen: Die mRNA-Expression von Grp78 war unter der Behandlung mit Irbesartan zwar tendenziell niedriger als in

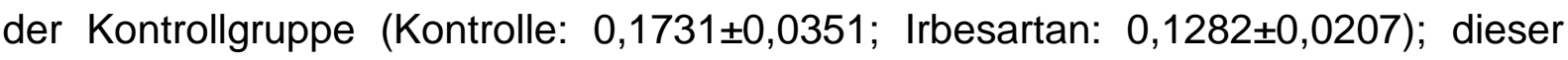
Unterschied war mit $p=0,1387$ jedoch nicht signifikant. Auch für Calreticulin ließ sich keine signifikante $(p=0,8621)$ Änderung der Expression nachweisen (Kontrolle:

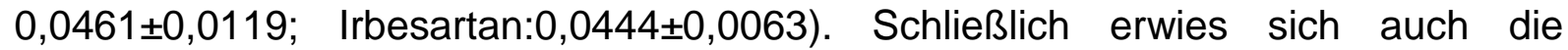
dehnungsabhängige Regulation der Expression von BNP als durch die Zugabe von Irbesartan nicht signifikant $(p=0,8103)$ beeinflusst (Kontrolle: 0,0104 $\pm 0,0019$; Irbesartan: 0,0113 $\pm 0,006)$.

\subsection{Untersuchungen im Monocrotaline-Modell}

Die zuvor beschriebenen Versuche untersuchten, wie sich akute Veränderungen der biomechanischen Last bzw. kurzzeitige Einwirkung von neurohumoralen Stimuli auf die Expression von ER-Chaperonen auswirkt. Das Vollbild einer 
Myokardhypertrophie entwickelt sich jedoch erst infolge einer chronischen Einwirkung von biomechanischen und/oder neurohumoralen Hypertrophie-Stimuli. Um zu untersuchen, ob es im Rahmen einer chronischen Last-induzierten Herzmuskelhypertrophie zu ER-Stress kommt, wurde die Expression von ERChaperonen im Modell der Druck-induzierten Rechtsherzhypertrophie der Monocrotaline-behandelten Ratte analysiert.

\subsubsection{Messung der Expression von ER-typischen Chaperonen auf mRNA- Ebene}

Wir untersuchten die mRNA-Expression von ER-Chaperonen in Gewebeproben aus den rechten Ventrikeln von MCT-behandelten Ratten im Vergleich zu Kontrolltieren.
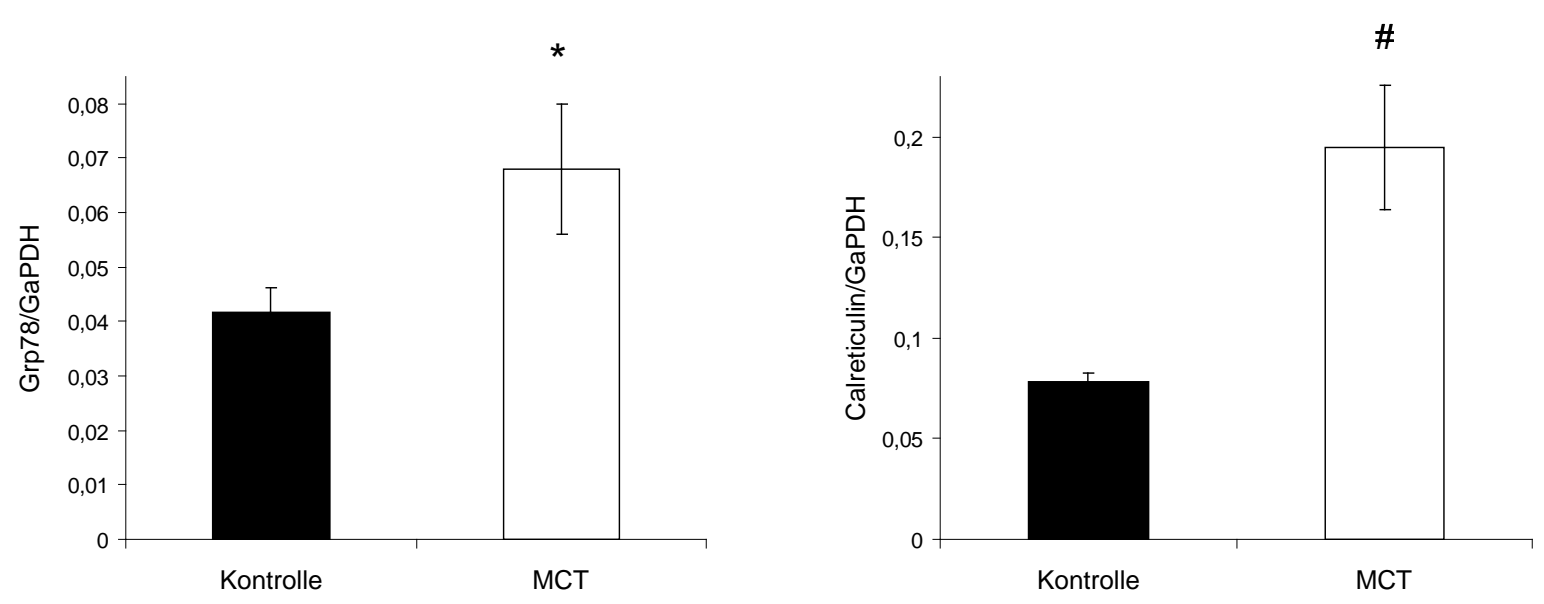

Abbildung 13: Expression von Grp78 (Kontrolle und MCT jeweils $n=6$ ) und CRT (Kontrolle: $n=6$; MCT: $n=7)$ in den rechten Ventrikeln von MCT-behandelten Ratten im Vergleich zu Kontrolltieren. (Signifikanzen: * $p<0,05 ; \# p<0,01$ )

Es fand sich eine im Vergleich zu Kontrolltieren $(0,042 \pm 0,005)$ signifikant erhöhte $(p=0,0355)$ Expression von Grp78-mRNA in den rechten Ventrikeln von MCTbehandelten Ratten $(0,068 \pm 0,012)$. Auch die Menge an CRT-mRNA im rechten Ventrikel war nach Behandlung mit MCT $(0,195 \pm 0,031)$ größer $(p=0,0087)$ als unter Kontrollbedingungen $(0,078 \pm 0,005)$.

\subsubsection{Messung von ER-typischen Chaperonen auf Proteinebene}

Um zu überprüfen, ob sich die Steigerung der mRNA-Expression auch tatsächlich auf die exprimierte Menge der entsprechenden Proteine auswirkt, und zusätzlich 
einen Vergleich zwischen rechtem und linkem Ventrikel anstellen zu können, wurden Western-Immunoblot-Analysen durchgeführt. Bei vier Tieren jeder Gruppe wurden die Herzen entnommen und rechter und linker Ventrikel voneinander getrennt. Nach der Aufarbeitung und Vorbereitung der Proben wurde zunächst eine Übersichtsdarstellung der erhaltenen Banden angefertigt. Als Kontrolle bezüglich der aufgetragenen Proteinmenge wurde Calsequestrin benutzt.

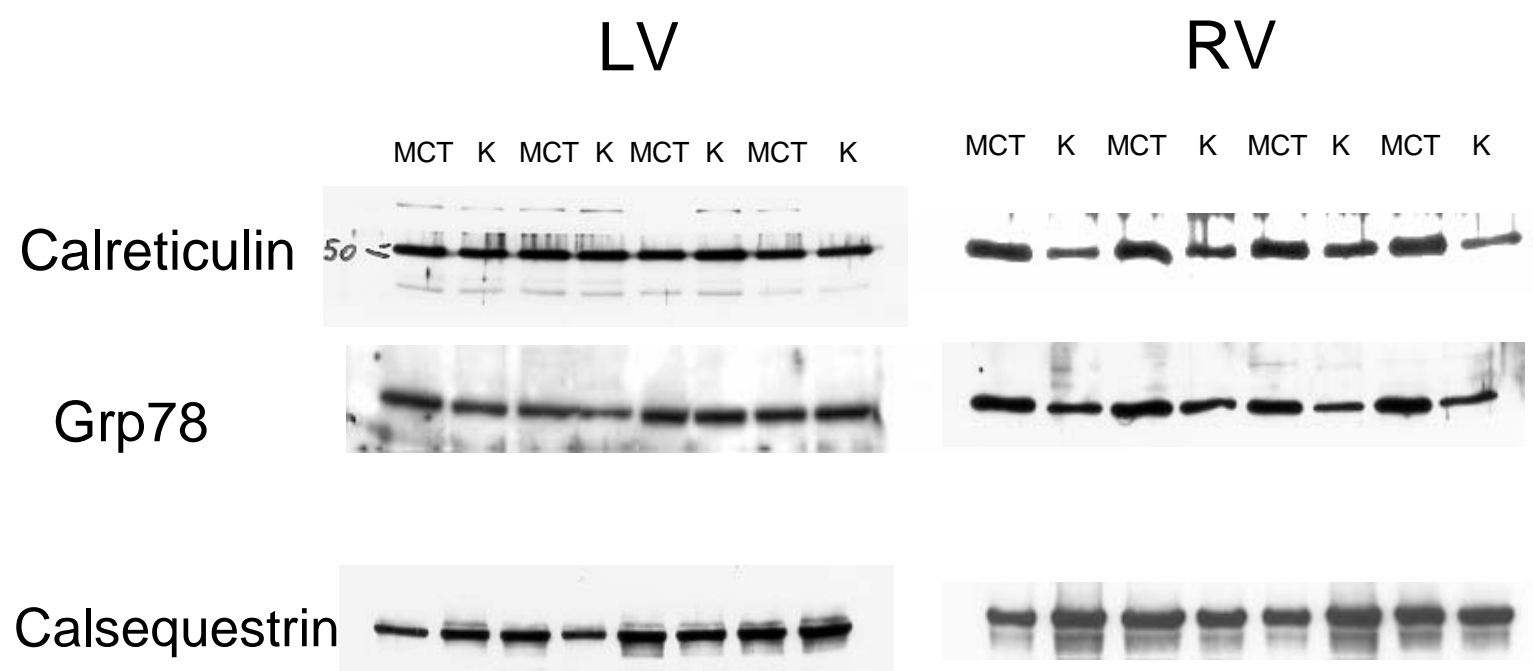

Abbildung 14: Übersicht über die Banden aus dem Western-Immunoblot. ( $K=$ Kontrolle; $M C T=M C T$ Behandlung)

Bereits in der Übersichtsdarstellung zeigte sich, dass die Banden für CRT und Grp78 aus den rechten Ventrikeln von MCT-behandelten Ratten deutlich ausgeprägter waren als bei den Kontrolltieren. In den Proteinhomogenaten aus den linken Ventrikeln war dagegen keine Änderung der Proteinexpression für CRT oder Grp78 zu erkennen.

Um den in der Übersicht gewonnenen Eindruck zu bestätigen, wurden die Banden mit Hilfe eines digitalen Kamerasystems quantifiziert. 

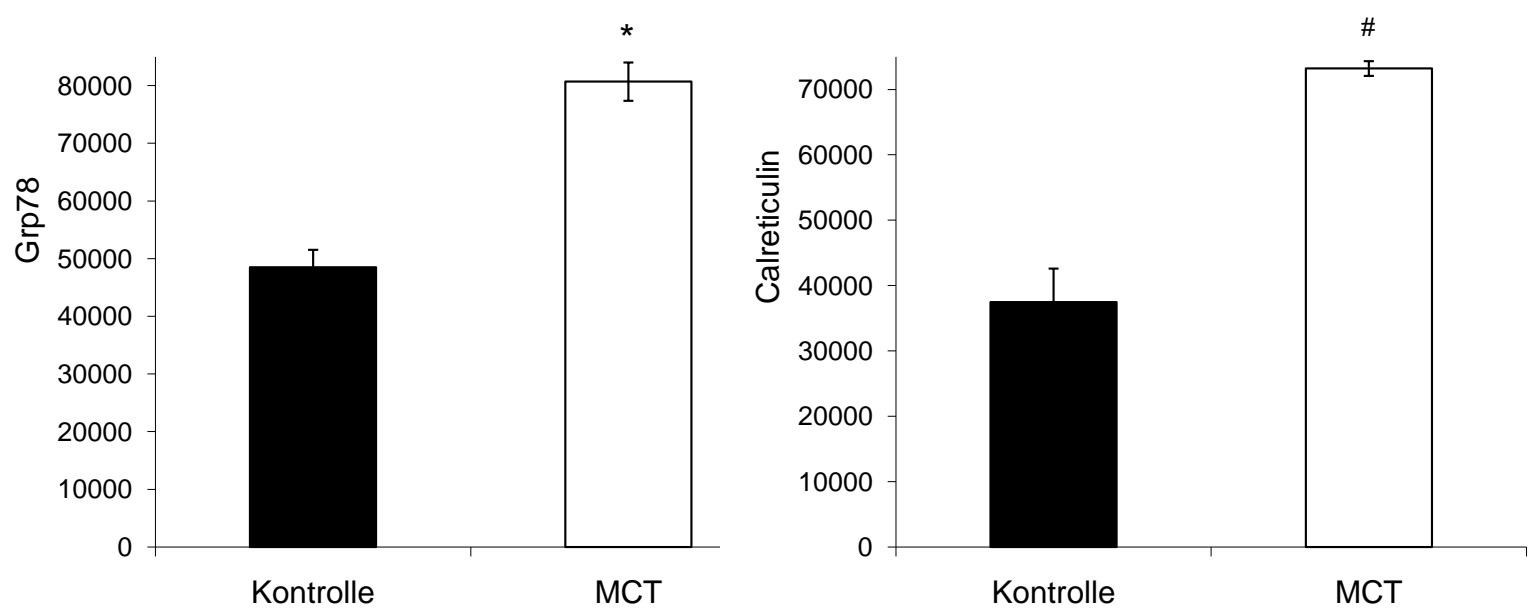

Abbildung 15: Quantifizierung der Proteinexpression von Grp78 und Calreticulin aus den rechten Ventrikeln von MCT-behandelten Ratten im Vergleich $\mathrm{zu}$ Kontrolltieren. $(n=4$; Signifikanzen: * $p<0,001, \# p<0,01)$

In den rechten Ventrikeln von MCT-behandelten Ratten zeigte sich eine im Vergleich zu den Kontrolltieren (48510 Pixel \pm 3031 ) signifikante $(p<0,001)$ Steigerung der Grp78-Expression (80685 \pm 3230 ). Auch für Calreticulin konnten wir auf Proteinebene eine signifikant $(p=0,0075)$ verstärkte Expression nach Behandlung mit Monocrotaline (MCT: 73211 \pm 1123 ; Kontrolle: $37468 \pm 5136)$ feststellen. Somit führte die im rechten Ventrikel gesteigerte mRNA-Expression für die entsprechenden ERChaperone auch auf Proteinebene zu einer Expressionszunahme.

Im Gegensatz dazu bestätigte sich bei der Quantifizierung der Proteinexpression in den linken Ventrikeln der Versuchstiere der bereits in der Übersicht gewonnene Eindruck: Weder bei der Messung von Grp78 (MCT: 74952 44410 ; Kontrolle: $64800 \pm 5706$ ) noch von Calreticulin (MCT: 48634 \pm 1579 ; Kontrolle: 50119 \pm 2059 ) zeigte sich ein signifikanter Unterschied in der Proteinexpression zwischen Monocrotaline-behandelten und Kontroll-Ratten. 

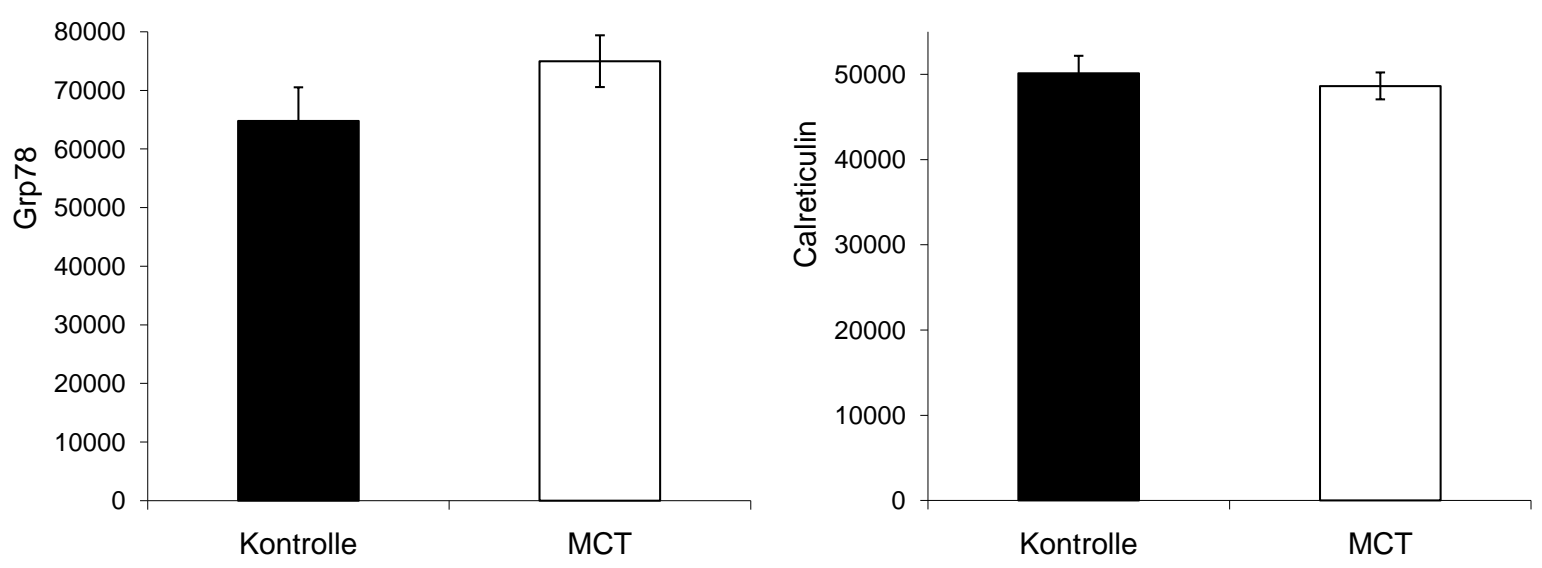

Abbildung 16: Quantifizierung der Proteinexpression von Grp78 und Calreticulin aus den linken Ventrikeln von MCT-behandelten Ratten im Vergleich zu Kontrolltieren. $(n=4)$

Zusammenfassend fand sich im Modell der chronischen Druck-induzierten Hypertrophie des rechten Ventrikels der Monocrotaline-behandelten Ratte eine auf den rechten Ventrikel begrenzte Expressionssteigerung der ER-Chaperonproteine Grp78 und Calreticulin, die sowohl auf mRNA- wie auch auf Protein-Ebene nachweisbar war. Im Gegensatz dazu war die Chaperonexpression im linken Ventrikel unverändert. 


\section{Diskussion}

An den Veränderungen des Herzens im Verlauf von Herzhypertrophie und Herzinsuffizienz sind sowohl neurohumorale Stimulation als auch biomechanische Stressoren beteiligt. Die Konzentration von Katecholaminen im Serum ist gesteigert (Thomas und Marks 1978), und es kommt zu einer Aktivierung des RAAS (Francis et al. 1990). Die positiv inotrope Wirkung von Angiotensin II (Moravec et al. 1990) und die Dichte von $\beta$-Adrenorezeptoren (Bristow et al. 1982, Brodde et al. 1989) sind allerdings vermindert. Neben diesen neurohumoralen Veränderungen hat auch mechanische Belastung einen direkten Einfluss auf das Herz. Für die SERCA konnte gezeigt werden, dass eine mechanische Entlastung des Herzens die Expression verringert (Heerdt et al. 2000, Terracciano et al. 2004), eine kurzzeitige Laststeigerung hingegen zu einer Expressionssteigerung führt (Kögler et al. 2006).

In dieser Studie sollte die Rolle von neurohumoraler Stimulation bzw. mechanischer Last bei der Entstehung von ER-Stress im Myokard untersucht werden. Zu diesem Zweck wurden in-vitro-Untersuchungen an isolierten intakten Herzmuskelstreifen des Kaninchens sowie in-vivo-Untersuchungen im Tiermodell der Monocrotalineinduzierten rechtsventrikulären Herzhypertrophie der Ratte, verbunden mit quantitativen Genexpressionsuntersuchungen auf mRNA- und Proteinebene, durchgeführt.

\subsection{Untersuchungen der Expressionsantwort des isolierten} Herzmuskels auf akute biomechanische Laständerungen

Um in isolierten Herzmuskelstreifen des Kaninchens selektiv den Einfluss einer akuten biomechanischen Laständerung oder einer neurohumoralen Stimulation auf die Genexpression nachweisen zu können, bedurfte es einer Methode, diese Muskelstreifen über mehrere Stunden unter stabilen und kontrollierten Bedingungen und insbesondere genau definierten Lastverhältnissen zu untersuchen. In diesem Modell sollte ER-Stress prinzipiell anhand von Expressionsänderungen molekularer Marker nachweisbar sein. Darüber hinaus sollte das Modell den Untersucher in die Lage versetzen, suffiziente biomechanische Reize auf das isolierte 
Herzmuskelgewebe auszuüben und andererseits nach Bedarf Überträger- bzw. Hemmstoffe neurohumoraler Signalwege einwirken zu lassen.

In dieser Arbeit wurde das Modell der Langzeitkultur isolierter Herzmuskelstreifen des Kaninchens angewendet, in dem Trabekel oder dünne Papillarmuskeln über eine Zeitspanne von mehreren Stunden bis wenigen Tagen bei weitgehend stabiler kontraktiler Funktion untersucht werden können (Janssen et al. 1998). Mithilfe dieser Methode ist es möglich, differenzierte Expressionsantworten auf einen mehrstündigen definierten biomechanischen Reiz auszulösen und unterschiedliche Lastformen (Vor- bzw. Nachlaststeigerung) auf das Gewebe einwirken zu lassen (Kögler et al. 2006, Schott et al., 2008). In Analogie zur Dehnung der Ventrikelwand während der Füllungsphase des Herzzyklus entspricht die passive Vordehnung der Muskelstreifen in diesem Versuchsaufbau der Vorlast. Durch den willkürlich wählbaren Grad der Vordehnung lässt sich eine erhöhte Vorlast simulieren. Dagegen entspricht der Widerstand während der isometrischen Kontraktion einer Situation mit maximaler Nachlast. Alternativ können die Muskelstreifen aus dem vorgedehnten Zustand isoton kontrahieren, also unter Ausschaltung jeglicher Nachlast.

Als Beleg dafür, dass ER-Stress in Muskelstreifen in dieser Art von Langzeitkultur im Verlauf weniger Stunden prinzipiell in Form einer Expressionsänderung molekularer Marker nachgewiesen werden kann, wurde eine Reihe von Präparaten mit Tunicamycin behandelt. Tunicamycin bewirkt eine Hemmung der ProteinGlykosylierung (Takatsuti und Tamura 1971), was wiederum zu einem Versagen der Qualitätskontrolle im ER (vgl. 1.5.2.2, S.16-18) und über eine Proteinakkumulation zu ER-Stress führt (Dorner et al. 1990). Die Behandlung mechanisch unbelasteter Präparate mit Tunicamycin über sechs Stunden führte im hier verwendeten Modell zu einer Induktion von ER-Stress, wie sich anhand einer signifikanten Steigerung der mRNA-Expression der beiden molekularen Marker Grp78 und Calreticulin feststellen ließ. Somit erfüllt das verwendete experimentelle Modell eine wesentliche Voraussetzung für die Durchführung der geplanten Untersuchungen zur Induzierbarkeit von ER-Stress im isolierten Herzmuskelgewebe.

Wurden Muskelstreifen über $6 \mathrm{~h}$ vorgedehnt und zu isotonen Kontraktionen angeregt (gesteigerte Vorlast, keine Nachlast), veränderte sich die Expression der molekularen ER-Stress-Marker Grp78 und Calreticulin nicht. In einer früheren Studie konnte unter identischen Bedingungen einer isolierten Vorlaststeigerung eine Hochregulation der Expression der SR-Ca ${ }^{2+}$-ATPase (SERCA) im isolierten 
Kaninchenmyokard nachgewiesen werden (Kögler et al. 2006). Daher ist es unwahrscheinlich, dass dem Ausbleiben einer Expressionsänderung der ER-StressMarker ein unzureichender mechanischer Stimulus zugrunde lag. Vielmehr ist anzunehmen, dass eine isolierte Vorlaststeigerung über 6 Stunden offenbar nicht hinreichend für die Auslösung einer ER-Stress-Situation ist.

Wenn hingegen Muskelstreifenpräparate über 6 Stunden aus dem vorgedehnten Zustand isometrisch kontrahierten und somit einer erhöhten Vor- und Nachlast ausgesetzt wurden, zeigte sich eine erhebliche und statistisch signifikante Zunahme der mRNA-Expression von Grp78 und Calreticulin. Gleichzeitig wurde auch die Expression von „brain natriuretic peptide“ (BNP) untersucht. BNP ist ein klinisch relevanter Marker der Herzinsuffizienz, der bei mechanischer Belastung sowohl unter in-vivo- als auch in-vitro-Bedingungen hochreguliert wird (Ogawa et al. 1991, Kinnunen et al. 1993). Im Einklang mit den Vorbefunden (Kögler et al. 2006) war die BNP mRNA-Expression in den mechanisch belasteten Streifen signifikant gesteigert. Diese Ergebnisse weisen darauf hin, dass es infolge einer akuten mechanischen Vor- und Nachlasterhöhung bereits nach sechs Stunden zur Entwicklung von ERStress und einer nachfolgenden Aktivierung der „unfolded protein response“ (UPR) kommt, die mit einer parallelen Induktion eines Hypertrophie-Expressionsmusters einher geht.

\subsection{Untersuchungen an einem Modell für chronische Last-induzierte Herzhypertrophie}

Wenn unter Einfluss einer erhöhten Vor- und Nachlast bereits nach wenigen Stunden im Herzmuskelgewebe eine Induktion von ER-Stress nachweisbar ist, die mit der Induktion des molekularen Hypertrophiemarkers BNP einher geht, so stellt sich die Frage, ob auch in einem chronischen tierexperimentellen Modell der Last-induzierten Herzhypertrophie ER-Stress vorliegt. Zur Untersuchung des Einflusses einer chronischen Steigerung der mechanischen Belastung des Herzens wurde in dieser Arbeit das Monocrotaline-Modell der Druck-induzierten rechtsventrikulären Hypertrophie der Ratte verwendet. Wie im Abschnitt 2.4 (S. 31 f) beschrieben, kommt es nach einer einmaligen Injektion des Pflanzenalkaloids Monocrotaline zu einer obliterierenden Vaskulitis der kleinen Lungenarterien und -arteriolen und infolgedessen zu einer Widerstandserhöhung im Lungenkreislauf, die für die rechte 
Herzkammer eine Druckbelastung darstellt. Kögler et al. konnten zeigen, dass die einmalige Applikation von Monocrotaline nach ca. drei Wochen zu einer ausgeprägten, auf den rechten Ventrikel begrenzten, myokardialen Hypertrophie führt (Kögler et al. 2003).

Vor diesem Hintergrund erfolgte die Untersuchung der Expression der ERChaperone Grp78 und Calreticulin (CRT) in Myokardproben aus dem rechten und linken Ventrikel von Monocrotaline-behandelten Ratten. Dabei ließ sich im rechten Ventrikel eine gesteigerte Expression von Grp78 und CRT auf mRNA- und ProteinEbene feststellen. In der Wand der linken Herzkammer dieser Tiere fand sich im Vergleich zu Kontrolltieren hingegen keine vermehrte Expression der beiden ERChaperone.

Beim Monocrotaline-Modell kommt es im Zuge der Entwicklung der Lungenveränderungen und der Herzhypertrophie zu einer generalisierten, systemischen Sympathikusaktivierung, die mit erhöhten KatecholaminSerumspiegeln einher geht (Leineweber et al. 2002, Kögler et al. 2003). Dem neurohumoralen Einfluss der im Kreislauf zirkulierenden adrenergen Botenstoffe ist das gesamte Herz - also rechter und linker Ventrikel gleichermaßen - ausgesetzt. Daher ist zu erwarten, dass sich Veränderungen auf molekularer Ebene, die hauptsächlich durch adrenergen Stress vermittelt werden, in der Wand beider Herzkammern nachweisen lassen. Im Gegensatz dazu betrifft die mechanische Laststeigerung nach Monocrotaline-Behandlung ausschließlich die rechte Herzkammer, sodass Veränderungen, die vorwiegend durch biomechanischen Stress ausgelöst werden, nur im rechtsventrikulären Myokard nachweisbar sind. Die in dieser Arbeit beschriebenen Expressionsänderungen der ER-Chaperone Grp78 und CRT waren nur im rechten Ventrikel - nicht jedoch im linken Ventrikel - der Monocrotaline-behandelten Ratten nachweisbar. Dies ist ein Beleg dafür, dass der relevante Stimulus, der diese Veränderungen auslöst, ein biomechanischer sein muss, und dass eine gesteigerte adrenerge Stimulation allein nicht hinreichend zur Induktion dieser Veränderungen ist.

Im Rahmen vorheriger Untersuchungen am Modell Monocrotaline-behandelter Ratten wurden sowohl morphologische als auch funktionelle Unterschiede zwischen dem rechten und linken Ventrikel festgestellt (Kögler et al. 2003). So war beim Vergleich mit Herzen von unbehandelten Ratten nur das Gewicht des rechten, nicht aber das des linken Ventrikels erhöht. Zudem zeigten Experimente mit aus diesen 
Herzen isolierten Muskelstreifen funktionelle Beeinträchtigungen, die ebenfalls nur in Präparaten aus dem rechten Ventrikel nachweisbar waren, während sich solche aus dem linken Ventrikel funktionell wie Muskelstreifen aus Kontrollherzen verhielten. Die Expression wichtiger in die Kalzium-Homöostase involvierter kardialer Proteine wie der SERCA, des Ryanodinrezeptors (RyR) oder von Phospholamban war im rechten Ventrikel verringert, während sich im linken Ventrikel keine Regulation der untersuchten Proteine nachweisen ließ. Diese Ergebnisse weisen darauf hin, dass gesteigerte mechanische Last auch für die Regulation einiger Proteine zwingend erforderlich ist.

In den Promotorregionen sowohl von Grp78 als auch von CRT findet sich ein sogenanntes „ER-stress-response-element“ (ERSE) (Yoshida et al. 1998), welches im Rahmen der UPR z.B. durch ATF6 aktiviert wird (vgl. 1.5.4.1, S. 19 f.). Zudem führt die Gabe ER-Stress auslösender Substanzen wie z.B. Tunicamycin zu einer gesteigerten Expression von Grp78 und Calreticulin (Dorner et al. 1990, Llewellyn et al. 1996). Aufgrund dieser Beobachtungen wird eine Hochregulation von ERChaperonen wie z.B. Grp78 oder Calreticulin von vielen Autoren als ein indirektes Zeichen für bestehenden ER-Stress genutzt (z.B. Ozcan et al. 2004, Hoozemans et al. 2005). Folglich kann auch die im Monocrotaline-Modell gezeigte Steigerung der rechtsventrikulären Expression von Grp78 und Calreticulin als Hinweis auf ER-Stress in diesem hypertrophierenden Myokardgewebe gedeutet werden.

Beim Monocrotaline-Modell handelt es sich um eine Druck-induzierte Herzhypertrophie. Diese ist abzugrenzen von anderen tierexperimentellen Hypertrophiemodellen, die das Herz einer Volumenbelastung aussetzen (z.B. Aortokavaler Shunt oder experimentelle Mitralklappeninsuffizienz) und dadurch eine exzentrische Hypertrophie mit Kammerdilatation bei nicht wesentlich vermehrter Wanddicke auslösen. In dieser Hinsicht ist das Monocrotaline-Modell der „transversalen aortalen Konstriktion“ (TAC) vergleichbar. Bei diesem beispielsweise bei Mäusen oder Ratten eingesetzten Verfahren wird operativ der Aortenquerschnitt eingeengt und somit die linke Herzkammer einer Druckbelastung ausgesetzt. Es entwickelt sich eine konzentrische Hypertrophie, vergleichbar derjenigen, die bei Menschen mit einer Aortenklappenstenose im linken Ventrikel zu beobachten ist. Okada K et al. (2004) konnten zeigen, dass es im Rahmen der kardialen Hypertrophie und des Herzversagens im Anschluss an TAC bei Mäusen zu einer gesteigerten Expression von Grp78 und Calreticulin sowohl auf mRNA- als auch auf 
Proteinebene kommt. Zusätzlich präsentierten sie Daten, die darauf hindeuten, dass es in versagenden humanen Herzen im Vergleich mit gesunden Herzen zu einer deutlichen Vermehrung von Grp78- und Calreticulin mRNA kommt (Okada K et al. 2004). Zusammen mit der vorliegenden Literatur stellen die von uns in einer zusätzlichen Spezies und in einem anderen experimentellen Modell gewonnenen Daten einen deutlichen Hinweis auf die Existenz von ER-Stress in hypertrophem und versagendem Herzmuskelgewebe dar.

Allerdings weist das TAC-Modell Limitierungen auf: So ist seit Langem bekannt, dass die Einengung der thorakalen Aorta mit einem hämodynamischen Druckabfall distal der Konstriktionsstelle einhergeht. Da die Abgänge der Nierenarterien aus der Aorta in dem vom Druckabfall betroffenen Gebiet liegen, erfolgt die Blutversorgung der Nieren unter reduziertem Perfusionsdruck, was zu einer schon kurz nach erfolgter Aortenkonstriktion nachweisbaren Zunahme der Renin-Freisetzung und somit Aktivierung des Renin-Angiotensin-Systems führt (Yagi et al 1968). Darüber hinaus führt das Aortenbanding zu einer generalisierten adrenergen Aktivierung (Ganguly et al. 1989). Daher können die Untersuchungen von Okada K et al. (2004) am TACModell nicht die Frage beantworten, ob es primär der biomechanische Stimulus der Druckerhöhung im linken Ventrikel ist oder aber die begleitende neuro-humorale Aktivierung, die ER-Stress ausgelöst haben. Dass diese Differenzierung mit den in der vorliegenden Arbeit angewandten Modellen (isolierte Muskelstreifen in Langzeitkultur und Monocrotaline-Modell der Ratte) möglich ist, stellt den wesentlichen Erkenntnisgewinn aus dieser Studie dar.

\subsection{Bedeutung von ER-Stress bei mechanischer Belastung des Herzens}

Es gibt eine Reihe von Daten, die ER-Stress mit der Entstehung verschiedener Erkrankungen in Verbindung bringen. So scheint er eine Rolle bei der Entstehung neurodegenerativer Krankheiten wie M. Alzheimer (Hoozemans et al. 2005, Unterberger et al. 2006) und M. Parkinson (Ryu et al. 2002, Conn et al. 2004) zu spielen. Von besonderer Bedeutung scheint ER-Stress weiterhin bei der Entwicklung eines Insulin-abhängigen Diabetes mellitus zu sein (Harding et al. 2001, Nozaki et al. 2004). Die Bedeutung von ER-Stress bei einer chronischen oder akuten 
mechanischen Belastung des Herzens wurde dagegen bislang nicht intensiv erforscht (vgl. 1.5.5, S.21).

Die in dieser Arbeit präsentierten Resultate und die Ergebnisse von Okada $\mathrm{K}$ et al. (2004) zeigen, dass es im Gewebe aus hypertrophierenden und versagenden Herzen zur Entstehung von ER-Stress und einer Aktivierung der UPR kommt. Die vorliegenden Daten lassen allerdings kaum Rückschlüsse auf die Ursache und Wirkung dieser Phänomene zu. Die Veränderungen im Verlauf der kardialen Hypertrophie und des anschließenden Versagens sind sehr vielseitig (vgl. 1.2, S. 813) und führen zu einer Belastung des endoplasmatischen Retikulums. So geht das Hypertrophie-assoziierte Wachstum der Herzmuskelzellen mit einer Vergrößerung der Membranoberfläche und einer gesteigerten Proteinbiosynthese einher. Sowohl die Synthese der hierfür benötigten Membranlipide als auch diejenige einiger wichtiger Transmembranproteine wie der SERCA, dem Ryanodinrezeptor oder dem NCX (vgl. 1.1.3, S. 6 f) findet am ER statt. Zudem ist im Rahmen der Herzinsuffizienz die Expression und Sekretion von BNP gesteigert, was zu einer zusätzlichen Belastung des ER führt. Neben der zusätzlichen Belastung durch vermehrte Biosyntheseprozesse kann es vor allem im versagenden Myokard darüber hinaus zur Einschränkung der Synthese- und Faltungskapazität des ER kommen. Der im Lauf der Herzinsuffizienz auftretende oxidative Stress (McMurray et al. 1993, Mallat et al. 1998) kann ebenso wie die Störung des Kalziumstoffwechsels (vgl. 1.2.2.3, S. 10 f) zu einer Beeinträchtigung der Funktion des ER führen. Welcher dieser Mechanismen genau zur Entstehung von ER-Stress im Herzen beiträgt, bedarf weiterer Erforschung.

Weiterhin ist nicht genau geklärt, welche Auswirkungen ER-Stress im Verlauf der Herzinsuffizienzentwicklung hat: So wäre denkbar, dass ER-Stress dabei lediglich ein funktionell unbedeutendes Begleitphänomen darstellt. ER-Stress könnte allerdings auch ein kompensatorischer Mechanismus sein, der durch eine Einschränkung der Proteinbiosynthese einer überschießenden Massenzunahme des Herzmuskels - und damit einer diastolischen Dysfunktion - entgegenwirkt. Schließlich könnte ER-Stress aber auch der funktionellen Beeinträchtigung des versagenden Herzmuskels Vorschub leisten (beispielsweise durch eine beeinträchtigte Synthese von Proteinen, die für eine reguläre Kalzium-Homöostase essenziell sind). Okada $\mathrm{K}$ et al. (2004) konnten zeigen, dass es zwar in versagendem, nicht aber in hypertrophiertem kardialem Gewebe zu ER-Stress- 
assoziierter Apoptose kommt. Die fortschreitende Überlastung des ER könnte auf diesem Weg zur Entstehung der Herzinsuffizienz beitragen.

Interessant ist in diesem Zusammenhang die Frage, ob ER-Stress erst spät während der Entstehung einer Herzinsuffizienz auftritt (dann wäre er eher ein begleitendes Phänomen), oder aber frühzeitig bereits mit Einsetzen eines pathologischen Stimulus, der die Entstehung einer Herzinsuffizienz auslösen kann. Die Ergebnisse der in dieser Arbeit durchgeführten Versuche zum akuten Einfluss biomechanischer Last auf isolierte Herzmuskelstreifen belegen, dass es dabei bereits innerhalb der ersten Stunden zu einer Zunahme der Expression von ER-spezifischen Chaperonen und somit zu ER-Stress kommt. Verschiedene Ursachen kommen für dieses Phänomen in Frage: Zum Einen könnte es sich um eine Aktivierung der UPR infolge einer verstärkten Beladung des ER mit neusynthetisierten Proteinen handeln. Schott et al. (2008) zeigten, dass es innerhalb von sechs Stunden nach Einsetzen einer biomechanischen Überlastung zu ausgeprägten Veränderungen im myokardialen Proteom mit Hochregulation einiger Proteine kommt. Prinzipiell wird somit die Proteinsynthese schnell genug aktiviert, dass es zu einer Auslastung des Proteinsynthese- und -faltungsapparats am bzw. im ER kommen könnte. Zur Klärung der Frage, ob bereits so rasch eine verstärkte Beladung des ER mit neusynthetisierten Proteinen ER-Stress mitverursacht, könnten Dehnungsexperimente in Gegenwart des Proteinsynthesehemmers Cycloheximid (Obrig et al. 1971) durchgeführt werden. Wenn nach Ausschalten der Proteinsynthese keine mRNA-Hochregulation der ER-Chaperone Grp78 bzw. CRT mehr nachweisbar wäre, spräche dies dafür, dass in der Tat die Beladung mit neusynthetisierten Proteinen maßgeblich zur Entstehung von ER-Stress beiträgt.

Zum Anderen könnte es sich auch um einen Teil des Hypertrophiesignalweges handeln. Einige Arbeiten geben Hinweise darauf, dass Grp78 über „p38mitogenaktivierte-Proteinkinasen“ (p38 MAPK) (Ranganathan et al. 2006) oder „extracellular-signal-regulated-kinase“ (ERK) (Song et al. 2001) -abhängige Signaltransduktion aktiviert werden kann. Diese Wege werden auch im Rahmen der Hypertrophieantwort im Herzen aktiviert (Hefti et al. 1997, Braz et al. 2003). Es könnte also begleitend zu einer Hypertrophie gewissermaßen „vorsorglich“ zu einer Verbesserung der Faltungskapazität des ER kommen. Zu diesem Zeitpunkt ist dies allerdings spekulativ, und es wird weitere Forschung nötig sein, um diese Frage abschließend zu klären. 


\subsection{Einfluss von Angiotensin II auf die Entstehung von kardialem ER-Stress}

In der vorliegenden Arbeit führte die Zugabe von Angiotensin II im Modell der isolierten Muskelstreifen zu einer Induktion von ER-Stress in mechanisch unbelasteten Muskelstreifen. Außerdem wurde eine signifikant erhöhte Expression von BNP festgestellt. Letzteres bestätigt Befunde von Wiese et al. (2000), die einen Einfluss von Angiotensin II auf die Expression von BNP beschrieben. Eine Blockade des Angiotensin-II-Typ-1-Rezeptors (AT1-Blockade) mit Irbesartan führte andererseits jedoch nicht zu einer Verminderung der durch Vor- und Nachlast verursachten Expressionssteigerung der Chaperonproteine Grp78 und Calreticulin. Dies bedeutet, dass Angiotensin II unabhängig von einem mechanischen Stimulus in der Lage ist, im isolierten Herzmuskelgewebe ER-Stress (und Hypertrophie) auszulösen. Andererseits scheint der durch mechanische Überlast ausgelöste ERStress aber unabhängig von einer Stimulation von AT1-Rezeptoren durch lokal unter Dehnung freigesetztes Angiotensin abzulaufen.

Im Modell der transversalen Aortenkonstriktion der Maus konnte durch die Behandlung mit dem AT1-Rezeptor-Antagonisten CS-866 (Olmesartan) die Entstehung von ER-Stress reduziert und die Ausbildung einer Herzhypertrophie oder Herzinsuffizienz überraschender Weise komplett verhindert werden (Okada $\mathrm{K}$ et al. 2004). Eine Interpretationsmöglichkeit für diesen Befund ist, dass die Nachlasterhöhung an sich, wie auch eine begleitende Sympathikusaktivierung, für die Entwicklung einer Herzhypertrophie nach transversalem Aortenbanding irrelevant sind. Dagegen sprechen jedoch nicht nur unsere eigenen an isolierten Muskelstreifen erhobenen Befunde sondern auch Beobachtungen von Hamawaki et al. (1998): Sie fanden nach transversalem Aortenbanding in knock-out Mäusen, die keinen AT1ARezeptor exprimierten, eine Herzhypertrophie, die sich nicht von der bei WildtypKontrollmäusen unterschied.

Wie könnte der Befund von Okada K et al. (2004) zustande gekommen sein? Dies muss vor dem Hintergrund der im Abschnitt 4.2 (S. 57-59) diskutierten Limitierungen dieses Tiermodells diskutiert werden: So ist der Anteil der Nachlasterhöhung, der in diesem Modell unmittelbar durch die Aortenkonstriktion bedingt ist, abzugrenzen von demjenigen, der durch die Angiotensin-vermittelte Vasokonstriktion und periphere Widerstandserhöhung beigesteuert wird. Unter pharmakologischer AT1- 
Rezeptorblockade - wie von Okada K et al. (2004) durchgeführt - könnte durch Wegfallen der peripheren Widerstandserhöhung die Nachlasterhöhung durch das Aortenbanding allein einen eher milden Hypertrophie-Reiz gesetzt haben, sodass es nicht zu einer relevanten Aktivierung Last-abhängiger Signalwege im Myokard kam.

Der Einfluss von Angiotensin II bzw. des AT1-Rezeptors auf die druckinduzierte Myokardhypertrophie im Monocrotaline-Modell der Ratte wurde in dieser Arbeit nicht untersucht. Interessanterweise konnten Okada M et al. (2008) jüngst im Monocrotaline-Modell bei Ratten durch Behandlung mit dem ACE-Hemmer Captopril eine geringer ausgeprägte - wenngleich nicht komplett unterbundene Hypertrophieentwicklung beobachten. Dies ging einher mit einer verminderten Induktion und Aktivierung der Matrix-Metalloproteinase-2 und -9. ER-Stress wurde in ihrer Studie allerdings nicht untersucht.

Die Blockade des Renin-Angiotensin-Aldosteron-Systems (RAAS) ist ein wichtiger Teil der modernen Herzinsuffizienztherapie. Dabei zielt man einerseits auf die Reduktion des peripheren Widerstandes und des zirkulierenden Blutvolumens und die daraus resultierende Senkung des Blutdrucks ab. Da Angiotensin II vor allem über den AT1-Rezeptor am Herzen auch direkte Effekte wie gesteigerte Inotropie (Moravec et al. 1990) vermittelt und darüber hinaus am kardialen Remodeling beteiligt ist (Paradis et al. 2000) werden der Blockade des RAAS auch kardioprotektive Eigenschaften zugeschrieben. Welche Relevanz dabei möglicher Weise einer Reduktion von ER-Stress zukommen könnte, muss Gegenstand zukünftiger Untersuchungen sein.

\subsection{Ethanol und ER-Stress}

Ein Zufallsbefund unserer Untersuchungen war die Beobachtung, dass die Anwesenheit von Ethanol in geringer Konzentration im Zellkulturmedium in mechanisch entlasteten isolierten Herzmuskelstreifen $\mathrm{zu}$ einer statistisch signifikanten Induktion der ER-Chaperone Grp78 und Calreticulin führte. Dabei entsprach die verwendete Ethanolkonzentration mit 0,1\% (V/V) einem Wert, der beim Menschen ohne Weiteres bereits nach maßvollem Genuss alkoholischer Getränke im Blut nachgewiesen werden kann.

Die Entstehung von ER-Stress im Rahmen einer alkoholtoxischen Kardiomyopathie wurde bereits im Rahmen vorheriger Studien beobachtet. Li SY und Ren J (2008) 
konnten zeigen, dass chronischer Alkoholkonsum bei Mäusen zu einer verstärkten Expression von Grp78, elF2 $\alpha$ und IRRA1 $\alpha$ f. Aufgrund der vielfältigen Auswirkungen von Ethanol und seinen Metaboliten auf den kardialen Zellstoffwechsel (Bing 1978) kommen verschieden Mechanismen als Ursache dieser Beobachtung in Frage. Besonders das vermehrte Anfallen radikaler Sauerstoffverbindungen (Zhang et al. 2004) kann mit der Entstehung von ER-Stress als Folge chronischer Ethanolaufnahme in Verbindung gebracht werden (Zhang et al. 2005). Diese Beeinflussung des oxidativen Milieus kann zur Störung der Proteinfaltung im ER, zur Akkumulation ungefalteter Proteine und schließlich zu ERStress führen (siehe auch 1.5.3, S. 18 f). Zudem kann eine Überexpression antioxidativ wirksamer Proteine typische, alkoholtoxische Effekte verhindern (Zhang et al. 2005, Nishitani und Matsumoto 2005).

Aber auch andere Mechanismen können zur Entstehung von ER-Stress im Rahmen einer alkoholtoxischen Kardiomyopathie beitragen. So kommt es durch chronische Exposition mit Ethanol zu einer Verminderung der sarkoplasmatischen Kalziumkonzentration und somit zu einer Störung der Funktion der ER-Chaperone (siehe auch 1.5.2.2, S. 16-18) sowie zu einer Störung des Lipidstoffwechsels (Hintz et al. 2003). Dies kann zu einer Akkumulation ungefalteter Proteine bzw. Lipide und schließlich zu ER-Stress führen.

Unsere Beobachtung einer Induktion von Grp78 und Calreticulin unter kurzzeitiger (6 h) Einwirkung von Ethanol in niedriger Konzentration ist prinzipiell vereinbar mit den angeführten möglichen Mechanismen einer alkoholtoxischen Herzschädigung. Eine eingehendere Untersuchung dieser Zusammenhänge - und insbesondere ihrer klinischen Relevanz - war im Rahmen dieser Arbeit jedoch nicht möglich und bleibt daher zukünftigen Forschungsarbeiten vorbehalten. 


\section{Zusammenfassung}

In den letzten Jahren wurde die Bedeutung von ER-Stress für die Pathogenese einiger wichtiger Erkrankungen entdeckt. Die Rolle von ER-Stress bei der Entstehung der Herzhypertrophie und -Insuffizienz ist dagegen noch weitestgehend ungeklärt. Das Ziel dieser Arbeit war es, die Rolle von biomechanischer Last bzw. neurohumoraler Stimulation bei der Entstehung von ER-Stress im Rahmen akuter und chronischer Lasterhöhung des Herzens zu untersuchen. Zudem sollte geklärt werden, ob eine erhöhte biomechanische Last nötig und ausreichend ist, um ERStress im Myokard zu induzieren.

Im in-vitro-Modell isolierter rechtsventrikulärer Muskelstreifen zeigte sich, dass eine Erhöhung der Vor- und Nachlast zur Induktion von ER-Stress führt. Dies konnte durch eine signifikant gesteigerte Expression der ER-Chaperone Grp78 und CRT auf mRNA-Ebene gezeigt werden. Eine alleinige Vorlasterhöhung hatte dagegen keinen Einfluss auf die Expression dieser Chaperone. Im in-vivo-Modell der chronischen Druckbelastung des rechten Ventrikels in MCT-behandelten Ratten ließ sich die Entstehung von ER-Stress im rechten, nicht aber im linken Ventrikel nachweisen.

Diese Ergebnisse weisen deutlich darauf hin, dass sowohl eine akute Erhöhung der kardialen Vor- und Nachlast als auch eine chronische, druckinduzierte Hypertrophie mit der Entstehung von ER-Stress im Myokard einhergehen. Die Ursachen hierfür können anhand der vorliegenden Ergebnisse nicht eindeutig geklärt werden. Eine vermehrte Belastung des ER mit neusynthetisierten Proteinen und Lipiden, wie z.B. mit BNP, könnte zu einem kompensatorischen Ablaufen der UPR führen. Der Hypertrophiemarker BNP wird konkordant zur Enstehung von ER-Stress in vitro nur bei gleichzeitiger Erhöhung von Vor- und Nachlast, nicht aber bei alleiniger Vorlaststeigerung hochreguliert. Auch das vermehrte Anfallen von radikalen Sauerstoffverbindungen im Rahmen der mechanischen Belastung kann zu einer Einschränkung der Faltungsfähigkeit im ER und nachfolgendem ER-Stress führen. Insbesondere bei der akuten Belastungsanpassung ist eine Regulation von ERChaperonen im Rahmen der hypertrophen Signaltransduktion zur präventiven Verbesserung der Funktion des ER zu diskutieren.

Wir konnten zeigen, dass die Zugabe von Angiotensin II in vitro zur Hochregulation von BNP und zur Entstehung von ER-Stress in mechanisch unbelastetem Myokard führt. Im in-vivo-Modell MCT-behandelter Ratten waren sowohl einige 
Veränderungen der Genexpression als auch die Entstehung von ER-Stress auf den rechten, druckbelasteten Ventrikel beschränkt, während beide Ventrikel der neurohumoralen Stimulation ausgesetzt waren. Ein Hemmstoff des AT1-Rezeptors kann den im Rahmen der mechanischen Belastung auftretenden ER-Stress in vitro nicht verhindern.

Diese Ergebnisse deuten darauf hin, dass neurohumorale Stimulation nicht ausreichend ist, um in Abwesenheit von mechanischer Belastung zu myokardialem ER-Stress zu führen. Allerdings scheint Angiotensin II im Rahmen seiner hypertrophen Wirkung unter Anderem auch zu einer vermehrten Expression von ERChaperonen zu führen. Die lokale Produktion von Angiotensin II im Herzen scheint dagegen nicht an der Entstehung von ER-Stress im Myokard beteiligt zu sein. 


\section{Abkürzungsverzeichnis}

\begin{tabular}{|c|c|}
\hline ACE & Angiotensin-Converting-Enzyme \\
\hline $\mathrm{ADH}$ & Antidiuretisches Hormon \\
\hline ANP & Atriales natriuretisches Peptid \\
\hline ATF4 & activating transcription factor 4 \\
\hline ATF6 & activating transcription factor 6 \\
\hline ATP & Adenosintriphosphat \\
\hline BDM & 2,3-Butane-Dione-Monoxime \\
\hline BNP & Brain-natriuretisches Peptid \\
\hline CICR & Kalzium-induzierte Kalzium-Freisetzung \\
\hline CRT & Calreticulin \\
\hline DMSO & Dimethylsulfoxid \\
\hline DNA & Desoxyribonukleinsäure \\
\hline EDEM & ER-degradation-enhancing a-mannosidase-like protein \\
\hline elF2 $\alpha$ & eukaryotic translation initiation factor $2 \alpha$ \\
\hline ER & Endoplasmatisches Retikulum \\
\hline ERAD & ER-assoziierte Degradation \\
\hline ERK & extracellular-signal-regulated-kinase \\
\hline ERSE & ER-stress-response-element \\
\hline FFR & Kraft-Frequenz-Beziehung \\
\hline GaPDH & Glycerinaldehyd-3-phosphat-Dehydrogenase \\
\hline Grp78 & glucose-related proteine 78 (auch BiP) \\
\hline $\mathrm{HF}$ & Herzfrequenz \\
\hline $\mathrm{HZV}$ & Herzzeitvolumen \\
\hline IRE1 & inositol-requiring protein 1 \\
\hline JAK & Familie Tyrosinkinasen \\
\hline LTCC & L-Typ-Kalziumkanal (L-type-calcium-channel) \\
\hline MAPK & Mitogen-aktiverte Proteinkinase \\
\hline MCT & Monocrotaline \\
\hline NCX & Natrium-Kalzium-Austauscher \\
\hline NYHA & New York Heart Association \\
\hline OS9 & Osteosarcoma 9 \\
\hline p38 & Proteinkinase (Familie der MAPK) \\
\hline p53 & Transkriptionsfaktor \\
\hline PERK & protein kinase RNA-like ER kinase \\
\hline RAAS & Renin-Angiotensin-Aldosteron-System \\
\hline RAS & Renin-Angiotensin-System \\
\hline RNA & Ribonukleinsäure \\
\hline RyR & Ryanodinrezeptor \\
\hline SERCA & Kalzium-ATPase des sarkoplasmatischen Retikulums \\
\hline SR & Sarkoplasmatisches Retikulum \\
\hline SRP & signal-recognition-particle \\
\hline STAT & Familien Transkriptionsfaktoren \\
\hline SV & Herzschlagvolumen \\
\hline TAC & transversale aortale Konstriktion \\
\hline $\mathrm{TnC}$ & Troponin C \\
\hline UPR & unfolded protein response \\
\hline XBP1 & X-box-binding protein 1 \\
\hline
\end{tabular}




\section{Literaturverzeichnis}

Alvarez BV, Pérez NG, Ennis IL, Camilión de Hurtado MC, Cingolani HE (1999): Mechanisms underlying the increase in force and $\mathrm{Ca}(2+)$ transient that follow stretch of cardiac muscle: a possible explanation of the Anrep effect. Circ Res $\underline{85}, 716-722$

Bers DM (2000): Calcium fluxes involved in control of cardiac myocyte contraction. Circ Res. 87(4), 275-81

Bers DM: Excitation-Contraction Coupling and Cardiac Contractile Force. 2. Auflage; Kluwer Academic Publisher, Dordrecht 2001

Bers DM, Weber CR (2002): Na/Ca exchange function in intact ventricular myocytes. Ann N Y Acad Sci $\underline{976}$, 500-12

Bertolotti A, Zhang Y, Hendershot LM, Harding HP, Ron D (2000): Dynamic interaction of BiP and ER stress transducers in the unfolded-protein response. Nat Cell Biol 2(6), 326-32

Beuckelmann DJ, Erdmann E (1992): Ca(2+)-currents and intracellular [Ca2+]itransients in single ventricular myocytes isolated from terminally failing human myocardium. Basic Res Cardiol 87 (Suppl 1), 235-43

Beuckelmann DJ, Näbauer M, Krüger C, Erdmann E (1995): Altered diastolic $[\mathrm{Ca} 2+] \mathrm{i}$ handling in human ventricular myocytes from patients with terminal heart failure. Am Heart J 129(4), 684-9

Bhamidipati A, Denic V, Quan EM, Weissman JS (2005): Exploration of the topological requirements of ERAD identifies Yos9p as a lectin sensor of misfolded glycoproteins in the ER lumen. Mol Cell 19(6), 741-51

Bing RJ (1978): Cardiac metabolsim: its contributions to alcoholic heart disease and myocardial failure. Circulation $\underline{58(6)}, 965-70$

Bing RJ, Tillmanns H, Fauvel JM, Seeler K, Mao JC (1974): Effect of prolonged alcohol administration on calcium transport in heart muscle of the dog. Circ Res 35(1), 33-8

Braz JC, Bueno OF, Liang Q, Wilkins BJ, Dai YS, Parsons S, Braunwart J, Glascock BJ, Klevitsky R, Kimball TF, Hewett TE, Molkentin JD (2003): Targeted inhibition of p38 MAPK promotes hypertrophic cardiomyopathy through upregulation of calcineurin-NFAT signaling. J Clin Invest $\underline{111(10)}, 1475-86$

Brenner B, Eisenberg E (1987): The mechanism of muscle contraction. Biochemical, mechanical, and structural approaches to elucidate cross-bridge action in muscle. Basic Res Cardiol 82 (Suppl 2), 3-16 
Bristow MR, Ginsburg R, Minobe W, Cubicciotti RS, Sageman WS, Lurie K, Billingham ME, Harrison DC, Stinson EB (1982): Decreased catecholamine sensitivity and beta-adrenergic-receptor density in failing human hearts. $\mathrm{N}$ Engl J Med 307(4), 205-11

Brixius K, Savvidou-Zaroti P, Mehlhorn U, Bloch W, Kranias EG, Schwinger RH (2002): Increased Ca2+-sensitivity of myofibrillar tension in heart failure and its functional implication. Basic Res Cardiol 97 (Suppl 1), I111-7

Brodde OE, Zerkowski HR, Doetsch N, Motomura S, Khamssi M, Michel MC (1989): Myocardial beta-adrenoceptor changes in heart failure: concomitant reduction in beta 1- and beta 2-adrenoceptor function related to the degree of heart failure in patients with mitral valve disease. J Am Coll Cardiol 14(2), 323-31

Carafoli E (1975): Mitochondria, Ca2+ transport and the regulation of heart contraction and metabolism. J Mol Cell Cardiol 7(2), 83-7

Caroni P, Carafoli E (1980): An ATP-dependent Ca2+-pumping system in dog heart sarcolemma. Nature 283(5749), 765-7

Caspersen C, Pedersen PS, Treiman M (2000): The sarco/endoplasmic reticulum calcium-ATPase $2 \mathrm{~b}$ is an endoplasmic reticulum stress-inducible protein. $\mathrm{J}$ Biol Chem 275(29), 22363-72

Chai SY, Fernando R, Peck G, Ye SY, Mendelsohn FA, Jenkins TA, Albiston AL (2004): The angiotensin IVIAT4 receptor. Cell Mol Life Sci 61(21), 2728-37

Clausmeyer S, Reinecke A, Farrenkopf R, Unger T, Peters J (2000): Tissuespecific expression of a rat renin transcript lacking the coding sequence for the prefragment and its stimulation by myocardial infarction. Endocrinology 141(8), 296370

Conn KJ, Gao W, McKee A, Lan MS, Ullman MD, Eisenhauer PB, Fine RE, Wells JM (2004): Identification of the protein disulfide isomerase family member PDIp in experimental Parkinson's disease and Lewy body pathology. Brain Res 1022(1-2), 164-72

Cowie MR, Wood DA, Coats AJ, Thompson SG, Poole-Wilson PA, Suresh V, Sutton GC (1999): Incidence and aetiology of heart failure; a population-based study. Eur Heart J 20(6), 421-8

Crespo LM, Grantham CJ, Cannell MB (1990): Kinetics, stoichiometry and role of the Na-Ca exchange mechanism in isolated cardiac myocytes. Nature 345(6276), 618-21

Danser AH, Deinum J (2005): Renin, prorenin and the putative (pro)renin receptor. Hypertension 46(5), 1069-76 
Dash R, Frank KF, Carr AN, Moravec CS, Kranias EG (2001): Gender influences on sarcoplasmic reticulum $\mathrm{Ca2+-handling} \mathrm{in} \mathrm{failing} \mathrm{human} \mathrm{myocardium.} \mathrm{J} \mathrm{Mol} \mathrm{Cell}$ Cardiol 33(7), 1345-53

de Bold AJ (1985): Atrial natriuretic factor: a hormone produced by the heart. Science 230(4727), 767-70

de Lannoy LM, Danser AH, van Kats JP, Schoemaker RG, Saxena PR, Schalekamp MA (1997): Renin-angiotensin system components in the interstitial fluid of the isolated perfused rat heart. Local production of angiotensin I. Hypertension 29(6), 1240-51

Donoghue M, Hsieh F, Baronas E, Godbout K, Gosselin M, Stagliano N, Donovan M, Woolf B, Robison K, Jeyaseelan R, Breitbart RE, Acton S (2000): A novel angiotensin-converting enzyme-related carboxypeptidase (ACE2) converts angiotensin I to angiotensin 1-9. Circ Res 87(5), E1-9

Dorner AJ, Wasley LC, Raney P, Haugejorden S, Green M, Kaufman RJ (1990): The stress response in Chinese hamster ovary cells. Regulation of ERp72 and protein disulfide isomerase expression and secretion. J Biol Chem 265(35), 22029-34

Dorner AJ, Wasley LC, Kaufman RJ (1992): Overexpression of GRP78 mitigates stress induction of glucose regulated proteins and blocks secretion of selective proteins in Chinese hamster ovary cells. EMBO J 11(4), 1563-71

Dzau VJ, Re RN (1987): Evidence for the existence of renin in the heart. Circulation $\underline{75(1 \mathrm{Pt} 2)}$, I134-6

Fabiato A (1983): Calcium-induced release of calcium from the cardiac sarcoplasmic reticulum. Am J Physiol Cell Physiol 245(1), C1-14

Ferrario CM (2006): Angiotensin-converting enzyme 2 and angiotensin-(1-7): an evolving story in cardiovascular regulation. Hypertension 47(3), 515-21

Flesch M, Schwinger RH, Schiffer F, Frank K, Südkamp M, Kuhn-Regnier F, Arnold G, Böhm M (1996): Evidence for functional relevance of an enhanced expression of the $\mathrm{Na}(+)-\mathrm{Ca} 2+$ exchanger in failing human myocardium. Circulation 94(5), 992-1002

Francis GS, Benedict C, Johnstone DE, Kirlin PC, Nicklas J, Liang CS, Kubo SH, Rudin-Toretsky E, Yusuf S (1990): Comparison of neuroendocrine activation in patients with left ventricular dysfunction with and without congestive heart failure. $A$ substudy of the Studies of Left Ventricular Dysfunction (SOLVD). Circulation 82(5), 1724-9

Ganguly PK, Lee SL, Beamish RE, Dhalla NS (1989): Altered sympathetic system and adrenoceptors during the development of cardiac hypertrophy. Am Heart $\mathrm{J}$ $\underline{118(3)}, 520-5$ 
Gannier F, White E, Garnier , Le Guennec JY (1996): A possible mechanism for large stretch-induced increase in $[\mathrm{Ca} 2+] \mathrm{i}$ in isolated guinea-pig ventricular myocytes. Cardiovasc Res 32(1), 158-67

Gerdes AM, Kellerman SE, Moore JA, Muffly KE, Clark LC, Reaves PY, Malec KB, McKeown PP, Schocken DD (1992): Structural remodeling of cardiac myocytes in patients with ischemic cardiomyopathy. Circulation 86(2), 426-30

Giacchetti G, Opocher G, Sarzani R, Rappelli A, Mantero F (1996): Angiotensin II and the adrenal. Clin Exp Pharmacol Physiol Suppl 3, 119-24

Grossman W, Jones D, McLaurin LP (1975): Wall stress and patterns of hypertrophy in the human left ventricle. J Clin Invest 56(1), 56-64

Gwathmey JK, Copelas L, MacKinnon R, Schoen FJ, Feldman MD, Grossman W, Morgan JP (1987): Abnormal intracellular calcium handling in myocardium from patients with end-stage heart failure. Circ Res $\underline{61(1)}, 70-6$

Hamada H, Suzuki M, Yuasa S, Mimura N, Shinozuka N, Takada Y, Suzuki M, Nishino T, Nakaya H, Koseki H, Aoe T (2004): Dilated cardiomyopathy caused by aberrant endoplasmic reticulum quality control in mutant KDEL receptor transgenic mice. Mol Cell Biol 24(18), 8007-17

Hamawaki M, Coffman TM, Lashus A, Koide M, Zile MR, Oliverio MI, DeFreyte G, Cooper G 4th, Carabello BA (1998): Pressure-overload hypertrophy is unabated in mice devoid of AT1A receptors. Am J Physiol 274(3 Pt 2), H868-73

Harding HP, Zhang Y, Ron D (1999): Protein translation and folding are coupled by an endoplasmic-reticulum-resident kinase. Nature 397(6716), 271-4

Harding HP, Novoa I, Zhang Y, Zeng H, Wek R, Schapira M, Ron D (2000):

Regulated translation initiation controls stress-induced gene expression in mammalian cells. Mol Cell $\underline{6(5)}, 1099-108$

Harding HP, Zeng H, Zhang Y, Jungries R, Chung P, Plesken H, Sabatini DD, Ron D (2001): Diabetes mellitus and exocrine pancreatic dysfunction in perk-/- mice reveals a role for translational control in secretory cell survival. Mol Cell $\underline{7(6)}$, 1153-63

Hasenfuß G, Mulieri LA, Holubarsch C, Pieske B, Just H, Alpert NR (1992):

Energetics of calcium cycling in nonfailing and failing human myocardium.

Basic Res Cardiol 87 (Suppl 2), 81-92

Hasenfuß G, Reinecke H, Studer R, Meyer M, Pieske B, Holtz J, Holubarsch C, Posival H, Just H, Drexler H (1994a): Relation between myocardial function and expression of sarcoplasmic reticulum $\mathrm{Ca}(2+)$-ATPase in failing and nonfailing human myocardium. Circ Res 75(3), 434-42

Hasenfuß G, Holubarsch C, Hermann HP, Astheimer K, Pieske B, Just H (1994b): Influence of the force-frequency relationship on haemodynamics and left ventricular function in patients with non-failing hearts and in patients with dilated cardiomyopathy. Eur Heart J 15(2), 164-70 
Haze K, Yoshida H, Yanagi H, Yura T, Mori K (1999): Mammalian transcription factor ATF6 is synthesized as a transmembrane protein and activated by proteolysis in response to endoplasmic reticulum stress. Mol Biol Cell 10(11), 3787-99

Heerdt PM, Holmes JW, Cai B, Barbone A, Madigan JD, Reiken S, Lee DL, Oz MC, Marks AR, Burkhoff D (2000): Chronic unloading by left ventricular assist device reverses contractile dysfunction and alters gene expression in end-stage heart failure. Circulation 102(22), 2713-9

Hefti MA, Harder BA, Eppenberger HM, Schaub MC (1997): Signaling pathways in cardiac myocyte hypertrophy J Mol Cell Cardiol 29(11), 2873-92

Hintz KK, Relling DP, Saari JT, Borgerding AJ, Duan J, Ren BH, Kato K, Epstein PN, Ren J (2003): Cardiac overexpression of alcohol dehydrogenase exacerbates cardiac contractile dysfunction, lipid peroxidation, and protein damage after chronic ethanol ingestion. Alcohol Clin Exp Res 27(7), 1090-8

Højmann Larsen A, Frandsen A, Treiman M (2001): Upregulation of the SERCAtype Ca2+ pump activity in response to endoplasmic reticulum stress in PC12 cells. BMC Biochem 2, 4

Hoozemans JJ, Veerhuis R, Van Haastert ES, Rozemuller JM, Baas F, Eikelenboom P, Scheper W (2005): The unfolded protein response is activated in Alzheimer's disease. Acta Neuropathol 110(2), 165-72

Huckle WR, Earp HS (1994): Regulation of cell proliferation and growth by angiotensin II. Prog Growth Factor Res 5(2), 177-94

Hughes AD (1998): Molecular and cellular mechanisms of action of angiotensin II (AT1) receptors in vascular smooth muscle. J Hum Hypertens 12(5), 275-81

Ito KM, Sato M, Ushijima K, Nakai M, Ito K (2000): Alterations of endothelium and smooth muscle function in monocrotaline- induced pulmonary hypertensive arteries. Am J Physiol Heart Circ Physiol 279, H1786-1795.

Jan Danser AH, Saris JJ (2002): Prorenin uptake in the heart: a prerequisite for local angiotensin generation? J Mol Cell Cardiol 34(11), 1463-72

Janssen PM, Lehnart SE, Prestle J Lynker JC, Salfeld P, Just H, Hasenfuß G (1998): The trabecula culture system: a novel technique to study contractile parameters over a multiday time period. Am J Physiol Heart Circ Physiol 274, H 1481-1488

Janssen PM, Lehnart SE, Prestle J, Hasenfuß G (1999): Preservation of contractile characteristics of human myocardium in multi-day cell culture. $\mathrm{J}$ Mol Cell Cardiol 31(8), 1419-1427

Jiang HY, Wek SA, McGrath BC, Lu D, Hai T, Harding HP, Wang X, Ron D, Cavener DR, Wek RC (2004): Activating transcription factor 3 is integral to the eukaryotic initiation factor 2 kinase stress response. Mol Cell Biol 24(3), 1365-77 
Jiang MT, Lokuta AJ, Farrell EF, Wolff MR, Haworth RA, Valdivia HH (2002):

Abnormal $\mathrm{Ca} 2+$ release, but normal ryanodine receptors, in canine and human heart failure. Circ Res 91(11), 1015-22

Kentish JC, Wrzosek A (1998): Changes in force and cytosolic Ca2+ concentration after length changes in isolated rat ventricular trabeculae. J Physiol $\underline{506(\mathrm{Pt} 2)}, 431$ 44

Kentish JC, ter Keurs HE, Ricciardi L, Bucx JJ, Noble MI (1986): Comparison between the sarcomere length-force relations of intact and skinned trabeculae from rat right ventricle. Influence of calcium concentrations on these relations. Circ Res 58(6), 755-68

Kinnunen P, Vuolteenaho O, Ruskoaho H (1993): Mechanisms of atrial and brain natriuretic peptide release from rat ventricular myocardium: effect of stretching. Endocrinology 132(5), 1961-70

Kögler H, Hartmann O, Leineweber K, Nguyen van P, Schott P, Brodde OE, Hasenfuss G (2003): Mechanical load-dependent regulation of gene expression in monocrotaline-induced right ventricular hypertrophy in the rat. Circ Res 93(3), 230-7

Kögler H, Schott P, Toischer K, Milting H, Van PN, Kohlhaas M, Grebe C, Kassner A, Domeier E, Teucher N, Seidler T, Knöll R, Maier LS, El-Banayosy A, Körfer R, Hasenfuss G (2006): Relevance of brain natriuretic peptide in preloaddependent regulation of cardiac sarcoplasmic reticulum $\mathrm{Ca} 2+$ ATPase expression. Circulation $\underline{113(23)}$, 2724-32

Koka V, Wang W, Huang XR, Kim-Mitsuyama S, Truong LD, Lan HY (2006): Advanced glycation end products activate a chymase-dependent angiotensin IIgenerating pathway in diabetic complications. Circulation 113(10), 1353-60

Laemmli UK (1970): Cleavage of structural proteins during the assembly of the head of bacteriophage T4. Nature 227(5259), 680-685

Lafranconi WM, Huxtable RJ (1984): Hepatic metabolism and pulmonary toxicity of monocrotaline using isolated perfused liver and lung. Biochem Pharmacol $\underline{33}$, 24792484.

Lafranconi WM, Duhamel RC, Brendel K, Huxtable RJ (1984): Differentiation of the cardiac and pulmonary toxicity of monocrotaline, a pyrrolizidine alkaloid. Biochem Pharmacol $\underline{33}, 191-197$.

Lee AH, Iwakoshi NN, Glimcher LH (2003): XBP-1 regulates a subset of endoplasmic reticulum resident chaperone genes in the unfolded protein response. Mol Cell Biol 23(21), 7448-59 
Leineweber K, Brandt K, Wludyka B, Beilfuss A, Pönicke K, Heinroth-Hoffmann I, Brodde OE (2002): Ventricular hypertrophy plus neurohumoral activation is necessary to alter the cardiac beta-adrenoceptor system in experimental heart failure. Circ Res 91(11), 1056-62

Leri A, Claudio PP, Li Q, Wang X, Reiss K, Wang S, Malhotra A, Kajstura J, Anversa P (1998): Stretch-mediated release of angiotensin II induces myocyte apoptosis by activating p53 that enhances the local renin-angiotensin system and decreases the Bcl-2-to-Bax protein ratio in the cell. J Clin Invest 101(7), 1326-42

Li M, Baumeister P, Roy B, Phan T, Foti D, Luo S, Lee AS (2000): ATF6 as a transcription activator of the endoplasmic reticulum stress element: thapsigargin stress-induced changes and synergistic interactions with NF-Y and YY1. Mol Cell Biol 20(14), 5096-106

Li SY, Ren J (2008): Cardiac overexpression of alcohol dehydrogenase exacerbates chronic ethanol ingestion-induced myocardial dysfunction and hypertrophy: role of insulin signaling and ER stress. J Mol Cell Cardiol. 44(6), 992-1001

Llewellyn DH, Kendall JM, Sheikh FN, Campbell AK (1996): Induction of calreticulin expression in HeLa cells by depletion of the endoplasmic reticulum $\mathrm{Ca} 2+$ store and inhibition of N-linked glycosylation. Biochem J 318 (Pt 2), 555-60

Mallat Z, Philip I, Lebret M, Chatel D, Maclouf J, Tedgui A (1998): Elevated levels of 8-iso-prostaglandin F2alpha in pericardial fluid of patients with heart failure: a potential role for in vivo oxidant stress in ventricular dilatation and progression to

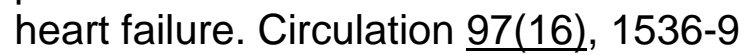

McMurray J (1996): Concise Guide to the Management of Heart Failure - World health Organization/Council on Geriatric Cardiology Task Force on Heart Failure Education. Am J Geriatr Cardiol 5(2), 13-30

McMurray J, Chopra M, Abdullah I, Smith WE, Dargie HJ (1993): Evidence of oxidative stress in chronic heart failure in humans. Eur Heart J 14(11), 1493-8

Meffert S, Stoll M, Steckelings UM, Bottari SP, Unger T (1996): The angiotensin II AT2 receptor inhibits proliferation and promotes differentiation in PC12W cells. Mol Cell Endocrinol 122(1), 59-67

Molinari M, Calanca V, Galli C, Lucca P, Paganetti P (2003): Role of EDEM in the release of misfolded glycoproteins from the calnexin cycle. Science 299(5611), 1397400

Moravec CS, Schluchter MD, Paranandi L, Czerska B, Stewart RW, Rosenkranz E, Bond M (1990): Inotropic effects of angiotensin II on human cardiac muscle in vitro. Circulation 82(6), 1973-84

Mosterd A, Cost B, Hoes AW, de Bruijne MC, Deckers JW, Hofman A, Grobbee DE (2001): The prognosis of heart failure in the general population: The Rotterdam Study. Eur Heart J 22(15), 1318-27 
Mulieri LA, Hasenfuß G, Ittleman F, Blanchard EM, Alpert NR (1989): Protection of human left ventricular myocardium from cutting injury with 2,3-butanedione monoxime. Circ Res 65(5), 1441-1449

Neely JR, Liebermeister H, Blattersby E, Morgan HE (1967): Effects of pressure development on oxygen consumption by the isolated rat heart. Am J Physiol 212 , 810-814

Nguyen G, Delarue F, Burcklé C, Bouzhir L, Giller T, Sraer JD (2002): Pivotal role of the renin/prorenin receptor in angiotensin II production and cellular responses to renin. J Clin Invest 109(11), 1417-27

Nguyen G, Burcklé CA, Sraer JD (2004): Renin/prorenin-receptor biochemistry and functional significance. Curr Hypertens Rep $\underline{6(2)}, 129-32$

Nishitani Y, Matsumoto $\mathbf{H}$ (2006): Ethanol rapidly causes activation of JNK associated with ER stress under inhibition of ADH. FEBS Lett $\underline{580(1)}, 9-14$

Nozaki J, Kubota H, Yoshida H, Naitoh M, Goji J, Yoshinaga T, Mori K, Koizumi A, Nagata K (2004): The endoplasmic reticulum stress response is stimulated through the continuous activation of transcription factors ATF6 and XBP1 in Ins2+/Akita pancreatic beta cells. Genes Cells 9(3), 261-70

Obrig TG, Culp WJ, McKeehan WL, Hardesty B (1971): The mechanism by which cycloheximide and related glutarimide antibiotics inhibit peptide synthesis on reticulocyte ribosomes. J Biol Chem 246(1), 174-81

Oda Y, Hosokawa N, Wada I, Nagata K (2003): EDEM as an acceptor of terminally misfolded glycoproteins released from calnexin. Science 299(5611), 1394-7

Ogawa Y, Nakao K, Mukoyama M, Hosoda K, Shirakami G, Arai H, Saito Y, Suga S, Jougasaki M, Imura H (1991): Natriuretic peptides as cardiac hormones in normotensive and spontaneously hypertensive rats. The ventricle is a major site of synthesis and secretion of brain natriuretic peptide. Circ Res $\underline{69(2)}$, 491-500

Okada K, Minamino T, Tsukamoto Y, Liao Y, Tsukamoto O, Takashima S, Hirata A, Fujita M, Nagamachi Y, Nakatani T, Yutani C, Ozawa K, Ogawa S, Tomoike H, Hori M, Kitakaze M (2004): Prolonged endoplasmic reticulum stress in hypertrophic and failing heart after aortic constriction: possible contribution of endoplasmic reticulum stress to cardiac myocyte apoptosis. Circulation 110(6), 705-12

Okada M, Kikuzuki R, Harada T, Hori Y, Yamawaki H, Hara Y (2008): Captopril attenuates matrix metalloproteinase-2 and -9 in monocrotaline-induced right ventricular hypertrophy in rats. J Pharmacol Sci 108(4), 487-94

Okamura K, Kimata Y, Higashio H, Tsuru A, Kohno K (2000): Dissociation of $\mathrm{Kar} 2 \mathrm{p} / \mathrm{BiP}$ from an ER sensory molecule, Ire1p, triggers the unfolded protein response in yeast. Biochem Biophys Res Commun 279(2), 445-50 
Ozcan U, Cao Q, Yilmaz E, Lee AH, Iwakoshi NN, Ozdelen E, Tuncman G, Görgün C, Glimcher LH, Hotamisligil GS (2004): Endoplasmic reticulum stress links obesity, insulin action, and type 2 diabetes. Science 306(5695), 457-61

Paradis P, Dali-Youcef N, Paradis FW, Thibault G, Nemer M (2000):

Overexpression of angiotensin II type I receptor in cardiomyocytes induces cardiac hypertrophy and remodeling. Proc Natl Acad Sci U S A 97(2), 931-6

Paul M, Wagner D, Metzger R, Ganten D, Lang RE, Suzuki F, Murakami K, Burbach JH, Ludwig G (1988): Quantification of renin mRNA in various mouse tissues by a novel solution hybridization assay. J Hypertens $\underline{6(3)}, 247-52$

Paul M, Wagner J, Dzau VJ (1993): Gene expression of the renin-angiotensin system in human tissues. Quantitative analysis by the polymerase chain reaction. $\mathrm{J}$ Clin Invest 91(5), 2058-64

Peters J, Clausmeyer S (2002): Intracellular sorting of renin: cell type specific differences and their consequences. J Mol Cell Cardiol 34(12), 1561-8

Piacentino V 3rd, Weber CR, Chen X, Weisser-Thomas J, Margulies KB, Bers DM, Houser SR (2003): Cellular basis of abnormal calcium transients of failing human ventricular myocytes. Circ Res 92(6), 651-8

Pieske B, Kretschmann B, Meyer M, Holubarsch C, Weirich J, Posival H, Minami K, Just H, Hasenfuss G (1995): Alterations in intracellular calcium handling associated with the inverse force-frequency relation in human dilated cardiomyopathy. Circulation 92(5), 1169-78

Pieske B, Maier LS, Bers DM, Hasenfuss G (1999): Ca2+ handling and sarcoplasmic reticulum $\mathrm{Ca} 2+$ content in isolated failing and nonfailing human myocardium. Circ Res 85(1), 38-46

Pieske B, Maier LS, Schmidt-Schweda S (2002): Sarcoplasmic reticulum Ca2+ load in human heart failure. Basic Res Cardiol 97 Suppl 1, 163-71

Ranganathan AC, Zhang L, Adam AP, Aguirre-Ghiso JA (2006): Functional coupling of p38-induced up-regulation of BiP and activation of RNA-dependent protein kinase-like endoplasmic reticulum kinase to drug resistance of dormant carcinoma cells. Cancer Res 66(3), 1702-11

Remme WJ, Swedberg K (2001): Guidelines for the diagnosis and treatment of chronic heart failure. Eur Heart J 22(17), 1527-60

Ribeiro AB, Kohlmann O Jr, Saragoça MA, Marson O, Ramos OL (1985): The renin-angiotensin system in the control of systemic arterial pressure. Drugs 30 (Suppl 1), 6-12

Rockman HA, Ross RS, Harris AN, Knowlton KU, Steinhelper ME, Field LJ, Ross J Jr, Chien KR (1991): Segregation of atrial-specific and inducible expression of an atrial natriuretic factor transgene in an in vivo murine model of cardiac hypertrophy. Proc Natl Acad Sci USA 88(18), 8277-81 
Rogers TB, Gaa ST, Allen IS (1986): Identification and characterization of functional angiotensin II receptors on cultured heart myocytes. J Pharmacol Exp Ther 236(2), 438-44

Ryu EJ, Harding HP, Angelastro JM, Vitolo OV, Ron D, Greene LA (2002):

Endoplasmic reticulum stress and the unfolded protein response in cellular models of Parkinson's disease. J Neurosci 22(24), 10690-8

Sadoshima J, Xu Y, Slayter HS, Izumo S (1993): Autocrine release of angiotensin II mediates stretch-induced hypertrophy of cardiac myocytes in vitro. Cell $\underline{75(5)}$, 97784

Saris JJ, van Dijk MA, Kroon I, Schalekamp MA, Danser AH (2000): Functional importance of angiotensin-converting enzyme-dependent in situ angiotensin II generation in the human forearm. Hypertension $\underline{35(3)}$, 764-8

Sasayama S, Franklin D, Ross J Jr (1977): Hyperfunction with normal inotropic state of the hypertrophied left ventricle. Am J Physiol 232(4), H418-25

Schaper J, Speiser B (1992): The extracellular matrix in the failing human heart. Basic Res Cardiol 87 (Suppl 1), 303-9

Schott P, Asif AR, Gräf C, Toischer K, Hasenfuss G, Kögler H (2008): Myocardial adaptation of energy metabolism to elevated preload depends on calcineurin activity : a proteomic approach. Basic Res Cardiol 103(3), 232-43

Schröder D, Heger J, Piper HM, Euler G (2006): Angiotensin II stimulates apoptosis via TGF-beta1 signaling in ventricular cardiomyocytes of rat. J Mol Med 84(11), 975-83

Schwinger RH, Böhm M, Koch A, Schmidt U, Morano I, Eissner HJ, Uberfuhr P, Reichart B, Erdmann E (1994): The failing human heart is unable to use the FrankStarling mechanism. Circ Res $\underline{74(5)}$, 959-69

Shen J, Chen X, Hendershot L, Prywes R (2002): ER stress regulation of ATF6 localization by dissociation of BiP/GRP78 binding and unmasking of Golgi localization signals. Dev Cell 3(1), 99-111

Solaro RJ, Van Eyk J (1996): Altered interactions among thin filament proteins modulate cardiac function. J Mol Cell Cardiol 28(2), 217-30

Song MS, Park YK, Lee JH, Park K (2001): Induction of glucose-regulated protein 78 by chronic hypoxia in human gastric tumor cells through a protein kinase Cepsilon/ERK/AP-1 signaling cascade. Cancer Res $\underline{61(22)}$, 8322-30

Sonnenblick H, Braunwald E, Morrow AG (1965): The Contractile Properties of Human Heart Muscle: Studies on Myocardial Mechanics of Surgically Excised Papillary Muscles. J Clin Invest 44(6), 966-977

Sriburi R, Jackowski S, Mori K, Brewer JW (2004): XBP1: a link between the unfolded protein response, lipid biosynthesis, and biogenesis of the endoplasmic reticulum. J Cell Biol 167(1), 35-41 
Stoll M, Meffert S, Stroth U, Unger T (1995): Growth or antigrowth: angiotensin and the endothelium. J Hypertens 13(12 Pt 2), 1529-34

Studer R, Reinecke H, Bilger J, Eschenhagen T, Böhm M, Hasenfuss G, Just H, Holtz J, Drexler H (1994): Gene expression of the cardiac $\mathrm{Na}(+)-\mathrm{Ca} 2+$ exchanger in end-stage human heart failure. Circ Res $\underline{75(3)}$, 443-53

Szathmary R, Bielmann R, Nita-Lazar M, Burda P, Jakob CA (2005): Yos9 protein is essential for degradation of misfolded glycoproteins and may function as lectin in ERAD. Mol Cell 19(6), 765-75

Takahashi M, Sasayama S, Kawai C, Kotoura H (1980): Contractile performance of the hypertrophied ventricle in patients with systemic hypertension. Circulation $\underline{62(1)}, 116-26$

Takatsuki A, Tamura G (1971): Tunicamycin, a new antibiotic. II. Some biological properties of the antiviral activity of tunicamycin. J Antibiot (Tokyo) 24(4), 224-31

Tarnavski O, McMullen JR, Schinke M, Nie Q, Kong S, Izumo S (2004): Mouse cardiac surgery: comprehensive techniques for the generation of mouse models of human diseases and their application for genomic studies. Physiol Genomics 16(3), $349-60$

Terracciano CM, Hardy J, Birks EJ, Khaghani A, Banner NR, Yacoub MH (2004): Clinical recovery from end-stage heart failure using left-ventricular assist device and pharmacological therapy correlates with increased sarcoplasmic reticulum calcium content but not with regression of cellular hypertrophy. Circulation 109(19), 2263-5

Thomas JA, Marks BH (1978): Plasma norepinephrine in congestive heart failure. Am J Cardiol $\underline{41(2)}, 233-43$

Tirasophon W, Welihinda AA, Kaufman RJ (1998): A stress response pathway from the endoplasmic reticulum to the nucleus requires a novel bifunctional protein kinase/endoribonuclease (Ire1p) in mammalian cells. Genes Dev 12(12), 1812-24

Unterberger U, Höftberger R, Gelpi E, Flicker H, Budka H, Voigtländer T (2006): Endoplasmic reticulum stress features are prominent in Alzheimer disease but not in prion diseases in vivo. J Neuropathol Exp Neurol 65(4), 348-57

Urata H, Kinoshita A, Misono KS, Bumpus FM, Husain A (1990): Identification of a highly specific chymase as the major angiotensin II-forming enzyme in the human heart. J Biol Chem 265(36), 22348-57

van der Velden J, Boontje NM, Papp Z, Klein LJ, Visser FC, de Jong JW, Owen VJ, Burton PB, Stienen GJ (2002): Calcium sensitivity of force in human ventricular cardiomyocytes from donor and failing hearts. Basic Res Cardiol 97 (Suppl 1), I11826

van Kats JP, Danser AH, van Meegen JR, Sassen LM, Verdouw PD, Schalekamp M (1998): Angiotensin production by the heart: a quantitative study in pigs with the use of radiolabeled angiotensin infusions. Circulation $\underline{98(1)}, 73-81$ 
Vibert P, Craig R, Lehman W (1997): Steric-model for activation of muscle thin filaments. J Mol Biol 266(1), 8-14

von Lutterotti N, Catanzaro DF, Sealey JE, Laragh JH (1994): Renin is not synthesized by cardiac and extrarenal vascular tissues. A review of experimental evidence. Circulation 89(1), 458-70

Wang X, Ren B, Liu S, Sentex E, Tappia PS, Dhalla NS (2003): Characterization of cardiac hypertrophy and heart failure due to volume overload in the rat. J Appl Physiol 94(2), 752-63

Wang YP, Fuchs F (1995): Osmotic compression of skinned cardiac and skeletal muscle bundles: effects on force generation, $\mathrm{Ca} 2+$ sensitivity and $\mathrm{Ca} 2+$ binding. $\mathrm{J}$ Mol Cell Cardiol 27(6),1235-44

Wiese S, Breyer T, Dragu A, Wakili R, Burkard T, Schmidt-Schweda S, Füchtbauer EM, Dohrmann U, Beyersdorf F, Radicke D, Holubarsch CJ (2000): Gene expression of brain natriuretic peptide in isolated atrial and ventricular human myocardium: influence of angiotensin II and diastolic fiber length. Circulation 102(25), 3074-9

Wolff MR, Buck SH, Stoker SW, Greaser ML, Mentzer RM (1996): Myofibrillar calcium sensitivity of isometric tension is increased in human dilated cardiomyopathies: role of altered beta-adrenergically mediated protein phosphorylation. J Clin Invest 98(1), 167-76

Wollenberger A (1985): Isolated heart cells as a model of the myocardium. Basic Res Cardiol 80 (Suppl 2), 9-1

Yagi S, Kramsch DM, Madoff IM, Hollander W (1968): Plasma renin activity in hypertension associated with coarctation of the aorta. Am J Physiol 215(3), 605-10

Yamada H, Fabris B, Allen AM, Jackson B, Johnston CI, Mendelsohn AO (1991): Localization of angiotensin converting enzyme in rat heart. Circ Res 68(1), 141-9

Ye Y, Shibata Y, Yun C, Ron D, Rapoport TA (2004): A membrane protein complex mediates retro-translocation from the ER lumen into the cytosol. Nature 429(6994), 841-7

Yoshida H, Haze K, Yanagi H, Yura T, Mori K (1998): Identification of the cis-acting endoplasmic reticulum stress response element responsible for transcriptional induction of mammalian glucose-regulated proteins. Involvement of basic leucine zipper transcription factors. J Biol Chem 273(50), 33741-9

Yoshida H, Matsui T, Yamamoto A, Okada T, Mori K (2001): XBP1 mRNA is induced by ATF6 and spliced by IRE1 in response to ER stress to produce a highly active transcription factor. Cell 107(7), 881-91

Yoshida H, Matsui T, Hosokawa N, Kaufman RJ, Nagata K, Mori K (2003): A time-dependent phase shift in the mammalian unfolded protein response. Dev Cell $\underline{4(2)}, 265-71$ 
Yoshimura M, Yasue H, Morita E, Sakaino N, Jougasaki M, Kurose M, Mukoyama M, Saito Y, Nakao K, Imura H (1991): Hemodynamic, renal, and hormonal responses to brain natriuretic peptide infusion in patients with congestive heart failure. Circulation 84(4), 1581-8

Zhang X, Li SY, Brown RA, Ren J (2004): Ethanol and acetaldehyde in alcoholic cardiomyopathy: from bad to ugly en route to oxidative stress. Alcohol $\underline{32(3)}, 175-86$

Zhang X, Dong F, Li Q, Borgerding AJ, Klein AL, Ren J (2005): Cardiac overexpression of catalase antagonizes $A D H$-associated contractile depression and stress signaling after acute ethanol exposure in murine myocytes. J Appl Physiol. 99(6), 2246-54 


\section{Publikationen}

Postervorträge:

Kochhäuser S, Kögler H, Hasenfuß H, Nguyen van P (2006): Biomechanical loadinduced ER stress in the heart. Acta Physiol 186 (Suppl 1), 205

Kochhäuser S, Toischer K, Nguyen van P, Leineweber K, Brodde O.-E., Knöll R, Hasenfuß G, Kögler H (2007): Biomechanische Last und neurohumorale Stimulation induzieren ER-Stress im Myokard. Clin. Res. Cardiol. 96, (Suppl 1) (Abstract).

Publikation in Vorbereitung:

Toischer $K^{*}$, Kochhäuser S*, Unsöld B, Teucher N, Nguyen Van P, Hasenfuss G, Kögler H: Afterload but not preload leads to cardiac ER stress in-vitro and in-vivo. * both authors contributed equal 


\section{Danksagung}

Ich möchte mich bei Prof. Dr. med Gerd Hasenfuß bedanken, der mir das Thema für diese Arbeit zur Verfügung stellte und in seiner Arbeitsgruppe die Möglichkeiten zu deren Durchführung bot.

Mein ganz besonderer Dank gilt meinem Betreuer PD Dr. med Harald Kögler für seine geduldige und ausdauernde Vermittlung vieler technischer und wissenschaftlicher Fertigkeiten und auch für seine Hllfe bei der Korrektur und Fertigstelluung dieser Arbeit zwischen Ingelheim, Göttingen und Münster.

Des Weiteren möchte ich mich bei Dr. med Karl Toischer für seine Hilfe und Motivation und bei Dr. Phuc van Nguyen für seine Ideen bedanken.

Bei der Durchführung der Experimente war ich besonders auf die Hilfe von Michael Kothe und Susanne Burkhardt angewiesen. Aber auch allen anderen MTA's und Mitarbeitern des Labors von Prof. Hasenfuß möchte ich für die gute Zusammenarbeit danken.

Ich danke der deutschen Forschungsgemeinschaft (DFG) für die Förderung des Projekts im Rahmen des Graduiertenkollegs 521 „Protein-Protein Interaktion beim intrazellulären Transport von Makromolekülen" und dem Vorsitzenden des Kollegs Prof. Dr. med Detlef Doenecke für seine Unterstützung. 


\section{Lebenslauf}

Am 11.12.1980 kam ich als zweites Kind von Manfred Kochhäuser und Monika Kochhäuser, geborene Wintrich, in Hilden zur Welt

Nach dem Besuch der Grundschule in Essen und Stadtlohn von 1987 bis 1991 wechselte ich auf das Gymnasium Georgianum in Vreden, das ich 2000 mit der allgemeinen Hochschulreife abschloss. Anschließend absolvierte ich meinen Ersatzdienst an der Rettungswache der Stadt Stadtlohn.

Von 2001 bis 2008 absolvierte ich das Studium der Humanmedizin an der Georg August-Universität in Göttingen, das ich im Juni 2008 mit der Ärztlichen Prüfung abschloss.

Von 2004 bis 2007 promovierte ich im Labor von Prof. Dr. G. Hasenfuß über das vorliegende Thema.

Seit August 2008 arbeite ich als Assistenzarzt und wissenschaftlicher Mitarbeiter in der Abteilung für Kardiologie und Angiologie am Universitätsklinikum Münster. 